\title{
Copyright
}

by

Carmen Alejandra Romo de Vivar y Sandoval 
The Dissertation Committee for Carmen Alejandra Romo de Vivar y Sandoval

Certifies that this is the approved version of the following dissertation:

\section{Control, Learning, and Innovation: A Syncretic Approach}

\section{Committee:}

Larry D. Browning, Supervisor

Reuben R. McDaniel

Dawna Ballard

Keri Stephens

Senem Guney 
Control, Learning, and Innovation: A Syncretic Approach

$$
\text { by }
$$

Carmen Alejandra Romo de Vivar y Sandoval, B.S., M.B.A.

\author{
Dissertation \\ Presented to the Faculty of the Graduate School of \\ The University of Texas at Austin \\ in Partial Fulfillment \\ of the Requirements \\ for the Degree of
}

Doctor of Philosophy

The University of Texas at Austin

May, 2010 


\section{Dedication}

To the two most influential women in my life: my mom, and my sister.

Dedico esta disertación a las dos mujeres que más me han influenciado en la vida: mi mamá y mi hermana. 


\section{Acknowledgements}

The road of discovery is never an easy one to travel. This body of research was a personal path to discovery for me, but luckily, I did not have to travel alone.

Guiding this journey was Professor Larry D. Browning. Without his incredible depth of knowledge in the area of organizational narratives none of this research would have been possible. He generously shared his time and expertise with me over the course of this endeavor and I cannot thank him enough.

Adding spice to this voyage was the knowledge and wisdom of Professor Reuben McDaniel. His work in complexity theory greatly enriched this research and my own personal understanding of this discipline.

I would also like to thank the other members of my committee for their time and attention during this long and often bumpy journey; Dawna Ballard, Keri Stephens, and Senem Guney.

Sadly, I must thank one person posthumously. Dr. Leslie Jarmon was a valued member of this dissertation committee and was taken from us suddenly near the end of this long voyage. Her input and support will always be remembered.

Of course, on any well-planned journey the first step is gathering all the proper equipment, in the case of research that means gathering the data. I want to thank the Center for Advance Studies of our host Company for generously opening their doors to us and allowing us access to the key players of the researched project and for funding the 
transcription of the interviews with them.

Lastly, I would like to thank those people who made the completion of this great journey possible: Sarah, Keith, Joaquín, William, Charlotte, Sally, Lalo, Mercedes, Padre Lara, Tanya, Dr. Boldt, Dr. Meier, Dr. Hall, Dr. Islas, Dr. Young, Dr. Blankmeyer, Dr. Tally, Dr. Marcus, Dr. Bloomer, Marcia, Kim, Donella, Cheryl, Miss Diane, Nurses and staff on the 6th floor, Leigh Clark, Olguita Núñez, Dr. Morehead, Antonia, Jesse and Jane Burrow, and Sergio Aguayo. I am honored and grateful to each and every one of these people for their generosity of time and spirit to help me along my way. 


\title{
Control, Learning, and Innovation: A Syncretic Approach
}

\author{
Publication No. \\ Carmen Alejandra Romo de Vivar y Sandoval, PhD \\ The University of Texas at Austin, 2010 \\ Supervisor: Larry D. Browning
}

\begin{abstract}
:
This research focuses on understanding the processes involved in successful innovation - a topic that has appeared in a large body of research, but no conclusive trend has emerged about it. For this reason, I chose a different lens in order to gain a more panoramic view of the events leading up to an innovation. In particular, this research utilized a methodology and ontology that set it apart from previous work. In previous research control/exploitation and learning/exploration are either presented as two categorically separate concepts or as continuum that runs between them. This research supports the idea that innovation operates on a continuum but does not support the idea that it only occurs when the pendulum settles toward the learning/exploration side. Instead, the data shows that innovation could indeed occur at any point along the learning/exploration side of the continuum and even at the central point where learning/exploration and control/exploitation weigh evenly. To conceptualize this middle point, I term this a "syncretism" of two normally opposing forces to account for a significant portion of the interview data.
\end{abstract}




\section{Table of Contents}

Table of Contents ........................................................................................... viii

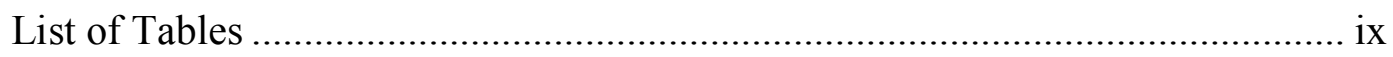

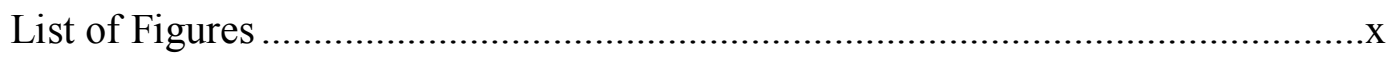

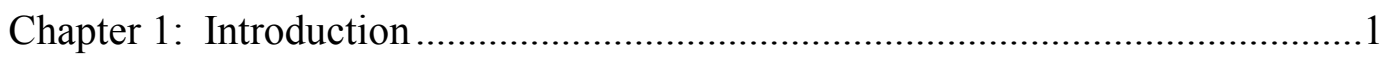

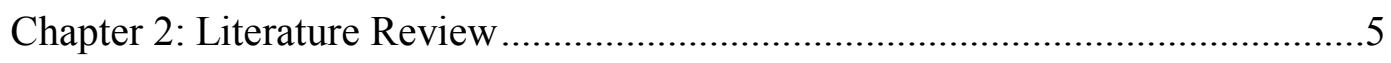

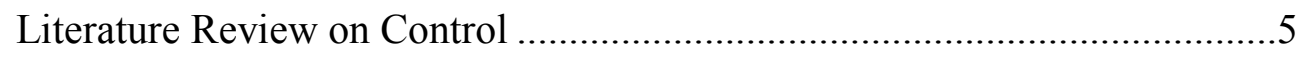

Literature Review on Learning ............................................................

Literature Review on control and learning ..................................................

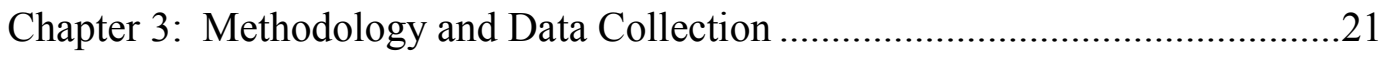

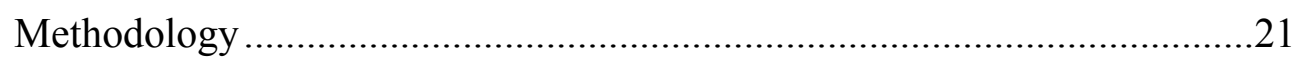

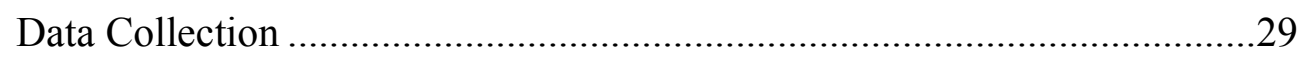

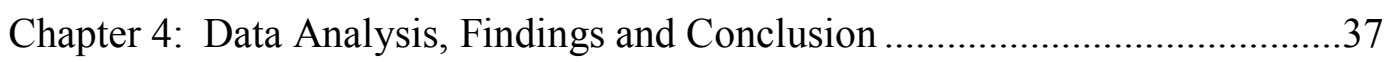

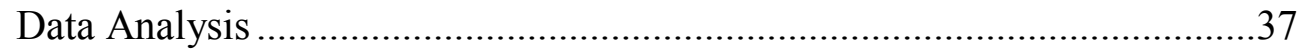

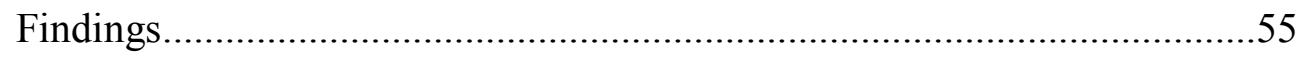

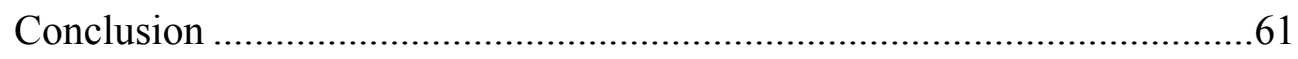

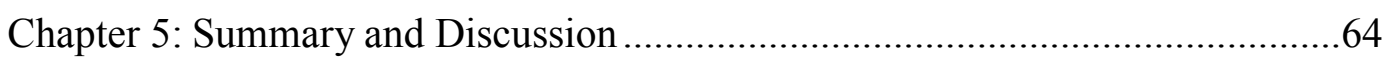

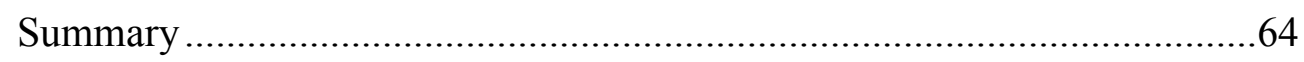

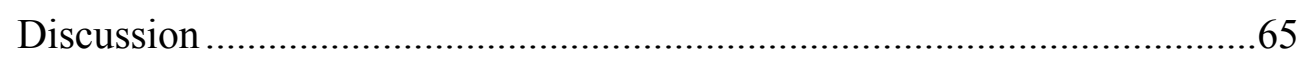

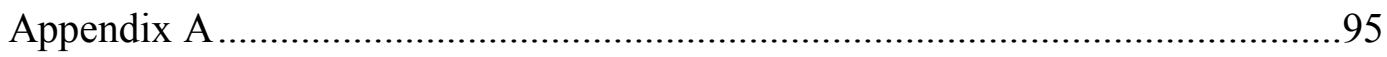

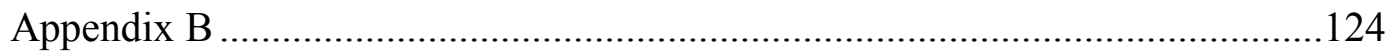

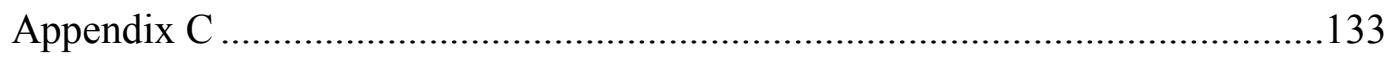

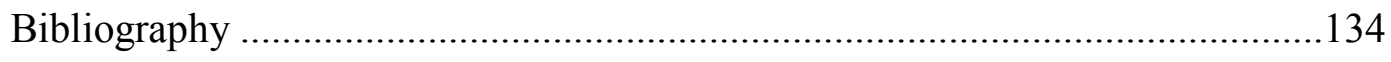

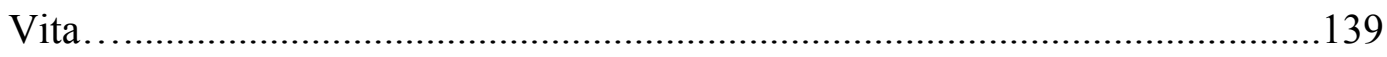




\section{List of Tables}

Table 1 Aggregated Consequential Matrix................................69 


\section{List of Figures}

Figure 1 Aggregated Column Chart for the Whole Project ..................................94 


\section{Chapter 1: Introduction}

In a world where everyday life has become so difficult that even mundane tasks are nearly impossible, society is no longer able to postpone the need for a paradigm shift (Kuhn, 1962) regarding the environment, economy, health, water, pollution, and other major challenges. We, as researchers in the social sciences, need to seek out ways to help our communities face a world on the brink of change in every aspect of life. We must develop the tools that will allow society to approach the impending paradigm shift in a flexible, creative, and global manner.

For any society on the cusp of monumental reorganization, knowledge is key. This is not only knowledge gained through historical analysis, but an understanding that can emerge organically when we are in sync with our environment. It is the synthesis of two forms of knowledge, learning and control that reveal our world as an ever changing entity that constantly refuses homeostasis. These two types of knowledge give new insight into our own abilities and how to exploit these abilities so that we may reap the utmost benefit from their existence. Most importantly we must understand how to combine these practices in order to be prepared to be flexible, creative, and innovative.

The purpose of this dissertation is to bring to light new data about the roles of control and learning in the innovation process; through the course of my analysis it became clear that control and learning in the field setting were behaving differently than all previous research had suggested. 
The project used for the development of this dissertation was the Blanco $4 * 1$ and Red River* silvex* project, which was a new product developed at XYZ* in the early 2000s. This innovation broke all the organization's time records for moving from drawing board to market. All data were collected after the innovation process had been completed. The key players were interviewed in a post mortem of the process and all responses were logged and coded. These codes serve as lessons learned at the end of a fast paced innovation process (March, Sproull, \& Tamuz, 2003).

The Red River Innovation emerged organically through the orchestration of many diverse variables including: human agents, cultures, time zones, and management styles. Therefore, it was imperative to gather as much detail as possible about the evolution of the Red River project and to let the data inform us about how, and why, the development of this product occurred.

In order to capture the complexity of the Red River project, I needed to utilize a unique methodology. I used a juxtaposition of two main concepts: grounded theory methodology (Glaser and Straus, 1967) and the complexity theory view of the world, specifically complex adaptive systems (Gell-Mann, 1994). This combination provided me with a complex enough structure to properly interpret the data.

Philosophically, I believe that organizations are best studied as an open system. We need to recognize and respect the characteristics of the organization that make it a complex adaptive system (CAS), including its non-linearity and non-determinism, complete with complex relationships with non-trivial feedback loops. This is true not

\footnotetext{
$1 *$ Texas county names were substituted for place names throughout this document.
} 
only among the human agents, but also true of the interaction between human agents and technology. The procedures and structure of the organization also play a key role in this process.

This research was undertaken in an attempt to explore the integrative approach to innovation employed by the XYZ Red River team. The uniqueness of this innovation process was in its organic evolution. Innovation is a phenomenon that occurs, in the social sciences along a continuum that ranges from physical and life sciences to humanism. To truly understand this innovation process we must bear in mind the social science heredity of the innovation phenomenon.

The academic origin of this dissertation emanates from previous research done on innovation by Sitkin, Sutcliffe, and Schroeder (1994), when the authors proposed that innovation was mediated (Baron \& Kenny, 1986) by control and learning, and worked as a continuum instead of two discrete variables. Sitkin, et al. (1994) opened a new path for research on innovation when they identified two central questions in need of further study:

- How do control and learning work together in the innovation process?

- Where along the continuum of control and learning does innovation happens?

Sutcliffe, Sitkin, and Browning, (2000) answered the first one when they presented a model that included three alternatives to assess control and learning: Antithetical, Orthogonal, and Synergistic. (See page 19 for a definition of these concepts) Although control and learning as a single continuum has already been researched extensively (See page 8 for references), the approach taken in this study differed from 
others in the sense that while control and learning are viewed as a continuous line, rather than two discrete categorical concepts, they are also viewed with the overarching lens of Complexity Theory, particularly as a Complex Adaptive System (CAS). The CAS lens allowed for a better understanding of the role of the non-trivial feedback loops on the Red River innovation process. This juxtaposition also gave me insight into the intricacies of the multiplicity of causal relationships.

Where innovation occurs along the continuum between control and learning and the role they play were the key questions guiding this research.

In my view the most straight forward definition of CAS for those of us that are not physicists is the one that Murray Gell-Man's gives in his book The Quark and the Jaguar (Gell-Mann, 1995):

A complex adaptive system acquires information about its environment and its own interaction with that environment, identifying regularities in that information, condensing those regularities into a kind of "schema", or model, and acting in the real world on the basis of that schema. In each case there are various competing schemata, and the results of the action in the real world feed back to influence the competition among those schemata. (p. 17) 


\section{Chapter 2: Literature Review}

Previous research on the innovation process and how it is influenced by control and learning are reviewed here. This review will cover Control, followed by Learning, and finally the conjunction of control and learning in order to arrive upon a description of the model utilized in this study.

\section{LITERATURE REVIEW ON CONTROL}

Control in organizations has been extensively researched since the early nineteenth century, taking on many incarnations according to the culture of the times. Otley, Broadbent, \& Berry (1995) developed a summary of all the academic work done in the area. Starting with the first approach in 1832, where cost accounting was used as a proxy for control, through Systems Theory, Cybernetics, Organizational Theory, and Scientific Management. More contemporary work involves open systems models, which recognize the external environment of the organization, as part of control.

Although Otley, et al. (1995) present a comprehensive time line on control and learning, to better inform this dissertation it is important to review others essays, as they are critical to understanding how to study the relationship between control and innovation.

Tannenbaum's (1962) psychological perspective of differentiated types of control marked the beginning of a concern for defining differences in the meaning of control and how they impacted the people experiencing it. He pointed out that control has been 
defined with words like power, authority, and influence, yet all these characteristics related to a top down imposition of control. Tannenbaum (1962) helped clarify two things. First, pragmatic implications outline what an individual must or must not do and second, symbolic implications including "superiority, inferiority, dominance, help, criticism, (or) reprimand tell a person the unwritten rules of a situation" (p. 240). Tanenbaum's research acknowledges the reality of bottom-level echelons mindlessly following imposed control. This change in perception of control opened the door to multidimensional and more sophisticated approaches for understanding control.

Flamholtz, K-Das, and Tsui (1985) provided academicians with a model of control "which identifies the major variables and specifies their interrelationships" (p. 36). Their model recognizes the context in which organizations are embedded, including the structure, culture, and landscape. They identify six core elements of this control system that include: 1) Planning element (goal setting and standards); 2) Operational subsystem (organizational roles); 3) Outcome element (performance, productivity, profit margin); 4) Measure element (inventories, production, budget); 5) Feedback element (delivering information regarding performance); and 6) Evaluation-reward element (administration of rewards). This model gave researchers a structure for building up our understanding of how multidimensional control could be. It also enhanced the development and robustness of the knowledge repository on control.

Ouchi (1979) proposed that the study of control can be categorized among three different mechanisms: markets, bureaucracies, and clans. Market forms of control are linked to an internalization of organizational goals, with social requirements nested in 
norms of reciprocity and information needs emanating from prices (objective quantification) without the need of any subjective forms of measurement to get recognition (e.g., control of a purchasing department). Bureaucratic mechanisms are associated with compliance to norms, recognition of legitimate authority, reciprocity, and information requirements emanating from the organizational rules; in other words, doing it by the book (e.g., control of a shipping department). Clan mechanisms are associated with identification, shared values and beliefs, legitimate authority, reciprocity, and information requirements that are congruent with tradition (e.g., political parties).

Ouchi's (1979) classification of control forms in organizations, established the basis for understanding how innovation develops in each of the three scenarios. Regardless of frequently having a combination of the three forms coexisting in the organization at any point in time, the dominant form of control will enable the feasibility of innovation.

\section{LITERATURE REVIEW ON LEARNING}

Huber (1991) presents the most thorough review of the research done on learning. His examination is highly descriptive, and he critiques the four main areas where research has been most frequently conducted: 1) knowledge acquisition, or the process by which knowledge is obtained; 2) information distribution, or the process by which information from different sources is shared; 3) information interpretation, or the process by which distributed information is given one or more commonly understood interpretations; and 4) organizational memory, or the process by which knowledge is stored for future use. 
Under the first area of learning research, Huber (1991) identifies a sub-category called experiential learning, which "Is enhanced by the availability and analysis of feedback. One approach to facilitating intentional organizational learning is to increase the accuracy of feedback. Another is to ensure the collection and analysis of such feedback.” (p. 91). Regardless of how critical feedback is for organizational learning, Huber asserts that "in spite of the importance of organizational experiments as learning mechanisms . . the literature contains very few studies of experimentation by organizations" (p. 92). The knowledge acquisition construct, as defined by Huber, became the focus of this research. More specifically, I focus on the sub-construct of experiential learning.

As a study of lessons learned, this dissertation falls into a realm of research Huber identifies as insufficiently explored. The scarcity of research in experiential learning may be related to the extremely time consuming and labor intensive procedures required to fully examine all data collected from an innovation process that includes multiple feedback loops.

\section{LITERATURE REVIEW ON CONTROL AND LEARNING}

The use of a combined construct of control and learning started within the life sciences-including cybernetics (Miyamoto, Kawato, Setoyama, \& Susuki, 1988), human motion (Bernstein, 1967), psychology (Ahissar \& Hochstein, 1993),etc. Later, in the early 1990s, the construct started appearing in the social sciences, particularly 
associated with research in Total Quality Management (TQM), set forth by Deming (Deming, 1986), Juran (Juran, 1986.), and Ishikawa (Ishikawa, 1984).

In their seminal work, Sitkin, Sutcliffe, and Schroeder (1994) presented an overview of inconsistencies that surface when a TQM approach is implemented in an organization with high task uncertainty. Their major objection resided in what they call universalism in the conceptualization and diffusion of TQM without taking into account the context in which each organization operates. They argue that in a highly competitive and rapidly changing world, organizations depend on both performance and adaptability, and their effectiveness will depend on the capacity to balance the conflicting goals of stability and reliability with those of exploration and innovation.

One of their core propositions is that TQM's goals should be modified depending on each situation's uncertainty; in routine situations, the goal needs to be control, and in non-routine situations, the goal should be learning. Sitkin, et al., (1994) advance a dual perspective to TQM: on one hand is the use of Total Quality Control (TQC) and on the other is Total Quality Learning (TQL). In obtaining the right balance between the two, the organization will more nearly gain effectiveness. As is obvious from their positions, the authors oppose emphatically the turn-key solution advocated by practitioners of TQM, arguing that each organizational task is located in a different point in the continuum between control and learning. Therefore, there is no single universal recipe on how to implement improvement methods.

Sitkin, et al. (1994) advance the concept of a continuous line running between control and learning, instead of looking at them as two categorical concepts. It is intuitive 
that a highly controlled routine activity is not likely to encourage innovation, but on the other extreme having no structure, rarely fosters innovation. It is somewhere along the control/learning continuum that the normative point is likely to reside. This point will always be contingent to the particular landscape/environment where the organization is embedded.

To further stress the above proposition, Cardinal, Sitkin and Long (2004), in a ten year longitudinal research project with Blue Whale moving company, were able to observe how this organization evolved from one extreme to the other in the controllearning continuum. The researchers used grounded theory to study how the evolution of control and learning appeared at each stage of the firm's growth. The selected tools included observation in a naturalistic environment, existing documentation, and in depth interviews. Over a decade, the authors documented how the founders intuitively sought an appropriate balance in each of the phases the organization was in. At their beginning, they were at stage of rapid growth; later they stabilized similar to the human life cycle. In complexity terms, this example suggests finding new local optima in the ever-changing landscape of a growing organization.

Cardinal et al.'s (2004) paper has, among other interesting characteristics, the use - for the first time - of a longitudinal approach to study control, allowing us to see a stepby-step movement from one end of the continuum to the other, until finding the appropriate level for the current stage of the company.

Sousa and Voss (2001) utilized Sitkin et al.'s (1994) research to answer the question of the universal applicability of quality management practices in organizations. 
They discovered that one cannot take a blanket approach to the application of quality practice; TQM is more effective when applied with consideration for the contingent context of the organization (Woodward, 1965). The authors were particularly interested in answering this question in relation to the manufacturing strategy context. This study shows that regardless of the kind of context the organization is in, e.g., manufacturing, marketing, or financial, the use of control tools has to be correlated to the appropriate context in which the organization is embedded.

Lau and Anderson (1998) argue that TQM has to be implemented using tridimensional characteristics (philosophical, strategic, and measurement dimensions) to be useful in all kinds of organizations. According to them, two-thirds of the attempts to implement TQM failed because the organizations did not adhere to TQM parameters. They reason that in America and the UK, organizations expect that the partial application of TQM will produce immediate results, contrary to implementation in Japan, where they take time to fully implement it, doing it one step at a time.

Their research examines the case of introducing TQM control tools in Research and Development (R\&D) organizations and shows that this kind of organization cannot be bounded by TQM control because mistakes are a source of learning (Lau and Anderson, 1998). If one tries to diminish mistakes then the opportunity to learn and innovate is also diminished. It is arguable that TQM's failures are not merely due to faulty implementation but due to the ideas stressed by Lau and Anderson (1998) of universality in its application. TQM is not appropriate in all circumstances, no matter how well it is employed. 
Brennan (2001) assessed the success of the implementation of TQM within a research and development facility and found that there are differences between research scientists and development engineers regarding the benefits that TQM brings to the organization. Scientists tend to believe that TQM, while a useful concept, cannot be implemented in a research and development facility and felt that no benefit had been derived from the implementation of TQM. The engineers perceived TQM as a helpful and productive tool to do their job. The difference between the two groups may be explained by the notion that engineers are not creating something, but rather bringing the scientists' innovations to life. Brennan's (2001) assessment confirms what Lau and Anderson proposed in their 1998 work. TQM is not applicable to Research and Development organizations.

Hackman and Wageman, (1995) offer an interesting critique regarding the learning process involved when using TQM. The TQM process is inherently single looped; this is in direct reference to the focus on what is being done but not how is done, which requires a double-loop learning process. Their main critique of TQM is its inability to convey member ideas or experiences about collective processes because it is designed for a single-loop and top-down management style. Direction, coaching, and tools only travel one way - from top to bottom. No feedback travels back up the pyramid. The TQM strategy of putting emphasis on the continuous improvement of work processes is very useful for attending the needs of the customers, but it is not well adapted to detecting changes in the environment that could lead to innovations and to keep the organization ahead of customer's desires in the future. 
Although Hackman and Wageman (1995) do not mention it specifically, it is plausible to assume that the top down managerial control enforced by TQM prevents the members who produce the bottom line to act upon the information that they are receiving from the environment and instead, they passively wait to receive approval from top management. Hackman and Wageman (1995) explain that "learning is indeed a core value in TQM organizations, but there are nontrivial constraints on what is to be learned about who is to do the learning, and when learning should be set aside in favor of performing" (p. 337).

In Sitkin et al.'s (1994) work, the general perception is that TQM could be useful for a wide spectrum of organizations if it is not as poorly implemented as it has been in the past. But Hackman and Wageman (1995) go further to say TQM is not only poorly implemented but it is badly designed because it does not allow changes to arise from the lower levels due to total managerial control. Hackman and Wageman (1995) continue by decrying TQM's fostering of pseudo-participation. The double feedback loop needed to learn within and between the organizations is rarely nurtured; therefore the opportunity for innovation and learning are lost.

Leonard-Barton (1992) described how a factory can be managed to be a "Learning Laboratory." She did research on Chaparral Steel, a steel mill then considered by Fortune as one of the ten best-managed factories in the United States. Among its many positive managerial characteristics, Chaparral Steel displays the single trait of two-way communication. This company exhibits egalitarianism with respect for the individual to such an extent that all employees have the potential and opportunity to contribute ideas, 
from line operator to the CEO. There is a mutually understood philosophy within the company that those working closer to the equipment or procedure are able to best perceive how to improve it -- because they are the ones best placed to see when and how to best address problems as they arise. As a result of the interconnectedness among the different organizational levels of Chaparral Steel, ideas come from everyone who can contribute a different perspective to the solution.

Another Chaparral Steel practice that supports the learning point of view is Continuous Experimentation. Though many organizations operate under the old adage "if it ain't broke, don't fix it" Chaparral Steel operates at all levels under the revised adage "if it ain't being fixed continuously, it's broke." This shows their commitment to constantly learning/exploring new processes all the while controlling/exploiting the task at hand. In the Chaparral organization they also understand that all inventions are a process of synthesis, and that the people working in a learning laboratory value the capability or freedom to absorb and use new knowledge as much as to create it.

Following the same line of research regarding control and learning, Dooley, Johnson, and Bush (1995), present a different framework. Instead of using TQM as a paradigm from control, they use Newtonian mechanics. In place of the Learning Organization, they substituted CAS, a complexity paradigm. Dooley et al., (1995) base their reframing on the argument that learning organizations are like CAS that welcome uncertainty and random events in order to foster learning and create market leverage. They adhere to Holland's (1995) definition, "Complex Adaptive System refers to a system that emerges over time into a coherent form, and adapts and organizes itself 
without any singular entity deliberately managing or controlling it." Holland's systems perspective states that interactions among organizational entities are the source of knowledge, rather than organizational entities themselves.

Dooley and associates' (1995) review does not mean that a systemic based analysis is always the right tool to use; the key concept is to match complexity of the tool with the complexity of the process. When the process is mechanical and rational (payroll calculations), the best tool to use is a deterministic one. On the other hand, if the process is non-linear (design improvement), it is better to use a systemic approach in order to avoid settling for a non-local optima, wherein one keeps getting better and better answers to the wrong question.

Dooley et al. (1995) claim that in order to practice quality improvement efforts "it is imperative to understand systemically the process being studied and data coming from that process that is indicative of its behavior. One needs to understand the social and technical factors involved in the process. Finally, one must know how to learn about the process in greater detail, and how human perception affects and is affected by such knowledge" (p. 16). Dooley et al.'s, (1995) idea of utilizing two different theoretical lenses in order to explain one phenomenon is close to the methodology used in this research; the difference resides in the deterministic approach the authors use to understand control.

In a subsequent conceptual note by Choi, Dooley, and Rungtusanatham (2001), the argument in support of using CAS when doing research on learning organizations is pursued even further than in the previous research (Dooley, Johnson, \& Bush, 1995); 
Choi, et al. (2001) suggest prompting researchers to use this idea: "when managing supply networks, managers must appropriately manage how much to control and how much let emerge" (p. 351).

Choi, et al.'s (2001) propositions are attuned with the findings of the XYZ Red River research; including the relationship they have with research on innovation. They suggests implementing tighter control tools like ISO, JIT, ERP, to produce higher efficiency, but express fear they will also lead to negative consequences like a reduction of innovative activities and even performance. Another proposition argues that organizations that deliberately include control and emergence in their managing style will perform better that the ones that use only either one of them.

Naveh and Erez (2004) presented experimental results on the implementation of Quality Improvement Paradigm, with their assumption that focus on detail could coexist with innovation. This is in clear opposition to the argument sustained by Sitkin et al., (1994) who proposed that if attention to details and adherence to rules increases, that innovation decreases. Naveh and Erez reasoned that among quality management philosophy options, continuous quality improvement requires attention to details and conformity to rules on the one hand and creativity and innovation on the other.

During an intervention, in a setting that included four different interventions at four different times and at six different plants of the same organization, Naveh and Erez (2004) tested their arguments. The intervention used was ISO 9002, one of the most common interventions of quality improvement. The results did not support the authors' arguments and instead confirmed Sitkin et al.'s (1994) proposition. After all the plants 
received the intervention, the correlation between attention to detail and innovation was negative, meaning that the more one focuses on details, the less emergence of innovation is enabled. Once again, the results suggest that in order to enable innovation, the organization needs to find the optimal point in the continuum between learning and control or exploration and exploitation.

Levinthal and Rerup (2004) responded to the call made by Sutcliffe, Sitkin, and Browning (2000) to more fully integrate the different types of work on organizational learning and reliability. They recognized the importance of that call. There are two basic and opposing traditions of organizational learning: one is the perspective that learning is an experiential activity that is ruled by somewhat standard routines. Among its proponents are Levitt and March, (1988). The second perspective suggests that agents choose among highly variable patterns of action with high levels of novelty. Proponents of this second view include Weick, Sutcliffe, and Obstfeld (1999); Weick and Sutcliffe (2001); and Fiol \& O’Connor (2003).

Levinthal and Rerup, (2004) argued that it is not useful to frame organizational learning as either one or the other. Instead, it is better to view them as interrelated. The authors integrated both perspectives into a model called Cycle of Learning and Action, where mindful and less mindful organizational learning is framed in a three stage process. The stages include:

- $\quad$ Learning Before Action

- $\quad$ Learning In Action

- $\quad$ Learning After Action. 
In all stages, they used mindful and less-mindful learning, the former with rationality, exploration, and sense making, and the later with routine, stimulus, and reinforced learning, respectively.

Perhaps most important is their acknowledgment that "ultimately our theories of organizational learning must recognize this fact and incorporate both perspectives in a broader Synthesis" (p. 23).

Regarding this Red River research, the models that most closely relate to what I have done are Levinthal, et al. (2004) and Sutcliffe, et al. (2000). Yet, there are still some other elements not present in any of those two models, including the use of complex adaptive systems to address the open system nature of the XYZ innovation process.

Bhatt (2000) proposed a four-phase model for a knowledge development cycle. Among the four phases of the model, two are particularly pertinent to the XYZ data in this research: the knowledge creation phase and the knowledge distribution cycle. The former stresses the need to give human agents freedom of experimentation in order to enable and promote innovation. The latter is interesting for the assertion it makes that communication among the agents is fundamental for the conversion of individual knowledge into organizational knowledge. The ways in which human agents interact within and between organizations affect how innovation may be enabled.

Prajogo and Sohal (2001) presented a framework that includes the kind of innovation that an organization is pursuing as a basis for determining if TQM could be beneficial or not. They suggest a differentiation between incremental innovation and radical innovation - or as Christensen, Anthony, and Roth (2004) described it, 
"Disruptive Innovation." They suggested that organizations focused on incremental innovation are amenable to the introduction of TQM tools without impacting the level of innovation. They reason that routinization which comes with TQM tools aids product improvement subject to incremental innovation. On the other hand, they acknowledge that an organization oriented to radical innovation cannot presume that TQM is the right tool to use.

This framework sounds promising, but the problem lies in the semantics. What they define as incremental innovation is not an innovation per se, but rather an improvement on a product. That changes the variables of the equation, significantly.

Finally, Sutcliffe, Sitkin, and Browning (2000), presented a model that most closely relates to the XYZ Red River research. Their main assertion was the need to examine an organization's context in order to accurately assess the point along the control/learning continuum at which innovation is most likely to occur. This model is the most holistic among all the others presented in this literature review.

Three alternatives are presented to assess control and learning (or exploitation/exploration). They include: a) Antithetical, a condition under which they are negatively related, meaning the more control, the less exploration (a zero sum world); b) Orthogonal, the condition under which they are not related and are managed like two different entities, generally with a site that is geographically different; and c) Synergistic, conditions under which they are positively related, which means that the pursuit of reliability and learning are mutually supportive. 
The model, among all those surveyed, best accounts for relationships between agents, stake holders, local conditions, and their landscape, and also provides the most precise fit of control and learning, is the one put forward by Sutcliffe, et al. (1994).

The combination in this research of complex adaptive systems framework and grounded theory methodology create a unique perspective from which to analyze the data collected from XYZ Red River project. This combining of multiple methodologies also allows for the treatment of this project as an open system viewed in its naturalistic environment. 


\section{Chapter 3: Methodology and Data Collection}

\section{METHODOLOGY}

\section{Research Questions}

The key question guiding this research was: Where along the continuum of control and learning does innovation occur?

1. How do control and learning interact, as evidenced by the collected data?

2. With what frequency, if at all, does innovation occur at each end of the controllearning spectrum within this data set?

3. How do the collected data compare to the current body of research on control and learning in product development?

\section{A Rationale for Method and Framework}

Qualitative research methods lend themselves to research questions that seek to gain a richer deeper picture of a particular phenomenon asking how, why, what, who, or when. Attending to those attributes, qualitative research methods are more fitting in contexts where a deeper understanding of the phenomenon is required.

Among the extensive number of qualitative research traditions utilized in current studies, are: Ethnography, Phenomenology, Case studies, Biography, Grounded Theory, Ethnomethodology, and Social Anthropology (Creswell, 1998). The approach used here was to concentrate on the traditions that lend themselves more naturally to the social sciences (as it fits the background of the XYZ phenomenon). For example, Biography is fitting for a discipline like history; Phenomenology is fitting for Psychology; and 
Ethnography is fitting for Anthropology. On the other hand, traditions like case studies and grounded theory are better utilized in the organizational structures, (Creswell, 1998). Qualitative methodology is utilized in this dissertation for these various reasons:

- $\quad$ richness of detail

- depth of analysis

- the ability to capture a social phenomenon in its naturalistic setting

- $\quad$ validity even when no homeostatic state is reached after multiple iterations

- the intrinsic ability of qualitative methodology to understand that social sciences are not bounded by a liner succession of events

The research phenomenon of this dissertation is better explained if approached through the lens provided by a qualitative methodology that gives me the opportunity to explore the phenomenon in depth, with flexibility, flow, and attention to the interactions. This research was also enriched by the theoretical framework of Complex Systems - in particular Complex Adaptive Systems (CAS) - mainly for its effectiveness in tracking feedback loops which are important to trace.

The XYZ research project also lent itself better to the grounded theory tradition, originally developed by sociologists, Barney Glaser and Anselm Strauss in their seminal work Discovery of grounded theory (Glaser \& Strauss, 1967).

Grounded Theory traditionally focuses on developing a theory grounded in data from the field. Collecting data from in-depth interviews with 20 to 30 individuals until theoretical saturation is obtained (where the different subjects start to repeat the same 
narrative) in the categories that later will be developed into theory (Glaser \& Strauss, 1967).

Grounded Theory allows a developing theory to have explanatory powers, meaning that given a situation similar to the original one that generated the theory we may plausibly use the theory to generate an explanation (Strauss \& Corbin, 1998). Additionally, with grounded theory, it is possible to identify the conditions that enable the phenomenon and explain what consequences could occur as a result of those actions.

Ideally, from the beginning of any research project, investigators have clear in their minds the research questions they wish to answer, understand, or explain. Once these questions have crystallized are acknowledged, the next step is to assess core assumptions regarding the ontology, human nature, and epistemology linked to those questions and also to the researchers themselves (Morgan \& Smircich, 1980).

If the answer to the ontological perspective is a view of the organization as an organism in an open system, evolving constantly iteration after iteration within and between the agents, then researchers should study them understanding their landscape/context in a synthetic fashion. The organization needs be examined from the micro level (or the agents that form the system, in this case the organization), and from the macro level (all stakeholders involved in organizational processes). It is most important to investigate how the interaction among the micro and macro levels reshapes the organization constantly.

If researchers assume human nature, the product of man's own construction of his social environment and symbols, then they should follow a theory that is not trying to 
evidence the relationship between the dependant variable and the independent, precisely because humans are the origin of those variations.

The epistemological perspective is tied inseparably to ontology and human nature in this research. CAS theories are useful if what constitutes adequate knowledge about the organization is viewed as the understanding and study of systems - the processes and changes through which agents concretize their relationship to their organizational world. This position stresses the importance of monitoring the way in which a phenomenon changes over time as well as interactions in relationship with their agents and context.

Morgan and Smircich (1980) presented an extensive and enlightening argument regarding the continuum that contains the assumptions concerning the ontological perception of the social reality and the grounds for claiming knowledge in each of the possible perspectives. On opposite ends of a continuum are the subjective and the objective takes on the fundamental view of the world. On one hand, a conception of the world as a machine in a closed system; on the other, it is conceived as an organism living in an open system. Therefore, the epistemology used to make sense of such conceptions is completely different. When the metaphors of machine and organism are used, it is obvious there is a need for different methods of research, since the knowledge required for examining a view of the world, as a closed, mechanical, structure is inadequate to examine it as an organic open system.

The purpose of this research project is to answer research question(s), generated in the organizational domain, based on a view of human beings as creators of their world instead of merely reactionaries. With this perspective in mind a positivist epistemology 
was unsatisfactory, and perhaps inappropriate. Since this research project was considered more than the sum of its parts, the system needed to be studied as a whole, utilizing a theory that allows grasping all the different levels of analysis: macro, micro, and synergetic.

The synergetic effects occur when a macroscopic structure becomes unstable and breaks down, immediately after which the microscopic agents self-organize to respond to that change. In doing so they create a new order or macro structure, also named coevolution. Complexity theories, in particular, provide researchers with models that help understand how forms of innovation can arise under certain conditions. Examples include supporting creativity and exploration or allowing nonlinear cooperation at all levels of the organization.

One of the prevalent characteristics of a complex system is its emergence not only from the self-organizing of the agents, but also from the entropy of the system. Therefore, by its own nature an open system with its ever-changing feedback loops is not adaptable to a linear construct model. Since Sir Isaac Newton in the late 1700s, open systems have been studied with the use of models from linear mathematics, classical mechanics, and thermodynamics. These mainstream approaches have been forced to include some certain ad hoc assumptions in order to achieve the principle of superposition; in other words, it is implying that the system as a whole does not differ from the sum of its parts.

Since complexity theories aim to understand open systems as a whole, it is not prudent to skew the data by trying to normalize the individual agents, behavior, reactions, 
and other factors that do not conform to the deterministic models of classic methodologies.

Scientists have managed to find in practice models that have helped them understand complex systems and nonlinear dynamics in nature with the use of data mining and time series analysis when studying an unknown dynamical system. They get a finite series of measured data, and from that time series analysis they must reconstruct the behavior of the system in order to guess the type of its dynamical equation (Mainzer, 2004). The purpose is to be able to explain what had happened and also to narrow down the probability of its future occurrence. This is done not from the point of view of the prediction of agent's actions, but from the probability of the system as a whole.

Complexity theories take emergence seriously. They do not try to include all the diversity in a single theory but take some aspects of complex systems one at a time. One has to look at the causal structure as a whole, exploring the system and the agents from all angles. This includes upward causation and downward causation to get a comprehensive grasp of the complexity of the composite.

Qualitative research methods are more amenable to research in an open system, since researchers have a wide view of the phenomenon and can slowly focus in on the agents narrowing the angle of the view until they catch sight of the emergence of patterns and are able to discern which ones are eccentric and why.

The scientific approach to complex systems does not reduce the theoretical framework, but expands it to accommodate more perspectives, more postulates, and more 
theoretical tools to filter out irrelevant microscopic details and define novel emergent macroscopic properties (Auyang, 1999).

Since Plato's time (early fourth century B.C.), the advancement of science has been linked to the scientist's ability to explain phenomena, and with complexity theories, we have the possibility to do that, regardless of lack of predictability. Philosophically, traditional topics of epistemology such as perception, recognition, and emotion that do not have material or physical existence may be better explored in the interdisciplinary framework of a complex system. Life is complex and random; we have to live it in order to experience it. The strength of complexity methodologies resides mainly in their explanatory capabilities, rather than in reducibility or predictability.

Although grounded theorists cannot know it all, providing even a small amount of understanding can make a difference (Strauss \& Corbin, 1998). The epistemology involved in grounded theory does not hold that the findings will be universally generalizable, but, claiming that they will provide insightful and significant knowledge about the nature of the social world relative and specific to the context and situation from which it is generated, is feasible.

Philosophically, everything goes back to answering the questions "What was this research all about?" and "What were the main issues, problems and patterns that emerge from these collected data?" With methodologies that are respectful of open systems -like grounded theory and complexity theory - we can claim to approach the answers. 


\section{Considering Network Theory}

It could be argued that the data of this research project, could also be analyzed utilizing the theory of networks, since it gives the ability to have a wider (tridimensional) view of the structure of a system, plus the microscopic view of its ties (or feedback loops of the agents). Regardless of being weak or strong, each of them provides the system with a map of the interconnectedness of the phenomenon (Barabási, 2002).

Nevertheless, network theory also has weaknesses, particularly within social systems, primarily due to the difference between the agents in a natural system and the agents in a social system. When looking at natural agents, they are considered independent of one another, but when we are looking at social agents, they are independent in some instances but dependent in others. Therefore, the model provided by network theory needs to be modified for its use on the social sciences.

In the natural sciences, network theory has been advancing steadily by uncovering different phenomena; especially phase transitions (small random events that, at a critical point, can push the system into a universally organized state when interacting only locally). These phase transitions are capable of explaining the similar emergent behavior among very different natural phenomena, like freezing liquids, ferromagnetism, and underground oil reservoirs. Physicists are hopeful that the understanding of this emergent behavior can also be useful in complex social and economic systems like friendship networks, firms, financial markets, and even societies.

Also, different classes of network system require researchers to explore different sorts of network properties like short path connections, more connections, individual 
identity, tight clusters, or loose ties. A useful classification of networks will enable us both to unify many different systems and to distinguish among them; depending on the particular questions we are asking (Watts, 2003).

In words of Barabási (2002):

Networks are only the skeleton of complexity, the highways for various processes that make our worlds hum. To describe society we must dress the links of the social network with actual dynamical interactions between people. To understand life we must start looking at the reaction dynamics along the links of the metabolic network. To understand the Internet, we must add traffic to its' entangle links. To understand the disappearance of some species in an ecosystem, we have to acknowledge that some prey is easier to catch than other (p. 225)

Thus having considered the possible methodologies, I decided that grounded theory and CAS were best suited for interpreting the data collected from the XYZ Red River project. These two methods will provide the clearest understanding possible of what the data are saying about the innovation process.

\section{Data Collection}

\section{Population and Instruments}

The instrument used with the XYZ research was in-depth interviews. The questions were generated in a collaborative effort with other members of the University based research team. They were very few and open ended (What is your recollection of what happened during the development of the Red River project?), the purpose was to let the interviewee explained in his/her words the most relevant actions that generated the 
final outcome. The data were collected from a Fortune 500 corporation with multiple locations in the US an internationally

\section{Interviews}

The process started with collecting data by conducting interviews in a natural setting. For the most part this meant meetings with interviewees in their own offices. The interviews were done in a collaborative effort with other members of the University based research team. The population was in total 24 key people directly involved in the Red River project. They were interviewed in-depth; all interviews were tape recorded and professionally transcribed. Those texts became the physical data used to start the process of coding.

Interviews were done over a period of six to eight months; this allowed for a preliminary coding of the initial interviews, it also helped with generating a draft of the initial categories emerging from the data. At the beginning, the interviews were initiated by asking open-ended questions with a broad spectrum; this strategy was useful to gain an overview of the interviewee's perception of what had happen according to his/her recollection of the phenomenon. This helped to comprehend the perception - by the actual actors - of the phenomenon's social construction as a whole.

The questioning in the interviews continued to be open ended, but then it became clearer where theoretical sampling was needed to gain further clarification.

Theoretical sampling, according to Strauss et al. (1998), is:

Data gathering driven by concepts derived from the evolving theory and based on the concept of "making comparisons," whose purpose is to go to places, 
people, or events that will maximize opportunities to discover variations among concepts and to densify categories in terms of their properties and dimensions (p. 201)

Interviews were scheduled with the most prominent actors (identified by our project sponsors) involved in the process. After that, a modified snow ball strategy was applied, meaning that the initial interviewee was asked to mention a couple of people that in his/her view were also integral parts of the experience. Those named people were not interviewed, but were asked for a couple (or more) names that in his/her view needed to have a voice as well. Those mentioned in the third tier were the ones interviewed next. Sometimes, interviewee were asked to provide the name of a specific person who was directly involved with a new area of interest for data collection.

This modified snow ball sampling process allowed for a broader pool of participants from which to sample, thus reducing the probability of hearing a repetitious story from each interviewee. The same process continued until a saturation of data was gained.

Glaser and Strauss (1967) give as a general rule to obtain theoretical saturation, (a) no new or relevant data seem to emerge regarding a category, (b) categories are well developed in terms of its properties and dimensions demonstrating variation and (c) relationships among categories are well established and validated.

Having the benefit of professionally transcribed interviews, it seemed appropriate to follow a Microanalysis of the data - a detailed line-by-line analysis necessary at the beginning of a research project - to generate initial categories with their properties and 
dimensions, and to suggest relationships among those categories (Strauss, et al., 1998). This included a combination of open and axial coding.

\section{Coding}

The flow of work between data collection and coding was like a spiral: It went back and forth often doubling back on itself though eventually moving forward. It was not a directly linear process, but some might say necessary side trips were taken to achieve the best result. Using grounded theory as the basis for analysis of the data, three types of coding were put into place: open, axial, and selective coding. Coding is defined as "the analytic processes through which data are fractured, conceptualized, and integrated to form theory" (Strauss, et al., 1998, p. 3).

Open coding is focused in examining, comparing, conceptualizing, and categorizing data. Two analytic procedures are basic to the coding process: a) making comparisons, used to stimulate thinking about properties and dimensions of categories and b) asking questions, used to open up the line of inquiry and direct theoretical sampling.

Axial coding focuses on specifying a category in terms of the conditions that give rise to it, the context in which it is embedded, and the action/interaction strategies by which it is carried out.

Selective coding is the process of selecting the core category, or the one that systematically relates to the others. It is used in validating these relationships and identifying categories that need further refinement and development. Although this 
process seems linear, the borders between types of coding are blurred and researchers can go back and forth among them.

Once the process of coding began, the categories generated from the data that started to emerge provided provisional propositions on how concepts related. At the beginning, the propositions were very roughly stated. For example, under which conditions "A" could happen and what would be the outcome, but later, as the data collection and sampling continued, they started to show variation and general patterns.

The use of grounded theory in this research project also permitted an analysis from the process point of view, which means that not only the properties and dimensions were allowed to emerge, but the emergence of the flow of the action and interaction that occurs over time and space within a context as well. This extended further the robustness of the explanatory powers of the theory being generated. For example, the "action bias" (Peters \& Waterman, 1982) was so intense that once learning occurred, they often moved quickly to the resulting control consequences.

The XYZ Red River project was understood, since the beginning, as a complex phenomenon not wholly contained within the walls of XYZ, but also being impacted by macro conditions (timing, competitors, price, attractiveness) that intersected and interacted with the micro ones (XYZ developers) in direct and indirect paths.

In order to properly attend to the complexity of the data, another of the tools used for developing grounded theory, the conditional or consequential matrix or diagram, was used (Corbin \& Strauss, 1996). 
A detailed description of this research's consequential matrix will be addressed in the next chapter, since the essence of the findings is derived from the organized/methodical feeding of the coded data into the structure of this matrix.

Grounded theory has certain functions that help researchers to be more objective and also to address the personal bias concerns, or non tabula rasa frame of mind, always posed to qualitative researchers. Among these functions are: use of microanalysis, asking questions, and making theoretical comparisons, Strauss and Corbin (1998).

Grounded theorists create theory out of data. If it is done correctly, then they are not speaking for the participants but rather are enabling them to have a voice that is clearly understood and represented. Theory derived from data is more likely to resemble the reality than theory derived by putting together a series of concepts based on experience or solely through speculation. Grounded theories, because they are drawn from data, are likely to offer insight, enhance understanding, and provide a meaningful guide to action.

The $\mathrm{XYZ}$ research project was known to be an innovation project; from that point of view one side of the equation was already solved. During the process, after the analysis of all interviews, the coding for exercising control emerged giving me the other side of the equation.

Expecting a process that was not only complicated but complex, it was necessary to develop a complexity framework that allowed classifying the actions pertaining to control and also the ones pertaining to learning. Once control and learning were catalogued on the consequential matrix, the logical next step was to map the actions with 
a combination of both: the ones that could not be cataloged as one or the other, but a synthesis of both. The codification of the data that emerged after the analysis of the interviews lent itself to comprehending this phenomenon as a synergetic relationship between control/exploitation and learning/exploration.

The use of grounded theory gave insight on how to catalogue the codes that were emerging; it was not decided a priori which theory to test. Instead, the data were allowed to speak and what emerged was a process-wide innovation that occurred within the many different restrictions imposed by the organization, and by the stakeholders of the XYZ system. Or in the words of complexity theory, XYZ was determined to find better local optima for the organization. There is no doubt that different researchers could use the $\mathrm{XYZ}$ data to find some other patterns of action, but with the complexity framework that was chosen and the coding that emerged from the data, a synthetic approach to control and learning was the most precise match.

Following Morgan and Smircich's (1980) advice, at the beginning of the research project, introspective stock was taken of the core assumptions regarding the ontology, human nature, epistemology, and researcher of the project.

In this research, the ontological perspective taken was to view the organization as an open system. Therefore it was not considered as a machine in a closed system with a structure composed of deterministic linear relationships among constituent parts; and it was not studied as an objective phenomenon that lent itself to accurate observation and measurement. In other words, there was no need to examine it in a linear, cause-andeffect format with no feedback loops. 
Although there has been research done with the use of juxtaposed methodology and framework before, this research is unique because it views the organization as an open system with feedback loops that keep it from going back to a homeostatic state, or in complexity terms, it remains far from equilibrium (FFE) (Boisot \& Child, 1999). In this case, FFE is evident in the following example: An engineer who was a part of this project went to a technical conference and determined from a private conversation while there that XYZ's major competitor was not as far along, technically, as they had previously presumed at XYZ. Armed with this intelligence upon returning from the conference, the XYZ group decided that their product was still more radically in front of the competition than they had previously thought. This example is FFE in that, rather than feeling smug because they were so far ahead of their competitor, they took the awareness of slack as an opportunity to push their product further into advancement so that when it was eventually launched, they would be still farther ahead. The intelligence gain caused them to set a more radical goal.

My next chapter will be an elaboration of the findings that the juxtaposed application of method and framework provide and an analysis of how the data came together to produce an original finding. 


\section{Chapter 4: Data Analysis, Findings and Conclusion}

\section{Data Analysis}

\section{Consequential Matrix}

The consequential matrix (see a summary of it on Table 1 and Appendix B) provided the scaffolding necessary to catalog all 1014 codeable pieces of data that were categorized after a few iterations of analyzing the 24 in depth interviews with the XYZ executives involved in the Red River project.

During the open coding phase, 1014 codeable pieces of data were identified and catalogued into three different concepts: control, meaning activities pertaining to the control end of the continuum; learning, meaning activities pertaining to the learning end of the continuum; and $S$, meaning activities where control and learning were nearly balanced (synthesized) in the middle of the continuum, or in Browning, et al.'s (2009) words, they were syncretic.

Once the open coding was catalogued and finished, the axial coding began. At this phase a finer categorization was needed for the data already catalogued within the control, learning, or synthesis/synergetic parameters.

Following what data were indicating, thirteen different sub-code categorizations were utilized; for codes pertaining to Control: $C 1, C 2, C 3, C 4, C 5$, and $C 6$. For codes pertaining to Learning: L1, L2, L3, LA, L5 and L6. Finally all codes pertaining to Syncretism did not need any finer categorization, according to what the data indicated (See Appendix B). 
What follows is a detailed description of the exact meaning and scope of each sub-code created for the purposes of this research. Further clarification is provided by offering sample data points for each coding category. These direct quotes from the interviews have been edited lightly for clarity and brevity.

When analyzing the data, the interviewee's perspective was always used as a frame of reference. In other words, each statement was evaluated using the unique position of the interviewee in the hierarchy of XYZ Corporation.

Additionally, it is necessary to understand that each code from the control category has a corresponding code in learning. At times these appear to be very similar, but discerning the force behind the action will clarify the appropriate classification. As an example of the difference between $\mathrm{C} 4$ and L4, these two statements, "(XYZ) makes sure that all the various organizations put their people in the right place" and "The way work gets done in the organization, especially a big complex one like $\mathrm{XYZ}$, is that everybody has a little bit of knowledge and you can't put something like a complex silvex out without tapping all that knowledge" the former is coded as an example of C4 because the interviewee is clearly stating that the company (XYZ) makes sure to put people in the right place, that denotes control; on the other hand the later example is coded L4 because it implies that a group had to be created from scratch, tapping into the resources that existed already in the company, which denotes learning. Another helpful analogy might be to think of a kitchen pantry that holds a set list of ingredients. In the first example we create an old family recipe using those ingredients, a recipe we have made successfully many times before. In the second example it would be more apt to say that we took those 
same standard ingredients and created something new and different that we had never made before. The ingredients are the same, the proportions, preparation, and methods are all different.

\section{The control codes}

Cl is sub-code for Control Budget Based; this sub-code was used when money was at the origin of decisions made. This means that management chose to use its position to give preference to monetary issues like budget reduction, monetary or human resource allocation, over or under stocking of supplies, using less than desirable amounts of supplies or needlessly expensive ones, or incentives of money or food. To give a sense of the statements that fell into the $C l$ category:

- I want the two of you to work together and find a solution; have you found the solution yet? Nope. OK. Well you just got a 10\% budget cut.

- We actually track the number of CPU usage hours while we were serving meals versus not serving meals.

- $\quad$ But at the end of the day what drives us, are last quarter's revenues. I mean last quarter's, because I ain't going to spend this quarter's if I don't show what I made last quarter.

- In order to make the same amount of money, given a delivery date, every week you want to slip it, it better be one percent faster or its life will produce one percent less money. 
In the above examples the threats of a budget cut, revenues or enticement of a meal were examples of monetary control.

The incidence of the $C l$ sub-code within the parameters of this research was 13 out of a total of 1,014 codeable data points, or a frequency of $1.28 \%$ of the time (See Figure 1).

C2 is sub-code for Control Time Based; this sub-code was used when time was the source of the decisions made or enforced. This means that management chose to use its position to give preference to time issues like: following or compressing the schedule, keeping (attending) meetings, early testing, timing for delivery, reducing time for development cycles, second shifts, etc. Statements made during the in depth interview are:

- $\quad$ By God, that schedule says I'm going to do something by that date, and we're going to do that by that date, regardless of whether or not it's the right thing to do at the time.

- $\quad$ Trust me, marketing drives that date; that date is set in concrete.

- We pretty much did what we say five years ago within a month of when we said we would do it.

- $\quad$ Most of the people that we have -- have families, social lives, not real crazy about working second shift, the second shift didn't go over with a real bang.

- We didn't have a lot of time with Red River; so we had to get people that were capable of coming up to speed very fast. 
- We had a pretty good feel. I think the actual elapsed time from when we got it in hardware system tests, our piece of the work, was about nine months, and that's what we projected.

These quotes illustrate the perceived power that time/timing held within the process.

The incidence of $\mathrm{C} 2$ sub-code within the parameters of this research was 23 out of a total of 1,014 codeable data points, or a frequency of $2.27 \%$ (See Figure 1).

C3 is sub-code for Control Personnel Based. This sub-code was used when particular individuals were the source of the decisions made or enforced, meaning that individuals chose to use their position for issues like controlling other's activities, pushing people's buttons, coordinating teams, setting priorities, doing whatever it takes, giving focus, sharing or not sharing processes, planning, risk taking, anticipating problems, committing, team building, goal reaching, leadership, offering technical, skilled leadership, forceful vision, dictating, etc. To give a sense of the statements made, several in depth interview statements are included:

- $\quad$ These are my 300 guys that I'm focused on right now; it's hard to keep the herd going.

- $\quad$ My role is to do whatever it takes to ship the system to customers.

- Well, we whooped Solei*'s tail. We did what we said we'd do five years ago.

- $\quad$ Once it is agreed what sequence and affordable resources (are available), from there on, it's tops down. 
- We were able to meet this schedule. That's a direct reflection on a lot of people.

- They basically would come to us and say, "Bet you can't do this," and we'd get it out and we'd ship it, and whether it was the right thing to do or not depended on who was the guy leading the charge.

These examples of $C 3$ data points show that the control issue was one of managing personnel and resources. The incidence of the $C 3$ sub-code within the parameters of this research was 118 out of a total of 1,014 codeable data points, or a frequency of $11.64 \%$ (See Figure 1).

C4 is sub-code for Control Organizational Structure Based; this sub-code was used when the organizational infrastructure was the source of the decisions made or enforced, meaning that management relied on the infrastructure already in place to exploit that previous knowledge for purposes like: ending other projects to reallocate resources, stopping error creation, making product variations, fast production, reliable and inexpensive products, vertical or horizontal integration, branding, traditional organizational model, organizational priorities, mergers, mechanisms, etc. Following are examples from the $C 4$ sub-code:

- There's no shortage of ideas. There's a couple of good things about XYZ, and one is there's really smart people here, and if you want to do something, you can always find some people in XYZ,

- $\quad(\mathrm{XYZ})$ makes sure that all the various organizations put their people in the right place. 
- There aren't many companies in the world that really have that level of ability, not just financial but in people skills and technology.

- $\quad$ You need the will; the only way we succeeded was we had the commitment of the entire corporation behind us.

- $\quad$ This is from a lot of history, we've done this for many years on systems, and we know how long it takes typically to get through the problem sets to get something out the door.

- $\quad$ The fact that we have built up the skills of the organization through a couple of generations of product, there's no way we could have done this just hiring new people.

These quotes highlight the extent to which participants felt the success of Red River relied on the XYZ infrastructure.

The incidence of the $C 4$ sub-code within the parameters of this research was 169 out of a total of 1,014 codeable data points, or a frequency of $16.67 \%$ (See Figure 1).

C5 is sub-code for Control Environment Based. This sub-code was used when the landscape of the organization was inserted to play a role in the decisions made or enforced. This means that management was driven by external forces like the market, physical location, parts providers, the industry, material constraints, the media, competition, organizations in charge of industry standards, and so forth. These data points exemplify the $C 5$ sub-code: 
- We had made a lot of forecasts about what the competition was going to be doing in the future and exactly what features we had to bring in to intercept and get better.

- In the meantime, your competition is not sitting still, he's busily trying to outdo you, and you might discover that there are some things that you thought, a place where you thought the competition was going to be where he's moved you've got to go back and revisit the current definition.

- I would say that it was obviously the necessity in the market.

- $\quad$ The demand for parts was always larger than the supply.

- And it helps to understand that there were constraints that we don't live in a perfect world. We have (only) this much silicon.

- I have one person who officially represents the Corporation on one of the key standards bodies as we're developing future benchmarks.

In these examples the market is clearly exerting force on the innovation process.

The incidence of the $C 5$ sub-code within the parameters of this research was 22 out of a total of 1,014 codeable data points, or a frequency of 2.17\% (See Figure 1).

C6 is sub-code for Control Geography Based. This sub-code was used when the geographical location of the organization played a role in the decisions made or enforced, meaning that management was accommodating for geographical locations. In most cases this referred to human agents operating in different locations with a significant geographic separation. For example: 
- You can always manage the site that you came from much easier than you can the remote site; on Monday morning he'll get on a plane most weeks, maybe three out of four weeks, and fly to Presidio*2, drive the organization from there, and on Friday night fly home.

- I said, you know, I can either be in Brazos* doing somewhat hardware-related stuff or I could be in Atascosa* doing hardware-related stuff. Of the two cities, where would I rather be unemployed? And at that time, Atascosa was the city.

- So the organizations seem to work real well together here, unlike other organizations where people snipe at each other. It seems to be a Medina* trait where none of that really happens.

- $\quad$ A guy asked his boss, you know, everybody in Atascosa's getting a raise; how come we're not getting raises, or interim raises? And the boss said, because you don't live in Atascosa. So, there's no place else to go in Presidio, so you either work here or go work at McDonald's. Now it's your choice. There were a lot of things that played into that.

The incidence of the C6 sub-code within the parameters of this research was seven out of a total of 1,014 codeable data points, or a frequency of $0.67 \%$ (See Figure 1). While there are few items in C6, their influence cannot be overestimated. Managing a developing organization out of a suitcase, while living in a weekly hotel, is an unbelievably difficult task for both managers and their families.

\footnotetext{
${ }^{2}$ Pseudonyms were used to disguise identities.
} 


\section{The learning codes}

L1 is sub-code for Learning Budget Based; this sub-code was utilized when money was the origin of the decisions made or enforced. Meaning that management used/pay money to learn, examples are: getting people with ideas, choose between scarce/limited resources, etc. To give a sense of the statements included in this category:

- Like in the real world there's a limited supply of resources, and so here's how much resource I have. Now you have to pick and choose.

- We had a number of those situations, and we would respond to it in different ways. We would buy—we would put in an emergency purchase.

- But then, now, there's -- the other side of it is that how many of this kind of project that a corporation can afford?

- When you're spending that much money, you get people with big egos who've got powerful ideas, so they had to learn how to deal with those big egos.

Regardless of the limitation or abundance of resources, agents were forced to learn how to make-do with the budget they had.

The incidence of the $L 1$ sub-code within the parameters of this research was five out of a total of 1,014 codeable data points, or a frequency of $0.49 \%$ (See Figure 1).

L2 is sub-code for Learning Time Based. This sub-code was used when time forced the pace of learning, meaning that time constraints were given preference when considering issues like: developing prototypes, optimizing, allow practice runs, compress schedule, etc. Statements made during the in depth interview are: 
- The longer it takes, since things change - trends in the industry, customer preferences, organizational structures, the rates of funding, perceived sustainable incomes. And the longer you take, the more that stuff changes, there's a project like this, and when you look back, it was never 100 percent right.

- An opportunity presented itself in that we were able to run the processor at a faster what you would call cycle time than we had thought. So we were able to get to where we intend to get to, but we got there in a slightly different way.

- $\quad$ So you know you're going to have to go back and figure it out later.

- $\quad$ There were plenty of novel ones certainly. The crisis $d u$ jour. There was always something threatening to upset the time line and get off schedule.

- $\quad$ Crunch the schedule. And the schedule always gets crunched down to the test time.

- $\quad$ So we can be executing two instruction strings at the same time. So we planned out-of-order. So they took the GP out-of-orderness, and doubled its complexity.

- I mean, this device, in the amount of time that we had to do it, I'm not sure if we've done anything like that before.

- While you're on the project, normally if somebody brings up something that happened three weeks ago, it seems like it might as well have been the Roman Empire. I mean, it's like things are going so fast that you normally don't think in terms of, let me understand exactly what was happening. 
The sole passing of time forces the agents to keep on learning, to keep up with the pace.

The incidence of L2 sub-code within the parameters of this research was 40 out of a total of 1,014 codeable data points, or a frequency of $3.94 \%$ (See Figure 1).

L3 is sub-code for Learning Personnel Based. This sub-code was used when particular individuals were the source of learning, or promoting learning, for issues like allowing risk taking, team building, sharing knowledge, sharing experience, etc. To give a sense of the statements made, a few in depth interview statements are included:

- $\quad$ You need to have the courage to try, and the capability to do it, because let me tell you, we did not know how to do it when we started and we knew it. Everybody else knew it, too. But we knew we could figure it out.

- $\quad$ And adapt to what you learn as you go.

- $\quad$ You need to have different styles of discussions depending on what you're trying to get done with whom.

- $\quad$ One of my people says I'm a peripatetic manager. So usually about once a day I try to walk around and have a feel for what my people was working on? And they may vent on me or but you learn a lot more by going to their office than trying to call meetings and those types of things.

- We're a fantastic team; they were really hungry folks for knowledge.

- $\quad$ Some of it would just be innovation, somebody coming up with an idea of a better way to implement something.

- $\quad$ And it's passion because it's not compensated for. 
- If there's a fork, it'll go down both sides, and say, Well, I can't really decide whether it's going to be going this way or going that way, but I'll go ahead and I'll start down both sides and hopefully before I get to far, I can figure out which one is right.

The above statements show how confident the agents were of their personal and personnel ability to figure out what needed to be done.

The incidence of the $L 3$ sub-code within the parameters of this research was 184 out of a total of 1,014 codeable data points, or a frequency of $18.15 \%$ codes (See Figure $1)$.

L4 is sub-code for Learning Organizational Structure Based, this sub-code was used when the organizational infrastructure provided the knowledge and infrastructure needed to learn. This means that the knowledge to innovate was already in-house, but needed to be utilized in new and creative ways for purposes like: alignment of priorities, stopping error creation, making product variations, outsourcing non interesting procedures, forcing change, branding, organizational priorities, mergers, mechanisms, etc. Here are some examples from the $L 4$ sub-code:

- We do somewhere around five products in parallel, with five different leaders with ownership; and if we have not-a-clear alignment of priorities of amongst all these organizations, you end up with total chaos.

- $\quad$ I think we managed it very, very careful. We knew that we always portrayed this as a high-risk project that we're doing, so we put the right risk-management and project-management measures in place to deal with it. 
- $\quad$ So we brought in probably a handful of people from various places in XYZ to help create this new team and the new team culture and as well as a rigorous project management.

- I had probably one of the best teams you can have, and I could tap into all our research facilities, which are world-class too at every problem that we face. So there was never a question about should we go out (side). I think we have fairly good resources within XYZ.

- $\quad$ Before the project started there was an effort in place to think about potentially buying a company, and that's effectively what kicked this project off. The conclusion was no, let's not, but why can't we do it ourselves, and then we just started from there.

- $\quad$ The way work gets done in the organization, especially a big complex one like $\mathrm{XYZ}$, is that everybody has a little bit of knowledge and you can't put something like a complex silvex out without tapping all that knowledge.

The incidence of the $L 4$ sub-code within the parameters of this research was 94 out of a total of 1,014 codeable data points, or a frequency of 9.27\% (See Figure 1).

L5 is sub-code for Learning Environment Based. This sub-code was used when the landscape where the Atascosa location is inserted was playing a role in prompting the learning. The Atascosa location served as an attractor for talent and resources throughout XYZ. And it was driven by external forces like: the market, physical location, parts providers, the industry, material constraints, the media, competition, XYZ as whole, etc. To give a sense of the statements made, a few in depth interview statements are included: 
- We're pretty good on the internal stuff. So we can keep that what we call the market environmental changes, are much more complex.

- $\quad$ And then the other movement is that markets are changing outside, so you need to bring in different requirements.

- We basically start from what are the customer requirements and design it back into what are the key things you have to put into the architecture.

- You can control to some extent how well you execute, but the competition you just have to assume they're going to do as well as they're capable of and base your plans on that.

- Well, competition of other people starting up business in Atascosa. There's a lot of competition for the talent on the team.

- Just the economic forces at place in the world around us: September 11 and the economy and how many people are investing in.

- Here is a technical interchange, an ongoing technical interchange of business intelligence in various forms to make sure that you're developing the right product.

- $\quad$ And we've got press because we happened to just be there at the exact same time that Intel was there with an approach that was very different than ours. You couldn't have planned it.

- $\quad$ There is no cookbook answer. You've got to put in perspective where XYZ was in the market then. 
- You have to modify those plans due to the reality of what's being shipped to you. And so you feel like a lot of your planning work has been invalidated.

The incidence of the $L 5$ sub-code within the parameters of this research was 177 out of a total of 1,014 codeable data points, for a frequency of $17.46 \%$ (See Figure 1).

L6 is sub-code for Learning Geography Based. This sub-code was used when the geographical location of the organization played a role on the learning, meaning that management was learning from having a few different geographical locations. To give a sense of the statements made, a few in-depth interview statements are included:

- $\quad$ Most of the people we work with are in Medina, Victoria*, Bandera*. Okay? And we've got a growing contingent in Bowles*.

- I think this is at least the first time I've been involved with a design team that was spread across multiple sites. We had three main sites that were actively involved in it and at times help from two or three other sites.

- If you had to point to what was something that went outstandingly well on the project it was the management across the multiple sites and the way people generally were kept all really in the same direction.

- A at that time, the job market in Atascosa was really hot, and we were the new place to be. Our competitors knew it.

- So that makes a huge difference as far as what people are doing and where they are willing to come then. I think having it in Atascosa helped. Whether it was done on purpose or not, it really helped draw a lot of talent to the project. 
- We were doing what is called distributed development, you know, where many of the developers were here, but some were in Refugio*, some were in Presidio. The suppliers, in fact, none of the suppliers were in Atascosa.

The incidence of the $L 6$ sub-code within the parameters of this research was 23 out of a total of 1,014 codeable data points, for a frequency of $2.27 \%$ (See Figure 1).

\section{“Syncretic Effect" Between control and learning}

Borrowing from Browning, Greene, Sitkin, Sutcliffe, and Obstfeld (2009), who stated that "The combination of control and learning in projects and organizations is a syncretic achievement," (p. 107) the term "Syncretic Effect" here refers to the finding of paradoxical behavior in how control and learning acted, at certain points in time, like two interrelated forces that preserved simultaneously the distinctive characteristics of each. In other words, it behaved with a geometric effect, instead of an arithmetical one or like the convenience marriage of antonymous ideas. In the language of complexity, this means the sum is greater than the parts.

The etymology of the word syncretism derives wholly from the Greek. The prefix syn, "with," and krasis, "mixture," combine in the word syngkretismos, direct forerunner of syncretism (Stewart \& Shaw, 1994, p. 3). This compound word first appears in the writings of Plutarch linked to the word kretoi, "Cretans." Plutarch seems to convey the complex sociopolitical penchant of the Cretans for quarreling fiercely amongst themselves but presenting an incredible unified front when confronted by an enemy. Thus, the first meaning of the word syncretism was "the coming together of Cretans." 
Although the term syncretism has been most closely associated with religion, (Morrison, 1990), (Mosse, 1994), (Webster, 1997), it has also been found in many other fields over the years such as: in anthropology settings (Stewart, 1999), in business setting (Lado, Boyd, \& Hanlon, 1997), in language settings (Baerman, Brown, \& Corbett, 2005), and in cultural settings (van der Veer, 1994). In every case the term is used to describe the working concert of two normally opposing ideas or forces.

In the data gathered from the XYZ Red River project, it quickly became clear that the two forces of control and learning though usually considered polar opposites were in fact acting with syncretism to allow the agents to reach their goal. This is seen in the circumstances that XYZ was embedded just before they embarked in the "Red River" micro-device* innovation; after enjoying for many years a privileged number one position on the market, they had slipped down to fifth place (out of five), and they were desperate to regain their leadership in the market. In many ways, the first interpretation Plutarch gave to Syncretism ("the coming together of Cretans"), is very similar to what happed within the walls of XYZ. The internal organizational culture of XYZ was like a conglomeration of four to five rival tribes that fought in two-year cycles for funding of their own individual projects to keep them alive. Some of them got killed and some others survived, depending on their return over investment; but to accomplish XYZ's goal of regaining the number one market position, the rival tribes worked together and succeeded, just like the Cretans. 


\section{FINDINGS}

\section{Analysis of syncretism}

This section offers an analysis of the syncretic dynamic among the categories by demonstrating some specific examples from the interviews. In the example presented below from a single interview, note the following statements. He first says, "But these communities came about from radically different histories with all sorts of conflicts over work for their town or money for their executives, personal advancement." This example shows that the different geographical locations require individuals to learn and adapt to each other because their relative personal power may be fairly equal. But in the next phrase of the interview, their initiative for advancement shows their willingness to exert personal power. Here he says:

One of the reason we started that was we said we need to create this new culture where everybody understands here's the priorities, here's the vision, here's where we're going. And it's very easy if you start out with ten people sitting in a room saying, Here is what we want to do, and here's why, and you argue back and forth, and finally you agree, okay, this is the vision; here's the three priorities; let's go and do it.

My analysis of this is as follows: when one is coming from radically different histories the situation requires amenability for learning/exploration ${ }^{3}$ on the agent's part to understand or make sense of the new conditions in the environment, on the other hand, seeking personal advancement is a trait that requires control/exploitation, of certain qualifications previously learned or acquired.

\footnotetext{
${ }^{3}$ The use of exploitation and exploration in this text comes from March's (1991) definition.
} 
The need to create something new is an acknowledgement of the desire to find a new local optima, which Boisot and Childs, (1999) describe as a new horizon or a grand redefinition of what they are doing. To make such a marked change, it was imperative to be open to learning/exploration of new ways to do things, while at the same time, enforcing the execution of requirements using terms such as, "this is the vision lets go and do it," which shows how control/exploitation was deeply rooted in the XYZ culture.

For another example, let me offer how this team that was in different geographical locations offered each other help across time and space. This person says, "I guess there's a couple of things. One is just the cross-area teamwork of people from Refugio, people from Presidio, people from Atascosa, some people from Gonzalez*, people from Irion* all working together, so that's the geographical teamwork." He then overlays geography with functionality by identifying how "the developers, the testers, the KIA* developers, the KIA testers, the hardware test groups, all of those people working together."

This functional cross-area teamwork shows how XYZ's control/exploitation of previously acquired experiences helped to overcome the challenges of learning/exploring of different work ethics and idiosyncrasies when the team is located all over the world. Still, all the differences in space and time required adaptations to be made. As the interview piece below shows, they did this via training that assisted in the product's development.

It worked out pretty well. There was a lot of training and learning on the new members of the team and people from other sites that hadn't been involved in this type of design before. And one thing that I think came out was less of the wild innovation and risky design types that people initially were looking at, were going to have to do all this blue sky sort of stuff to make the goals, the performance 
target that we were shooting for and so forth, that everything was going to have to be very unique and inventive.

This demand for novelty and invention was offset by an awareness of the risks involved and how to control them. He says, "in the end in a lot of areas we were able to minimize risk by saying, How much more -or basic design style will be much safer and much less going to cause much less problems in the end and will still meet the needs of the project." As a result, they were constantly playing learning and control off of each other to keep an appropriate balance between the two. Having members training and learning shows the exploring/learning involved in the project, on other hand, being able to minimize risk exemplifies the control/ exploitation side of the managers' minds.

The next example shows their view that despite the requirement for innovation, they saw the project as relatively stable, this interviewee says, "A surprisingly high amount (went according to plan), maybe $75-80$ percent. There were all sorts of little deviations along the way that would be unforeseen things that came up, but by and large, the high-level schedule was really close." A high amount of things going according to plan shows control/exploitation of previously acquired knowledge, on the other hand, as the next piece of interview demonstrates, deviations along the way were unforeseen. This shows how they were forced to complete learning/exploration extemporaneously as they moved through the phases of product development. This person says, "We're much more conscious of escapes through the next level than we have ever been which is a good thing, because it makes us constantly improve what we're doing." Escapes through the next level is a technical term that refers to keeping bugs in the product from slipping 
through undetected. Their consciousness of keeping mistakes at their own level and being solved shows their focus on control of this item. Throughout the project they were able to design "traps" to control the quality of the technology they were producing. When XYZ was constantly improving it showed a predisposition to learning/exploration, on the other hand, being much more conscious of escapes shows their control/exploitation of previous knowledge.

The next example exemplifies the double-looped learning I have made one of the themes of this project. The example addresses how information is both send up and sent down the hierarchy. This interviewee says, "I think I've already stated what I thought was the key driver and that was the focus, the top-down focus, the bottom-up responses. I think that's key."

He notes that such attention to communication both up and down the project was unusual, or at least not the norm for project communication. He adds, "I've been on projects where we didn't have that and the schedules slips, nobody seemed to mind or notice, and they just kept slipping." His view of the consequence of this oversight is fairly remarkable. He continues, "We got the product out the door but by the time it got there, it was a day late and a dollar short, the competition was already ahead of you." The last statement is crucial for this dissertation because it summarizes the issue that faced XYZ at the beginning. They had rested on their reputation to the extent that they did not show much concern when a product was late because their brand name would save them.

Having a top-down focus on communication shows the side that enforces the project's control/exploitation; on the other hand, allowing the bottom-up responses shows 
the side that appreciates the importance of self organizing or in my concept for this dissertation, continuously exploring/learning.

This example, while somewhat like earlier ones, is different because it shows that the plan was both important, but overridden by the exigencies of the situation. In this example, the interviewee relates device development to the demands of the final product. "Well, I think the project itself is kind of woven around the central focal point which was the device development activity." He makes the point that while device development was critical, "the actual development of the product, the final version of the product was kind of a multi-step process.” By multi-step process, he is referring to changes that took place along the way to a final product. He concludes by saying, "Before I came aboard, there had been a lot of activity on device designing products, but the final version of the product migrated over those iterations." In this example, having a central focal point, shows the control/exploitation side of the equation and the exploring/learning side is displayed with the reference to product migration after the course of iterations.

The next example is communication specific because it focuses on a common vision that allows agents to move in the same direction together. The control and learning thesis in this instance is simply honest communication about the strengths and weaknesses of any given choice. This person comments, "Part of the team building, you know, is honest communication and sometimes over-communication to make sure that, you know, all of the pluses and minuses about the situation and the alternatives were put on the table." He goes on to emphasize that "nobody held back from what they thought 
was the right thing. So that the best decision could be made based on the best information that we had."

In this example, knowing the pluses and minuses about a situation denotes control/exploitation of previous experiences; on the other hand, new team building by sharing honest communication is learning/exploration, which I develop in the following example on how teamwork developed out of the pains and gains that came from their common experience. Here is his artful commentary on this topic. "If you can laugh together and you can cry together you become one team, which was painful, but I think it finally did create a single team. People understood — finally began to understand - roles that different folks were playing." The process of become one team requires selforganizing or learning/exploration from the team members' part, but on the other hand understand roles that different folks were playing denotes control/exploitation of previous experiences.

The next example offers a kind of resilience by denoting how people's roles changed throughout the project. This person says, "You have to remember this is a long project, too, so it took roughly five years from the time I started to go out so during that time, people change. Right?" He goes on to acknowledge that the obvious but rarely mentioned metamorphosis that can take place in people's lives affected the project. "People's careers change; people grow; people atrophy; people leave. So it's not static to say what roles you play. Different -- for most people the role they play at the end is different than the role they played at the beginning." One of the themes of this dissertation is the dynamical change that occurs in a non-linear fashion in organizations. 
This person's statement captures this idea cogently. When you are playing a role you are exercising control/exploitation of some previously acquired experiences by enacting a role that may be somewhat prescribed or culturally defined, but, mutating the role played according to evolutionary needs into something different requires learning/exploration.

This final example of the balance or alternation between control and learning is instructive for two reasons. It shows you are capable of making the proper decision if you are communicating and it also shows that you are disciplined about that communication to the extent you make it a routine that is followed religiously. He says, "We had meetings just about every single day where we were making decisions based on what was happening right at that time." This attention to current activity in a careful and reliable manner is a form of control. To continue with the terms of my analysis, the purpose of having meetings every day is control/exploitation, but making decisions based on what was happening right at that time denotes the not so obvious learning/exploring process needed to read the current state of the environment.

\section{CONCLUSION}

The incidence of the "Syncretic Effect" codes, within the parameters of this research, amounted to 139 out of a total of 1,014 analyzable pieces of data (See Figure 1), which amounts to a frequency of $13.71 \%$. After a detailed analysis of all the 1,014 codeable pieces of data, described above, I am able to present one core finding: The recognition of the Syncretic Effects (Sutcliffe, Sitkin, \& Browning, 2000), that emerged from the data and affect the continuum of control and learning. Further, my review of the 
literature on control and learning, found no research that would help us estimate the contribution of the synthetic/syncretic contribution to a project. With $13.71 \%$ of the data in this research project established as operating in this unique position, we now have a single example of how much action is required at this middle point to function effectively. While I am not claiming that more or less syncretic codes could function effectively, from an applied perspective, having $14 \%$ of action operating in this balance appears to be a goal for organizations to aim for and for future research to use as a benchmark for comparisons.

My intent for this finding is to give a deeper level of understanding regarding the behavior these two variables when control and learning are both required on a project. My position regarding the emergence of this finding is tied to the theoretical addition of the complexity framework (Gell-Mann, 1994). This framework enabled me to recognize the feedback loops as demonstrated by having top-down communication operate simultaneous to bottom-up communication. The complexity analysis also includes nontrivial interactions such as the meetings which are sometimes derided as a waste of time, but in this instance were celebrated as a useful way of keeping up with the strengths and weaknesses of what they were doing, day-to-day, as the project progressed. The complexity analysis also shows the non-linear relationships among the whole network of stakeholders in which the organization was embedded. The non-linearity of their behavior is evidenced by their flexibility in locating resources, even if there was an in-house provider that had the product; they exercised the freedom to go anywhere to get anything that was needed for the advancement of the product. Complexity is also evidenced in the 
dynamism of the agents. This product was developed during the period of the dot-com bubble where technical/engineering talent was a hot commodity. The dynamism is evidenced in the team's ruthlessness in seeking the talent they needed and in some instances recovering the talent they had lost to competitors who came in with higher offers.

The study of the relationship between control and learning using grounded theory and a complexity framework, also, has not been researched previously. They have been studied independently, but not together. This additional step, I think, better informs the phenomenon because it recognizes the dynamism in which the relationship between control and learning is always located. My view here is not toward the agents as single individuals, but in their combined interactions. I argued that linearity was not going to solve the problem, given the complexity premise that the outcome is greater than the simple sum of the parts (Laughlin, 2005). Therefore I needed to account for that compound effect, and I think that with this approach I have substantiated that. 


\section{Chapter 5: Summary and Discussion}

\section{SUMMARY}

On October 4, 2001 Ronald Archer*, General Manager XYZ e-silver p-lines shared with the world the news that eventually provided the data on which this dissertation has focused.

Five years ago, set out to reinvent the , and today we are delivering groundbreaking technologies never before seen in systems. There is nothing in today's marketplace -and on the horizon - that begins to match its performance, reliability and flexibility to consolidate diverse workloads. 's innovation doesn't stop here; our next step will be to leverage 's main technology to reinvent the -based high-end market.

Although the information Mr. Archer provided is impressive, he had omitted a key detail; at the time XYZ was sitting on the bottom rung of the ladder in the silvexs' marketplace. This was a source of corporate shame for XYZ, particularly after holding onto first place for so many years. This lackluster marketplace performance was a wakeup call for $\mathrm{XYZ}$ and prompted them to take action.

During $2001 \mathrm{XYZ}$ invited a team of researchers, from The University of Texas at Austin, to conduct a lessons learned study, in order to understand what had happened during the Red River Blanco 4 micro-device innovation project. XYZ opened its doors and gave the research team access to executives involved with the project. 


\section{DISCUSSION}

It was known from the beginning that this project revolve around the creation of a micro-device that was done in record time for the industry standards that allowed $\mathrm{XYZ}$ to perform a quantum leap in the market to place them at the top, a true innovation.

With this picture of the context for the Red River innovation in mind, I positioned myself to discover where along the continuum of control and learning the innovation occurred. Using the wealth of earlier innovation literature as my beginning I first focused on the questions posed by Sitkin, Sutcliffe, and Schroeder, (1994) identified as in need of further study. Therefore, the umbrella research question was: where along the continuum of control and learning does innovation happen?

After an exhaustive review of the data and careful codification and categorization in a consequential matrix, this dissertation is a grand mapping or middle-range theory (Nonaka, 1994) of the categories into a causal system. A distinct pattern emerged from this analysis that prompted me to look into a set of research sub-questions.

The data were behaving somewhat differently from what the existing theory described; although control and learning theories, as mentioned in chapter two, portray innovation processes as settling around the learning end of the control learning continuum, my data was uncovering a behavior that differed from previous research.

Thus, the first sub-question - out of three- that derived from the umbrella research question was:

1. How do control and learning interact, as evidenced by the collected data? 
My data was describing a behavior that settled $13.71 \%$ of the time at the center of the continuum, which means that both ends of the continuum were weighing with the same force on the decisions taken. Each side, control and learning, were distinctively working in concert to help the team reach their target. When the need to work together disappeared they returned to working independently. An apt analogy would be to say that red and blue worked perfectly as stripes but never combined to become purple. It became clear that this was not a case of synthesis in the work place, rather a true case of syncretism (Browning, Greene, Sitkin, Sutcliffe, \& Obstfeld, 2009). The frequency of the actions coded as syncretism was $13.71 \%$, appears to have a significant function during innovation processes.

In previous research done by Brown and Eisenhardt (1997), reviewing a tangentially related industry, they found that "Managers with successful multiple-product innovation improvise current projects by combining clear responsibilities and priorities with extensive communication and freedom" (p. 25).

Although other codes, like $L 3, L 5$, and $C 4$ occur more frequently, a majority of the pivotal decisions in this innovation occurred at the point of syncretism.

The second sub-question emerging from the data:

2. With what frequency, if at all, does innovation occur at each end of the controllearning spectrum within this data set?

The answer is it all depends, which is the same qualifier that Kerlinger used in his classic summary of behavioral research (1965). Since the frequency of the codeable data 
points catalogued as only learning (including all sub-coding L1 to L6) occurred $51.58 \%$ of the time, on the other hand, actions catalogued as only control (C1 to C6) occurred $34.71 \%$ of the time, this shows us that in an innovation process the pendulum tends to swing toward the learning side of the continuum.

The third sub-question that emerged from the data was:

3. How do the collected data compare to the current body of research on control and learning in product development?

To this question there is no clear answer. The emergence of the syncretic effects in an innovation process has not been previously documented; therefore we have no basis for true comparison. Although syncretism appeared in a significant portion of the data, the majority of the data codes fell on the learning side, as previously recorded in the literature.

As the data coding unfolded, and armed with my knowledge on innovation theories, I was surprised to observe the sort of patterns that were emerging (Strauss \& Corbin, 1998). The pattern emerging differed from what had been previously known to occur during an innovation process.

From the Glaser and Strauss (1967) discovery of theory perspective, I argue that the contribution of this research project expands our tri-dimensional view of the innovation phenomenon; we now know that syncretic effects are also part of the controllearning continuum. 
I also assert that this research addresses the paucity of experimental learning as identified by Huber (1991).

Although this research brings more clearly into focus the role of control and learning in the innovation process, there are still many questions that remain unanswered. For example:

- How significant is the weight that budget, time, personnel, organizational structure, environment, and geography, place on the control end of the controllearning continuum, when innovating?

- How significant is the weight that budget, time, personnel, organizational structure, environment, and geography, place on the learning end of the controllearning continuum, when innovating?

- What is the significance of communication among agents, during an innovation process?

- How can research hubs/centers/universities foster innovation?

- Is there a way to design a "Petri Dish" that provides the rich broth needed to promote innovation's growth?

The innovation phenomenon is so broad that it needs to be continuously researched if our purpose is to foster and nurture it, at least, within the boundaries/walls of the academic world. 
Table 1

Aggregated Consequential Matrix

\begin{tabular}{|c|c|c|c|c|c|c|c|c|c|c|c|c|c|c|}
\hline & C1 & $\mathrm{C2}$ & C3 & C4 & C5 & C6 & L1 & L2 & L3 & L4 & L5 & L6 & I & SUM \\
\hline I-01-01 & & & & $\mathrm{X}$ & & & & & & & & & & \\
\hline I-01-02 & & & $X$ & & & & & & & & & & & \\
\hline I-01-03 & & & $X$ & & & & & & & & & & & \\
\hline \multirow[t]{3}{*}{ I-01-04 } & & & $X$ & & & & & & & & & & & \\
\hline & 0 & 0 & 3 & 1 & 0 & 0 & 0 & 0 & 0 & 0 & 0 & 0 & 0 & 4 \\
\hline & C1 & $\mathrm{C2}$ & C3 & C4 & C5 & C6 & L1 & L2 & L3 & L4 & L5 & L6 & I & SUM \\
\hline I-02-01 & & & & & & & & & & $\mathrm{X}$ & & & & \\
\hline I-02-02 & & & & & & & & & & $\mathrm{X}$ & & & & \\
\hline I- $02-03$ & & & & & & & & & & & $X$ & & & \\
\hline I-02-04 & & & & & & & & & & $X$ & & & & \\
\hline I-02-05 & & & & & & & & & & $X$ & & & & \\
\hline I-02-06 & & & & & & & & & & & $X$ & & & \\
\hline $\mathrm{I}-02-07$ & & & & & & & & & & & $\mathrm{X}$ & & & \\
\hline $\mathrm{I}-02-08$ & & & & & & & & & & & $\mathrm{X}$ & & & \\
\hline I-02-09 & & & & & & & & & & & $X$ & & & \\
\hline $\mathrm{I}-02-10$ & & & & & & & & & & & $X$ & & & \\
\hline $\mathrm{I}-02-11$ & & $X$ & & & & & & & & & & & & \\
\hline $\mathrm{I}-02-12$ & & & & & & & & & & & $\mathrm{X}$ & & & \\
\hline $\mathrm{I}-02-13$ & & & & $X$ & & & & & & & & & & \\
\hline $\mathrm{I}-02-14$ & & & & & & & & & & $X$ & & & & \\
\hline I- $02-15$ & & & & $X$ & & & & & & & & & & \\
\hline I- $02-16$ & & & & $X$ & & & & & & & & & & \\
\hline $\mathrm{I}-02-17$ & & & & $X$ & & & & & & & & & & \\
\hline I- $02-18$ & & & & & & & & & $X$ & & & & & \\
\hline I-02-19 & & & & & & & & & & & $X$ & & & \\
\hline I- $02-20$ & & & & & & & & & & & $X$ & & & \\
\hline I- $02-21$ & & & & & & & & & & & $X$ & & & \\
\hline $\mathrm{I}-02-22$ & & & & & & & & & $X$ & & & & & \\
\hline $\mathrm{I}-02-23$ & & & $\mathrm{X}$ & & & & & & & & & & & \\
\hline I- $02-24$ & & & & & & & & & & & & $X$ & & \\
\hline I- $02-25$ & & & & & & & & & & & & $X$ & & \\
\hline $\mathrm{I}-02-26$ & & & & $X$ & & & & & & & & & & \\
\hline $\mathrm{I}-02-27$ & & & & $X$ & & & & & & & & & & \\
\hline $\mathrm{I}-02-28$ & & & & & & & & & & $X$ & & & & \\
\hline I- $02-29$ & & & & & & & & & & & $X$ & & & \\
\hline $\mathrm{I}-02-30$ & & & & & & & & & & $\mathrm{X}$ & & & & \\
\hline I- $02-31$ & & & & & & & & $X$ & & & & & & \\
\hline $\mathrm{I}-02-32$ & & & & & & & & & $X$ & & & & & \\
\hline $\mathrm{I}-02-33$ & & & & & & & & & $X$ & & & & & \\
\hline I- $02-34$ & & & & & & & & & & & & & $\mathrm{X}$ & \\
\hline I- $02-35$ & & & & & & & $X$ & & & & & & & \\
\hline & 0 & 1 & 1 & 6 & 0 & 0 & 1 & 1 & 4 & 7 & 11 & 2 & 1 & 35 \\
\hline
\end{tabular}




\section{Consequential Matrix}

(Aggregated)

\begin{tabular}{|c|c|c|c|c|c|c|c|c|c|c|c|c|c|c|}
\hline & C1 & $\mathrm{C2}$ & $\mathrm{C3}$ & C4 & C5 & C6 & L1 & L2 & L3 & L4 & L5 & L6 & I & SUM \\
\hline I-03-01 & & & & & & & & & $\mathrm{X}$ & & & & & \\
\hline I-03-02 & & & & & & & & & & & $X$ & & & \\
\hline I- $03-03$ & & & $X$ & & & & & & & & & & & \\
\hline I-03-04 & & & $X$ & & & & & & & & & & & \\
\hline I-03-05 & & & & $X$ & & & & & & & & & & \\
\hline I-03-06 & & & $X$ & & & & & & & & & & & \\
\hline I-03-07 & & & $X$ & & & & & & & & & & & \\
\hline I-03-08 & & & & & $X$ & & & & & & & & & \\
\hline I-03-09 & & & & & $X$ & & & & & & & & & \\
\hline I-03-10 & & & & & & & & & & & $X$ & & & \\
\hline I-03-11 & & & & $X$ & & & & & & & & & & \\
\hline I-03-12 & & & & & $X$ & & & & & & & & & \\
\hline I-03-13 & & & $X$ & & & & & & & & & & & \\
\hline I-03-14 & & & $X$ & & & & & & & & & & & \\
\hline I-03-15 & & & & & & & & & $X$ & & & & & \\
\hline I-03-16 & & & & & & & & & & $X$ & & & & \\
\hline I-03-17 & & & & & & & & & $X$ & & & & & \\
\hline I-03-18 & & & & $X$ & & & & & & & & & & \\
\hline I-03-19 & & & $X$ & & & & & & & & & & & \\
\hline I- $03-20$ & & & $X$ & & & & & & & & & & & \\
\hline I-03-21 & & & $\mathrm{X}$ & & & & & & & & & & & \\
\hline I-03-22 & & & & & & & & & $X$ & & & & & \\
\hline I- $03-23$ & & & & & & & & & $X$ & & & & & \\
\hline I-03-24 & & & & & & & & & & & & & $X$ & \\
\hline I-03-25 & & & & & & & & & $X$ & & & & & \\
\hline I- $03-26$ & & & $X$ & & & & & & & & & & & \\
\hline I-03-27 & & & & $X$ & & & & & & & & & & \\
\hline I-03-28 & & & & $X$ & & & & & & & & & & \\
\hline I-03-29 & & & $X$ & & & & & & & & & & & \\
\hline I- $03-30$ & & & $X$ & & & & & & & & & & & \\
\hline I-03-31 & & & & & & & & $X$ & & & & & & \\
\hline I-03-32 & & & $X$ & & & & & & & & & & & \\
\hline \multirow[t]{3}{*}{ I-03-33 } & & & & $X$ & & & & & & & & & & \\
\hline & 0 & 0 & 13 & 6 & 3 & 0 & 0 & 1 & 6 & 1 & 2 & 0 & 1 & 33 \\
\hline & C1 & $\mathrm{C2}$ & C3 & $\mathrm{C4}$ & C5 & C6 & L1 & L2 & L3 & L4 & L5 & L6 & I & SUM \\
\hline I-04-01 & & & & & & & & & & & & $X$ & & \\
\hline I-04-02 & & & & & & & & & $X$ & & & & & \\
\hline I-04-03 & & & & & & & & & $X$ & & & & & \\
\hline I-04-04 & & & & & & & & $X$ & & & & & & \\
\hline I-04-05 & & & $X$ & & & & & & & & & & & \\
\hline I-04-06 & & & & & & & & & & & & $X$ & & \\
\hline I-04-07 & & & & & & & & & $X$ & & & & & \\
\hline I-04-08 & & & & & & & & & X & & & & & \\
\hline
\end{tabular}




\section{Consequential Matrix}

(Aggregated)

\begin{tabular}{|c|c|c|c|c|c|c|c|c|c|c|c|c|c|c|}
\hline & C1 & $\mathrm{C} 2$ & $\mathrm{C3}$ & C4 & C5 & C6 & L1 & L2 & L3 & L4 & L5 & L6 & I & SUM \\
\hline I-04-09 & & & & & & & & & & & & & $\bar{X}$ & \\
\hline I-04-10 & & & & X & & & & & & & & & & \\
\hline I-04-11 & & & & & & & & & $X$ & & & & & \\
\hline I-04-12 & & & & & & & & & & X & & & & \\
\hline I-04-13 & & & & X & & & & & & & & & & \\
\hline \multirow[t]{3}{*}{ I-04-14 } & & & & & & & & & $X$ & & & & & \\
\hline & 0 & 0 & 1 & 2 & 0 & 0 & 0 & 1 & 6 & 1 & 0 & 2 & 1 & 14 \\
\hline & C1 & $\mathrm{C2}$ & $\mathrm{C3}$ & C4 & C5 & C6 & L1 & L2 & L3 & L4 & L5 & L6 & I & SUM \\
\hline I-06-01 & & & & & & & & & & & & & $\mathrm{X}$ & \\
\hline I-06-02 & & & & & & & & & & $X$ & & & & \\
\hline I- $06-03$ & & & & & & & & & & & & & X & \\
\hline I-06-04 & & & & & & & & & & & & & $X$ & \\
\hline I-06-05 & & & & X & & & & & & & & & & \\
\hline I-06-06 & & & & $X$ & & & & & & & & & & \\
\hline I-06-07 & & & & & & & & & & & & & X & \\
\hline I-06-08 & & & & & & & & & & $X$ & & & & \\
\hline I-06-09 & & & & & & & & & $X$ & & & & & \\
\hline I-06-10 & & & & & & & & & & $X$ & & & & \\
\hline I-06-11 & & & & & & & & & X & & & & & \\
\hline I-06-12 & & & & & & & & & & & X & & & \\
\hline I-06-13 & & & & & & & & & & & $\mathrm{X}$ & & & \\
\hline I-06-14 & & & & & & & & & & $X$ & & & & \\
\hline I-06-15 & & & & & & & & & X & & & & & \\
\hline I-06-16 & & & $X$ & & & & & & & & & & & \\
\hline I-06-17 & & & & & & & & $X$ & & & & & & \\
\hline I-06-18 & & $X$ & & & & & & & & & & & & \\
\hline I-06-19 & & & & & & & & & & & $X$ & & & \\
\hline I-06-20 & & & & X & & & & & & & & & & \\
\hline I-06-21 & & & & & & & & $X$ & & & & & & \\
\hline I-06-22 & & & & $X$ & & & & & & & & & & \\
\hline $\mathrm{I}-06-23$ & & & & & & & & & & & & & X & \\
\hline I-06-24 & & & & $X$ & & & & & & & & & & \\
\hline I-06-25 & & & & & & & & & X & & & & & \\
\hline I-06-26 & & & & $X$ & & & & & & & & & & \\
\hline I-06-27 & & & & & $X$ & & & & & & & & & \\
\hline I-06-28 & & & & & & & & & & X & & & & \\
\hline I-06-29 & & & & & & & & & & & & & X & \\
\hline I-06-30 & & & & $X$ & & & & & & & & & & \\
\hline I-06-31 & & & X & & & & & & & & & & & \\
\hline I-06-32 & & & & X & & & & & & & & & & \\
\hline I-06-33 & & & & X & & & & & & & & & & \\
\hline I-06-34 & & & & X & & & & & & & & & & \\
\hline I-06-35 & & & & & & & & & $\mathrm{X}$ & & & & & \\
\hline
\end{tabular}




\section{Consequential Matrix}

(Aggregated)

\begin{tabular}{|c|c|c|c|c|c|c|c|c|c|c|c|c|c|c|}
\hline & C1 & C2 & C3 & C4 & C5 & C6 & L1 & L2 & L3 & L4 & L5 & L6 & I & SUM \\
\hline \multirow[t]{3}{*}{ I-06-36 } & & & & $\mathrm{X}$ & & & & & & & & & & \\
\hline & 0 & 1 & 2 & 11 & 1 & 0 & 0 & 2 & 5 & 5 & 3 & 0 & 6 & 36 \\
\hline & C1 & $\mathrm{C} 2$ & $\mathrm{C3}$ & C4 & C5 & C6 & L1 & L2 & L3 & L4 & L5 & L6 & I & SUM \\
\hline I-08-01 & $\mathrm{X}$ & & & & & & & & & & & & & \\
\hline I-08-02 & $X$ & & & & & & & & & & & & & \\
\hline I- $08-03$ & & & & & & & & & & X & & & & \\
\hline I-08-04 & & & & & & & & & & & X & & & \\
\hline I-08-05 & & & & & & & & & & & X & & & \\
\hline I-08-06 & & & & & & & & & & & $\mathrm{X}$ & & & \\
\hline I-08-07 & & & $X$ & & & & & & & & & & & \\
\hline I-08-08 & & & & & & & & & & & $X$ & & & \\
\hline I-08-09 & & & & $X$ & & & & & & & & & & \\
\hline I- $-08-10$ & & & & & & & & & & & X & & & \\
\hline I-08-11 & & & & & & & & & & & X & & & \\
\hline I- $08-12$ & & & & & & & & & & & $X$ & & & \\
\hline I-08-13 & & & $X$ & & & & & & & & & & & \\
\hline I-08-14 & & & $X$ & & & & & & & & & & & \\
\hline I-08-15 & & & & & & & & & & & $X$ & & & \\
\hline I-08-16 & & & & & & & & & $\mathrm{X}$ & & & & & \\
\hline I-08-17 & X & & & & & & & & & & & & & \\
\hline I-08-18 & & & & & & & $X$ & & & & & & & \\
\hline I-08-19 & & & & & & & & & $\mathrm{X}$ & & & & & \\
\hline I-08-20 & & & $X$ & & & & & & & & & & & \\
\hline I-08-21 & & $X$ & & & & & & & & & & & & \\
\hline I- $08-22$ & & & & & & & & & & & & & $X$ & \\
\hline I- $08-23$ & & & & & & & & & & & & & X & \\
\hline I-08-24 & & & & & & & & X & & & & & & \\
\hline I- $08-25$ & & & & & & & & $X$ & & & & & & \\
\hline I-08-26 & & & & & & & & & & & & & X & \\
\hline I-08-27 & & & & & & & & & X & & & & & \\
\hline I-08-28 & & & & & & & & & & & & & X & \\
\hline I-08-29 & & & & & & & & & & & $X$ & & & \\
\hline $\mathrm{I}-08-30$ & & & & & & & & & X & & & & & \\
\hline I-08-31 & & & & & & & & & X & & & & & \\
\hline I-08-32 & & & $X$ & & & & & & & & & & & \\
\hline $\mathrm{I}-08-33$ & & & & & & & & & & & & X & & \\
\hline I-08-34 & & & & & & X & & & & & & & & \\
\hline I-08-35 & & & & & & X & & & & & & & & \\
\hline I-08-36 & & & & & X & & & & & & & & & \\
\hline I-08-37 & & & & & & & & & X & & & & & \\
\hline I-08-38 & & & & & & & & & X & & & & & \\
\hline I-08-39 & & & & & & & & & $\mathrm{X}$ & & & & & \\
\hline I- $08-40$ & & & & & & & & & & & X & & & \\
\hline
\end{tabular}




\section{Consequential Matrix}

(Aggregated)

I- $08-41$

I- $08-42$

I- $08-43$

I- $08-44$

I- $08-45$

I-09-01

I-09-02

I-09-03

I-09-04

I-09-05

I-09-06

I-09-07

I- $09-08$

I-09-09

I- $09-10$

I-09-11

I- $09-12$

I- $09-13$

I-09-14

I-09-15

I- $09-16$

I- $09-17$

I- $09-18$

I-09-19

I- $09-20$

I-09-21

I- $09-22$

I- $09-23$

I-09-24

I- $09-25$

I-09-26

I-10-01

I-10-02

I- $10-03$

I-10-04

I-10-05

I-10-06

I-10-07

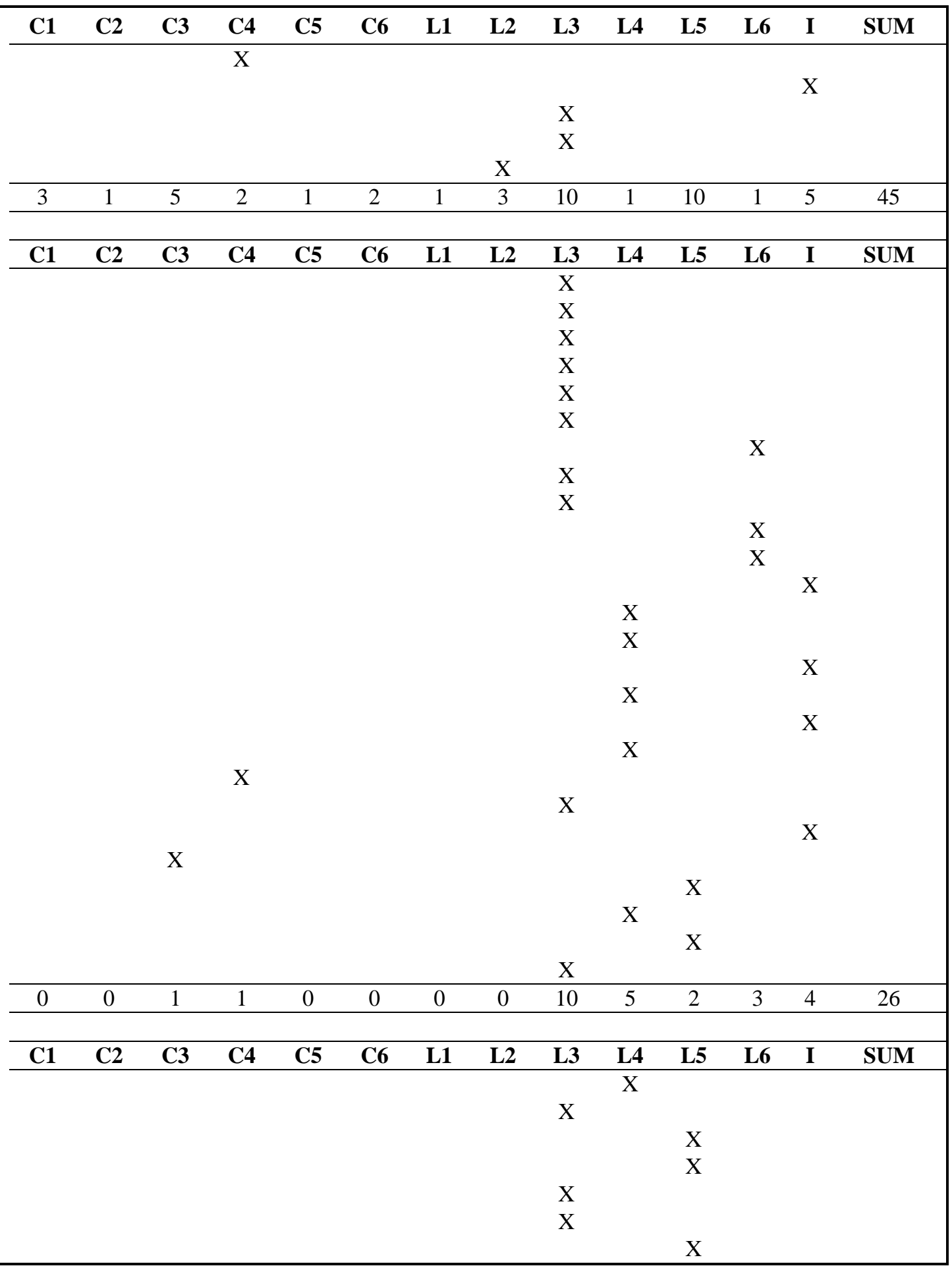




\section{Consequential Matrix}

(Aggregated)

\begin{tabular}{|c|c|c|c|c|c|c|c|c|c|c|c|c|c|c|}
\hline & C1 & C2 & $\mathbf{C 3}$ & C4 & C5 & C6 & L1 & L2 & $\mathbf{L 3}$ & L4 & L5 & L6 & I & SUM \\
\hline I-10-08 & & & & & & & & & & & & & $\mathrm{X}$ & \\
\hline I-10-09 & & & & $X$ & & & & & & & & & & \\
\hline I-10-10 & & & & & & & & & $\mathrm{X}$ & & & & & \\
\hline I-10-11 & & & & & $X$ & & & & & & & & & \\
\hline I-10-12 & & & & X & & & & & & & & & & \\
\hline I-10-13 & & & & & & & & & X & & & & & \\
\hline I-10-14 & & & & & & & & & X & & & & & \\
\hline I- $10-15$ & & & & X & & & & & & & & & & \\
\hline I-10-16 & & & & $X$ & & & & & & & & & & \\
\hline I-10-17 & & & & & & & & & & & & $X$ & & \\
\hline I-10-18 & & $\mathrm{X}$ & & & & & & & & & & & & \\
\hline I-10-19 & & & & & & & & & X & & & & & \\
\hline I-10-20 & & & & $X$ & & & & & & & & & & \\
\hline I-10-21 & & & & & & & & & & & & & $X$ & \\
\hline I-10-22 & & & & & & & & & & & & & $X$ & \\
\hline $\mathrm{I}-10-23$ & & & & & & & & & & & & & X & \\
\hline I-10-24 & & & & & & & & & & $X$ & & & & \\
\hline I- $10-25$ & & & & & & & & & $X$ & & & & & \\
\hline I-10-26 & & & & & & & & & & & $X$ & & & \\
\hline I-10-27 & & & & & & & & & & & & & X & \\
\hline I-10-28 & & & & & & & & & $X$ & & & & & \\
\hline I-10-29 & & & & & & & & & X & & & & & \\
\hline \multirow[t]{3}{*}{ I-10-30 } & & & $X$ & & & & & & & & & & & \\
\hline & 0 & 1 & 1 & 5 & 1 & 0 & 0 & 0 & 10 & 2 & 4 & 1 & 5 & 30 \\
\hline & C1 & $\mathrm{C} 2$ & $\mathbf{C 3}$ & C4 & C5 & C6 & L1 & $\mathbf{L 2}$ & L3 & L4 & L5 & L6 & I & SUM \\
\hline I-14-01 & & & & & & & & & & & $X$ & & & \\
\hline I-14-02 & & & & & & & & & & & $X$ & & & \\
\hline I-14-03 & & & & $X$ & & & & & & & & & & \\
\hline I-14-04 & & & & $X$ & & & & & & & & & & \\
\hline I-14-05 & & & & & & & & & X & & & & & \\
\hline I-14-06 & & & & & & & & & & & $X$ & & & \\
\hline I-14-07 & & & & & & & & & & & $X$ & & & \\
\hline I-14-08 & & & $\mathrm{X}$ & & & & & & & & & & & \\
\hline I-14-09 & & & & & & & & & & & & & X & \\
\hline I-14-10 & & & $X$ & & & & & & & & & & & \\
\hline I-14-11 & & & & X & & & & & & & & & & \\
\hline I-14-12 & & & X & & & & & & & & & & & \\
\hline I-14-13 & & & & & & & & & & & & & $X$ & \\
\hline I-14-14 & & & & & & & & & & & X & & & \\
\hline I-14-15 & & & & & & & & & & X & & & & \\
\hline I-14-16 & & & & & X & & & & & & & & & \\
\hline I-14-17 & & & & & & & & & X & & & & & \\
\hline I-14-18 & & & & & X & & & & & & & & & \\
\hline
\end{tabular}


Consequential Matrix

(Aggregated)

\begin{tabular}{|c|c|c|c|c|c|c|c|c|c|c|c|c|c|c|}
\hline & C1 & $\mathrm{C} 2$ & C3 & C4 & C5 & C6 & L1 & L2 & L3 & L4 & L5 & L6 & I & SUM \\
\hline I-14-19 & & & & & & & & & & & & & $\mathrm{X}$ & \\
\hline I-14-20 & & & & & & & & & X & & & & & \\
\hline I-14-21 & & & & & & & & & & & X & & & \\
\hline I-14-22 & & & & & & & & & X & & & & & \\
\hline I-14-23 & & & X & & & & & & & & & & & \\
\hline I- $14-24$ & & & & & & & & & & & & & $X$ & \\
\hline I-14-25 & & & & & & & & & & & $X$ & & & \\
\hline \multirow[t]{3}{*}{ I-14-26 } & & & & & & & & & & & $X$ & & & \\
\hline & 0 & 0 & 4 & 3 & 2 & 0 & 0 & 0 & 4 & 1 & 8 & 0 & 4 & 26 \\
\hline & C1 & C2 & C3 & C4 & C5 & C6 & L1 & L2 & L3 & L4 & L5 & L6 & I & SUM \\
\hline I-15-01 & & & & $X$ & & & & & & & & & & \\
\hline I-15-02 & & $X$ & & & & & & & & & & & & \\
\hline I- $15-03$ & & & & & & & & & & & & & $X$ & \\
\hline I- $15-04$ & & & & $X$ & & & & & & & & & & \\
\hline I- $15-05$ & & & & $X$ & & & & & & & & & & \\
\hline I-15-06 & & & $X$ & & & & & & & & & & & \\
\hline I-15-07 & & & & $X$ & & & & & & & & & & \\
\hline I- $15-08$ & & & & & & & & & & & & & X & \\
\hline I-15-09 & & & $X$ & & & & & & & & & & & \\
\hline I- $15-10$ & & & & & & & & & X & & & & & \\
\hline I- $15-11$ & & & & & & & & & $X$ & & & & & \\
\hline I- $15-12$ & & & & & & & & & $X$ & & & & & \\
\hline I- $15-13$ & & & & & & & & & & & X & & & \\
\hline I- $15-14$ & & & & & & & & & & & $X$ & & & \\
\hline I- $15-15$ & & & & X & & & & & & & & & & \\
\hline I- $15-16$ & & & & & & & & & & & & & $X$ & \\
\hline I- $15-17$ & & $X$ & & & & & & & & & & & & \\
\hline I- $15-18$ & & & & & & & & & & $X$ & & & & \\
\hline I- $15-19$ & & & & & & & & & $X$ & & & & & \\
\hline I- $15-20$ & & & & & & & & & & & $X$ & & & \\
\hline I- $15-21$ & & & $X$ & & & & & & & & & & & \\
\hline I- $15-22$ & & & & $X$ & & & & & & & & & & \\
\hline I- $15-23$ & & & & & & & & & & & X & & & \\
\hline I- $15-24$ & & & & & & & & & & & $X$ & & & \\
\hline I- $15-25$ & & & & & & & & & & & $X$ & & & \\
\hline I- $15-26$ & & & & & & & & $X$ & & & & & & \\
\hline I- $15-27$ & & & $X$ & & & & & & & & & & & \\
\hline I- $15-28$ & & & & & & & & & & X & & & & \\
\hline I- $15-29$ & & & & & & & & & & $X$ & & & & \\
\hline & 0 & 2 & 4 & 6 & 0 & 0 & 0 & 1 & 4 & 3 & 6 & 0 & 3 & 29 \\
\hline
\end{tabular}




\section{Consequential Matrix}

(Aggregated)

\begin{tabular}{|c|c|c|c|c|c|c|c|c|c|c|c|c|c|c|}
\hline & C1 & C2 & C3 & C4 & C5 & C6 & L1 & L2 & L3 & L4 & L5 & L6 & I & SUM \\
\hline I-18-01 & & & & $\mathrm{X}$ & & & & & & & & & & \\
\hline I-18-02 & & & & & & & & & & & $\mathrm{X}$ & & & \\
\hline I-18-03 & & & & $X$ & & & & & & & & & & \\
\hline I-18-04 & & & & & & & & & & X & & & & \\
\hline I-18-05 & & & & & & & & & & & & & X & \\
\hline I-18-06 & & & & & & & & & & & X & & & \\
\hline I-18-07 & & & & & & & & & & X & & & & \\
\hline I- $18-08$ & & & & & & & & & X & & & & & \\
\hline I-18-09 & & & & & & & & & X & & & & & \\
\hline I- $18-10$ & & & & & & & & & $X$ & & & & & \\
\hline I-18-11 & & & & & & & & & & & & & X & \\
\hline I- $18-12$ & & & & & & & & & & X & & & & \\
\hline I-18-13 & & & & & & & & & & $X$ & & & & \\
\hline I- $18-14$ & & & & & & & & & X & & & & & \\
\hline I- $18-15$ & & & & & & & & & & X & & & & \\
\hline I-18-16 & & & & & & & & & & $X$ & & & & \\
\hline I- $18-17$ & & & & & & & & & X & & & & & \\
\hline I- $18-18$ & & & & & & & & & X & & & & & \\
\hline I-18-19 & & & & & & & & & & & X & & & \\
\hline I- $18-20$ & & & & & X & & & & & & & & & \\
\hline I- $18-21$ & & & & & & & & & & & & & X & \\
\hline I-18-22 & & & & & & & & & & & X & & & \\
\hline I- $18-23$ & & & & & & & & & X & & & & & \\
\hline I- $18-24$ & & & & & & & & & & & & & X & \\
\hline I- $18-25$ & & & & & & & & & & $X$ & & & & \\
\hline I-18-26 & & & & & & & & & & & X & & & \\
\hline I-18-27 & & & & & & & & & & & $X$ & & & \\
\hline I- $18-28$ & & & & & & & & & & & $\mathrm{X}$ & & & \\
\hline I-18-29 & & & & & & & & & X & & & & & \\
\hline I- $18-30$ & & & & & & $\mathrm{X}$ & & & & & & & & \\
\hline I-18-31 & & & & & & & & & & & & X & & \\
\hline I-18-32 & & & & & & & & & & & & X & & \\
\hline I-18-33 & & & & & & & & & $X$ & & & & & \\
\hline I-18-34 & & & & & & & & & $X$ & & & & & \\
\hline I- $18-35$ & & & X & & & & & & & & & & & \\
\hline I-18-36 & & & & & & & & & $X$ & & & & & \\
\hline I-18-37 & & & & & & & & & & & & X & & \\
\hline I- $18-38$ & & & & & & & & & $X$ & & & & & \\
\hline I-18-39 & & & & & & & & & X & & & & & \\
\hline I- $18-40$ & & & & & & & & & $X$ & & & & & \\
\hline I-18-41 & & $\mathrm{X}$ & & & & & & & & & & & & \\
\hline I- $18-42$ & & & $\mathrm{X}$ & & & & & & & & & & & \\
\hline I- $18-43$ & & & & & & & & & & & & & $X$ & \\
\hline I- $18-44$ & & & & & & & & & & & X & & & \\
\hline
\end{tabular}




\section{Consequential Matrix}

(Aggregated)

\begin{tabular}{|c|c|c|c|c|c|c|c|c|c|c|c|c|c|c|}
\hline & C1 & C2 & C3 & C4 & C5 & C6 & L1 & L2 & $\mathbf{L 3}$ & L4 & L5 & L6 & I & SUM \\
\hline & 0 & 1 & 2 & 2 & 1 & 1 & 0 & 0 & 14 & 7 & 8 & 3 & 5 & 44 \\
\hline & C1 & C2 & C3 & C4 & C5 & C6 & L1 & L2 & L3 & L4 & L5 & L6 & I & SUM \\
\hline I-19-01 & & & & & & & & & & & $X$ & & & \\
\hline I-19-02 & & & & & & & & & & & $X$ & & & \\
\hline I-19-03 & & & & & $X$ & & & & & & & & & \\
\hline I-19-04 & & & & $X$ & & & & & & & & & & \\
\hline I-19-05 & & & & & & & & & $X$ & & & & & \\
\hline I-19-06 & & & & $X$ & & & & & & & & & & \\
\hline I-19-07 & & & & $X$ & & & & & & & & & & \\
\hline I-19-08 & & & & $X$ & & & & & & & & & & \\
\hline I-19-09 & & & & & & & & & & & & & X & \\
\hline I-19-10 & & & & X & & & & & & & & & & \\
\hline I-19-11 & & & & & & & & & & X & & & & \\
\hline I-19-12 & & & & X & & & & & & & & & & \\
\hline I-19-13 & & & & & & & & & X & & & & & \\
\hline I-19-14 & & & & & & & & & & & & & X & \\
\hline I-19-15 & & & & & & & & & & X & & & & \\
\hline I-19-16 & & & & & & & & & & & X & & & \\
\hline I-19-17 & & & & X & & & & & & & & & & \\
\hline I-19-18 & & & & & & & & & & & X & & & \\
\hline I-19-19 & & & & & & & & & & & $X$ & & & \\
\hline I-19-20 & & & & & & & & & & & & & X & \\
\hline I-19-21 & & & & & & & & & & & X & & & \\
\hline I-19-22 & & & & & & & & & & & & & X & \\
\hline I-19-23 & & & & & & & & & X & & & & & \\
\hline I-19-24 & & & & & & & & & & & X & & & \\
\hline I-19-25 & & & X & & & & & & & & & & & \\
\hline I-19-26 & & & & & & & & & X & & & & & \\
\hline I-19-27 & & & & & & & & & & & X & & & \\
\hline I-19-28 & & & & & & & & & & & $X$ & & & \\
\hline I-19-29 & & & & & & & & & & & $X$ & & & \\
\hline I-19-30 & & & & & & & & & & & $X$ & & & \\
\hline I-19-31 & & & & & & & & & & & & & $X$ & \\
\hline I-19-32 & & & X & & & & & & & & & & & \\
\hline I-19-33 & & & & & & & & & & & X & & & \\
\hline I-19-34 & & & & X & & & & & & & & & & \\
\hline I-19-35 & & & & & & & & & & X & & & & \\
\hline I-19-36 & & & & & X & & & & & & & & & \\
\hline I-19-37 & & & & X & & & & & & & & & & \\
\hline I-19-38 & & & & $X$ & & & & & & & & & & \\
\hline I-19-39 & & X & & & & & & & & & & & & \\
\hline I-19-40 & & & & & & & & $\mathrm{X}$ & & & & & & \\
\hline I-19-41 & & & & & & & & & & & & & $X$ & \\
\hline
\end{tabular}


Consequential Matrix

(Aggregated)

\begin{tabular}{|c|c|c|c|c|c|c|c|c|c|c|c|c|c|c|}
\hline & C1 & C2 & C3 & C4 & C5 & C6 & L1 & L2 & L3 & L4 & L5 & L6 & I & SUM \\
\hline I-19-42 & & & & & & & & & & & & & $\mathrm{X}$ & \\
\hline I-19-43 & & & & & & & & & & $X$ & & & & \\
\hline I-19-44 & & & & & & & & & X & & & & & \\
\hline I-19-45 & & & X & & & & & & & & & & & \\
\hline I-19-46 & & & & $X$ & & & & & & & & & & \\
\hline I-19-47 & & & & & & & X & & & & & & & \\
\hline I-19-48 & & & & & & & & & & & X & & & \\
\hline I-19-49 & & & & & & & & & & & X & & & \\
\hline I-19-50 & & & & & & & & & & & X & & & \\
\hline I-19-51 & & & & & & & & & X & & & & & \\
\hline I-19-52 & & & & & & & & & & & X & & & \\
\hline I-19-53 & & & & & & & & & & & $X$ & & & \\
\hline I-19-54 & & & & & & & & & & X & & & & \\
\hline I-19-55 & & & & & & & & & X & & & & & \\
\hline I-19-56 & & & & & & & & & & X & & & & \\
\hline I-19-57 & & & & & & & & & $X$ & & & & & \\
\hline I-19-58 & & & & & & & & & $X$ & & & & & \\
\hline I-19-59 & & & & & & & & & & & & X & & \\
\hline I-19-60 & & & & & & & & & & & & & X & \\
\hline I-19-61 & & & & & & & & & & & & X & & \\
\hline I-19-62 & & & & & & & & & & X & & & & \\
\hline I-19-63 & & & & & & & & & X & & & & & \\
\hline I-19-64 & & & & & & & & & & & X & & & \\
\hline I-19-65 & & & X & & & & & & & & & & & \\
\hline I-19-66 & & & & & & & & & X & & & & & \\
\hline I-19-67 & & & & & & & & & & X & & & & \\
\hline \multirow[t]{3}{*}{ I-19-68 } & & & & & & & & & $X$ & & & & & \\
\hline & 0 & 1 & 4 & 11 & 2 & 0 & 1 & 1 & 12 & 8 & 18 & 2 & 8 & 68 \\
\hline & C1 & C2 & C3 & C4 & C5 & C6 & L1 & L2 & L3 & L4 & L5 & L6 & I & SUM \\
\hline I-20-01 & & & & & & & & $\mathrm{X}$ & & & & & & \\
\hline I-20-02 & & & $X$ & & & & & & & & & & & \\
\hline I-20-03 & & & & & & & & & & X & & & & \\
\hline I-20-04 & & & & & & & & & & & $X$ & & & \\
\hline I-20-05 & & & & & & & & & X & & & & & \\
\hline I-20-06 & & & & $X$ & & & & & & & & & & \\
\hline I-20-07 & & & & & & & & & & & $X$ & & & \\
\hline I-20-08 & & & $X$ & & & & & & & & & & & \\
\hline I-20-09 & & & & $X$ & & & & & & & & & & \\
\hline I-20-10 & & & & & & & & & & $X$ & & & & \\
\hline I-20-11 & & & & $X$ & & & & & & & & & & \\
\hline I-20-12 & & & & & & & & & & X & & & & \\
\hline I-20-13 & & & & & & & & & & X & & & & \\
\hline I-20-14 & & & X & & & & & & & & & & & \\
\hline
\end{tabular}


Consequential Matrix

(Aggregated)

\begin{tabular}{|c|c|c|c|c|c|c|c|c|c|c|c|c|c|c|}
\hline & C1 & C2 & C3 & C4 & C5 & C6 & L1 & L2 & L3 & L4 & L5 & L6 & I & SUM \\
\hline I-20-15 & & & & & & & & & & & $X$ & & & \\
\hline I-20-16 & & & & & & & & & & & $X$ & & & \\
\hline I-20-17 & & & & & & & & & $X$ & & & & & \\
\hline I-20-18 & & & & & & & & & $X$ & & & & & \\
\hline I-20-19 & & & & & & & & & $X$ & & & & & \\
\hline I-20-20 & & & X & & & & & & & & & & & \\
\hline I-20-21 & & & & & & & & & X & & & & & \\
\hline I-20-22 & & & X & & & & & & & & & & & \\
\hline I-20-23 & & & & & & & & & & X & & & & \\
\hline I-20-24 & & & & & & & & & & & $X$ & & & \\
\hline I-20-25 & & & & & & & & & & X & & & & \\
\hline I-20-26 & & & & & & & & & & & X & & & \\
\hline I-20-27 & & & & & & & & & & & $\mathrm{X}$ & & & \\
\hline I-20-28 & & & & & & & & & X & & & & & \\
\hline I-20-29 & & & & X & & & & & & & & & & \\
\hline I-20-30 & & & & $X$ & & & & & & & & & & \\
\hline I-20-31 & & & & X & & & & & & & & & & \\
\hline I-20-32 & & & & & & & & & & X & & & & \\
\hline I-20-33 & & & X & & & & & & & & & & & \\
\hline I-20-34 & & & $X$ & & & & & & & & & & & \\
\hline I-20-35 & & & & & & & & & X & & & & & \\
\hline I-20-36 & & & & & & & & & X & & & & & \\
\hline I-20-37 & & & & & & & & & & & & & X & \\
\hline I-20-38 & & & & & & & & & & & & & $X$ & \\
\hline I-20-39 & & & $X$ & & & & & & & & & & & \\
\hline I-20-40 & & & $X$ & & & & & & & & & & & \\
\hline I-20-41 & & & & & & & & & & & X & & & \\
\hline I-20-42 & & & X & & & & & & & & & & & \\
\hline I-20-43 & & & & & & & & X & & & & & & \\
\hline I-20-44 & & & & & & & & $X$ & & & & & & \\
\hline I- $20-45$ & & $\mathrm{X}$ & & & & & & & & & & & & \\
\hline I-20-46 & & & & & & & & & $\mathrm{X}$ & & & & & \\
\hline I-20-47 & & X & & & & & & & & & & & & \\
\hline I-20-48 & & & $X$ & & & & & & & & & & & \\
\hline I-20-49 & & & & $X$ & & & & & & & & & & \\
\hline I-20-50 & & & & & & & & & & X & & & & \\
\hline I-20-51 & & & & $\mathrm{X}$ & & & & & & & & & & \\
\hline I-20-52 & & & & & & & & & & & & & $\mathrm{X}$ & \\
\hline I-20-53 & & & X & & & & & & & & & & & \\
\hline I-20-54 & & & & & & & & & $X$ & & & & & \\
\hline I-20-55 & & & & & & & & & & & & & $X$ & \\
\hline I-20-56 & & & & & & & & & & $X$ & & & & \\
\hline I-20-57 & & & & & & & & & & & X & & & \\
\hline I- $20-58$ & & & & & & & & & $\mathrm{X}$ & & & & & \\
\hline
\end{tabular}


Consequential Matrix

(Aggregated)

\begin{tabular}{|c|c|c|c|c|c|c|c|c|c|c|c|c|c|c|}
\hline & C1 & C2 & $\mathbf{C 3}$ & C4 & C5 & C6 & L1 & L2 & L3 & L4 & L5 & L6 & I & SUM \\
\hline I-20-59 & & & & & & & & $\mathrm{X}$ & & & & & & \\
\hline I-20-60 & & & & $\mathrm{X}$ & & & & & & & & & & \\
\hline I-20-61 & & & $X$ & & & & & & & & & & & \\
\hline I-20-62 & & & & & & & & & $\mathrm{X}$ & & & & & \\
\hline I-20-63 & & & $X$ & & & & & & & & & & & \\
\hline I-20-64 & & & & & & & & & $\mathrm{X}$ & & & & & \\
\hline I-20-65 & & & & $\mathrm{X}$ & & & & & & & & & & \\
\hline I-20-66 & & & & & & & & & $\mathrm{X}$ & & & & & \\
\hline I-20-67 & & & & & & & & & $X$ & & & & & \\
\hline I-20-68 & & & & & $X$ & & & & & & & & & \\
\hline I-20-69 & & & & & & & & & & & $X$ & & & \\
\hline I-20-70 & & & & $\mathrm{X}$ & & & & & & & & & & \\
\hline I-20-71 & & & & & & & & & $\mathrm{X}$ & & & & & \\
\hline I- $20-72$ & & & & $\mathrm{X}$ & & & & & & & & & & \\
\hline I-20-73 & & & & & & & & & & & $\mathrm{X}$ & & & \\
\hline I-20-74 & & & & & & & & $\mathrm{X}$ & & & & & & \\
\hline I-20-75 & & & & & & & & & $\mathrm{X}$ & & & & & \\
\hline I-20-76 & & & & & & & & & $\mathrm{X}$ & & & & & \\
\hline I-20-77 & & & $\mathrm{X}$ & & & & & & & & & & & \\
\hline I-20-78 & & & & & & & & & $\mathrm{X}$ & & & & & \\
\hline I-20-79 & & & & & & & & & & $X$ & & & & \\
\hline I-20-80 & & & & & & & & & & $X$ & & & & \\
\hline I-20-81 & & & & & & & & & & $X$ & & & & \\
\hline I-20-82 & & & & & & & & & & $\mathrm{X}$ & & & & \\
\hline I-20-83 & & & & & & & & & & & $X$ & & & \\
\hline I-20-84 & & & & & & & & & & & $X$ & & & \\
\hline I-20-85 & & & & $\mathrm{X}$ & & & & & & & & & & \\
\hline I-20-86 & & & & & & & & & & $\mathrm{X}$ & & & & \\
\hline I-20-87 & & & & & $\mathrm{X}$ & & & & & & & & & \\
\hline I-20-88 & & & & & & & & & & & $X$ & & & \\
\hline I-20-89 & & & & & & & & & & & & & $X$ & \\
\hline I-20-90 & & & & & $\mathrm{X}$ & & & & & & & & & \\
\hline I-20-91 & & & & & & & & & & & & & $X$ & \\
\hline I-20-92 & & & & & & & & & & & & & $\mathrm{X}$ & \\
\hline I-20-93 & & & & & & & & & & $\mathrm{X}$ & & & & \\
\hline I-20-94 & & & & $X$ & & & & & & & & & & \\
\hline I-20-95 & & & & & & & & & & $X$ & & & & \\
\hline I-20-96 & & & & $\mathrm{X}$ & & & & & & & & & & \\
\hline I-20-97 & & & & & & & & & & & $X$ & & & \\
\hline I-20-98 & & & $\mathrm{X}$ & & & & & & & & & & & \\
\hline I-20-99 & & & & & & & & & $X$ & & & & & \\
\hline I-20-100 & & & $X$ & & & & & & & & & & & \\
\hline I-20-101 & & & $X$ & & & & & & & & & & & \\
\hline I-20-102 & & & & & & & & & $X$ & & & & & \\
\hline
\end{tabular}




\section{Consequential Matrix}

(Aggregated)

\begin{tabular}{|c|c|c|c|c|c|c|c|c|c|c|c|c|c|c|}
\hline & C1 & C2 & $\mathbf{C 3}$ & C4 & C5 & C6 & L1 & L2 & L3 & L4 & L5 & L6 & I & SUM \\
\hline I-20-103 & & & $\mathrm{X}$ & & & & & & & & & & & \\
\hline I-20-104 & & & & & & & & & & & $\mathrm{X}$ & & & \\
\hline I-20-105 & & & & $\mathrm{X}$ & & & & & & & & & & \\
\hline I-20-106 & & & & & & & & & $\mathrm{X}$ & & & & & \\
\hline I-20-107 & & & & & & & & & & $\mathrm{X}$ & & & & \\
\hline I-20-108 & & & & & & & & & & $X$ & & & & \\
\hline I-20-109 & & & & & & & & & & $X$ & & & & \\
\hline I-20-110 & & & & & & & & & & & & & $X$ & \\
\hline \multirow[t]{3}{*}{ I-20-111 } & & & & & & & & & $\mathrm{X}$ & & & & & \\
\hline & 0 & 2 & 19 & 16 & 3 & 0 & 0 & 5 & 23 & 19 & 16 & 0 & 8 & 111 \\
\hline & C1 & C2 & C3 & C4 & C5 & C6 & L1 & L2 & L3 & L4 & L5 & L6 & I & SUM \\
\hline I-21-01 & & & & & & & & & & & & & $\mathrm{X}$ & \\
\hline I-21-02 & & & & & & & & & & & & & $X$ & \\
\hline I-21-03 & & & & & & & & & & & & & $X$ & \\
\hline I-21-04 & & & & $\mathrm{X}$ & & & & & & & & & & \\
\hline I-21-05 & $\mathrm{X}$ & & & & & & & & & & & & & \\
\hline I-21-06 & $\mathrm{X}$ & & & & & & & & & & & & & \\
\hline I-21-07 & & $\mathrm{X}$ & & & & & & & & & & & & \\
\hline I-21-08 & & & & & $X$ & & & & & & & & & \\
\hline I-21-09 & & & & & & & & & & & $\mathrm{X}$ & & & \\
\hline I-21-10 & & & & & $X$ & & & & & & & & & \\
\hline I-21-11 & & & & & & & & & & & & & $\mathrm{X}$ & \\
\hline I-21-12 & & & $\mathrm{X}$ & & & & & & & & & & & \\
\hline I-21-13 & & & & & & & & & & & & & $X$ & \\
\hline I-21-14 & & $\mathrm{X}$ & & & & & & & & & & & & \\
\hline I-21-15 & & & & & & & & & & & & & $\mathrm{X}$ & \\
\hline I-21-16 & & & & & & & & & & & & & $X$ & \\
\hline I-21-17 & & & & $\mathrm{X}$ & & & & & & & & & & \\
\hline I-21-18 & & & & & & & & & & & & & $X$ & \\
\hline I-21-19 & & & & $X$ & & & & & & & & & & \\
\hline I-21-20 & & & & & & & & & & & & & $X$ & \\
\hline I-21-21 & & & & $X$ & & & & & & & & & & \\
\hline I-21-22 & & & & $X$ & & & & & & & & & & \\
\hline I-21-23 & & & & $\mathrm{X}$ & & & & & & & & & & \\
\hline I-21-24 & & & & & & & & & & & $\mathrm{X}$ & & & \\
\hline I-21-25 & & & & & & & & & & & $X$ & & & \\
\hline I-21-26 & & & & & & & & & & & & & $X$ & \\
\hline I-21-27 & & & & & & & & & & & $\mathrm{X}$ & & & \\
\hline & 2 & 2 & 1 & 6 & 2 & 0 & 0 & 0 & 0 & 0 & 4 & 0 & 10 & 27 \\
\hline
\end{tabular}


Consequential Matrix

(Aggregated)

\begin{tabular}{|c|c|c|c|c|c|c|c|c|c|c|c|c|c|c|}
\hline & C1 & C2 & C3 & $\mathrm{C4}$ & C5 & C6 & L1 & L2 & L3 & L4 & L5 & L6 & I & SUM \\
\hline I-22-01 & & & & $X$ & & & & & & & & & & \\
\hline I-22-02 & & & & $X$ & & & & & & & & & & \\
\hline I-22-03 & & & & & & & & & & & & & X & \\
\hline I-22-04 & & & & X & & & & & & & & & & \\
\hline I-22-05 & & & & & & & & & & & X & & & \\
\hline I-22-06 & & & & X & & & & & & & & & & \\
\hline I-22-07 & & & & & & & & & & & X & & & \\
\hline I-22-08 & & & & & & & & & & & $X$ & & & \\
\hline I-22-09 & & & X & & & & & & & & & & & \\
\hline I-22-10 & & & & X & & & & & & & & & & \\
\hline I-22-11 & & & & & & & & & & X & & & & \\
\hline I-22-12 & & & & X & & & & & & & & & & \\
\hline I-22-13 & & & & & & & & & & & & & X & \\
\hline I-22-14 & & & & & & & & & & & & & $X$ & \\
\hline I-22-15 & & & & & & & & & & X & & & & \\
\hline I-22-16 & & & & & & & & & $X$ & & & & & \\
\hline I-22-17 & & & & & & & & & $X$ & & & & & \\
\hline I-22-18 & & & & & & & & & $X$ & & & & & \\
\hline I-22-19 & & & & $X$ & & & & & & & & & & \\
\hline I-22-20 & & & & & & & & & & $X$ & & & & \\
\hline I-22-21 & & & & & & & & & & $X$ & & & & \\
\hline I-22-22 & & & & & & & & & & & & & $X$ & \\
\hline I- $22-23$ & & & & & & & & & $X$ & & & & & \\
\hline I-22-24 & & & & & & & & & & X & & & & \\
\hline I- $22-25$ & & & & & & & & & $X$ & & & & & \\
\hline I-22-26 & & & & X & & & & & & & & & & \\
\hline I-22-27 & & & & X & & & & & & & & & & \\
\hline I-22-28 & & & & & & & & & & & X & & & \\
\hline I-22-29 & & & & X & & & & & & & & & & \\
\hline I-22-30 & & & & X & & & & & & & & & & \\
\hline I-22-31 & & & & & & & & & $X$ & & & & & \\
\hline I-22-32 & & & & & & & & & & & & & X & \\
\hline I-22-33 & & & & & & & & & & X & & & & \\
\hline I-22-34 & & & & & & & & & $X$ & & & & & \\
\hline I-22-35 & & & $X$ & & & & & & & & & & & \\
\hline I-22-36 & & & & X & & & & & & & & & & \\
\hline I-22-37 & & & & & & & & & $X$ & & & & & \\
\hline I-22-38 & & & & & & & & & & & X & & & \\
\hline I-22-39 & & & & X & & & & & & & & & & \\
\hline I-22-40 & & & & & & & & & & & & & X & \\
\hline I-22-41 & & & & & & & & & & & X & & & \\
\hline I-22-42 & & & & & & & & & & & X & & & \\
\hline I-22-43 & & & & & & & & & $X$ & & & & & \\
\hline I-22-44 & & & & & & & & & & X & & & & \\
\hline
\end{tabular}


Consequential Matrix

(Aggregated)

\begin{tabular}{|c|c|c|c|c|c|c|c|c|c|c|c|c|c|c|}
\hline & C1 & C2 & C3 & C4 & C5 & C6 & L1 & L2 & L3 & L4 & L5 & L6 & I & SUM \\
\hline I- $22-45$ & & & & & & & & & & & $X$ & & & \\
\hline I-22-46 & & & & & & & & & & & & & X & \\
\hline I-22-47 & & & & & & & & & X & & & & & \\
\hline I-22-48 & & & X & & & & & & & & & & & \\
\hline I-22-49 & & & & & & & & & & X & & & & \\
\hline I-22-50 & & & & X & & & & & & & & & & \\
\hline I-22-51 & & & & & & & & X & & & & & & \\
\hline I-22-52 & & & & & & & & & X & & & & & \\
\hline I-22-53 & & & & & & & & & & & X & & & \\
\hline I-22-54 & & & X & & & & & & & & & & & \\
\hline I-22-55 & & & $X$ & & & & & & & & & & & \\
\hline I-22-56 & & & & X & & & & & & & & & & \\
\hline I-22-57 & & & & & & & & & X & & & & & \\
\hline I- $22-58$ & & & & & & & & & $X$ & & & & & \\
\hline I- $22-59$ & & & X & & & & & & & & & & & \\
\hline I-22-60 & & & & & & & & & X & & & & & \\
\hline I-22-61 & & X & & & & & & & & & & & & \\
\hline I-22-62 & & & & & & & & X & & & & & & \\
\hline I-22-63 & & & & X & & & & & & & & & & \\
\hline I-22-64 & & & & & X & & & & & & & & & \\
\hline I-22-65 & & & & & & & & & & & & & X & \\
\hline I-22-66 & & & & & & & & & & & & & $\mathrm{X}$ & \\
\hline I-22-67 & & & & & & & & & & & & & X & \\
\hline I-22-68 & & & & & & & & & & & & & $X$ & \\
\hline I-22-69 & & & & & & & & & $X$ & & & & & \\
\hline I-22-70 & & & & & & & & & $X$ & & & & & \\
\hline I-22-71 & & & & & & & & & & & X & & & \\
\hline I-22-72 & & & & & & & & & & & $X$ & & & \\
\hline I- $22-73$ & & & & & & & & & $X$ & & & & & \\
\hline I-22-74 & & & & & & & & & $X$ & & & & & \\
\hline I- $22-75$ & & & & & & & & & & & X & & & \\
\hline I-22-76 & & & & & & $X$ & & & & & & & & \\
\hline I-22-77 & & & & & & & & & & & & $X$ & & \\
\hline I- $22-78$ & & & & $X$ & & & & & & & & & & \\
\hline I-22-79 & & & & & & & & & X & & & & & \\
\hline I-22-80 & & & $X$ & & & & & & & & & & & \\
\hline I-22-81 & & & & & & & & & $X$ & & & & & \\
\hline I-22-82 & & & & & & & & & $X$ & & & & & \\
\hline I-22-83 & X & & & & & & & & & & & & & \\
\hline I-22-84 & & & & & & & & & & & & & $\mathrm{X}$ & \\
\hline I-22-85 & $X$ & & & & & & & & & & & & & \\
\hline I-22-86 & $\mathrm{X}$ & & & & & & & & & & & & & \\
\hline I-22-87 & & & & & & & & & $X$ & & & & & \\
\hline I- $22-88$ & & & & & & & & & & & & $X$ & & \\
\hline
\end{tabular}


Consequential Matrix

(Aggregated)

\begin{tabular}{|c|c|c|c|c|c|c|c|c|c|c|c|c|c|c|}
\hline & C1 & C2 & C3 & C4 & C5 & C6 & L1 & L2 & $\mathbf{L 3}$ & L4 & L5 & L6 & I & SUM \\
\hline I- $22-89$ & & & & & & & & & $\mathrm{X}$ & & & & & \\
\hline I- $22-90$ & & & & & & & & & & & X & & & \\
\hline I-22-91 & & & & $X$ & & & & & & & & & & \\
\hline \multirow[t]{3}{*}{ I-22-92 } & & & & & & & & & & $X$ & & & & \\
\hline & 3 & 1 & 7 & 18 & 1 & 1 & 0 & 2 & 23 & 9 & 13 & 2 & 12 & 92 \\
\hline & C1 & $\mathrm{C} 2$ & C3 & C4 & C5 & C6 & L1 & L2 & L3 & L4 & L5 & L6 & I & SUM \\
\hline I-23-01 & & & & $X$ & & & & & & & & & & \\
\hline I-23-02 & & & & & & & & & $X$ & & & & & \\
\hline I-23-03 & & & & & & & & & & & & & $X$ & \\
\hline I-23-04 & & & & & & & & & & & X & & & \\
\hline I-23-05 & & & & & & & & & & & & X & & \\
\hline I-23-06 & & & & & & & & & & & X & & & \\
\hline I-23-07 & & & & & & & & & & & & $X$ & & \\
\hline I- $23-08$ & & & & & & & & & & & & & $X$ & \\
\hline I-23-09 & & & & & & & & X & & & & & & \\
\hline I- $23-10$ & & & & X & & & & & & & & & & \\
\hline I-23-11 & & & & $X$ & & & & & & & & & & \\
\hline I- $23-12$ & & & & $X$ & & & & & & & & & & \\
\hline I- $23-13$ & & & & & & & & & & & & & $X$ & \\
\hline I-23-14 & & & $X$ & & & & & & & & & & & \\
\hline I- $23-15$ & & & & & & & & & & & X & & & \\
\hline I- $23-16$ & & & & & & & & & & & $X$ & & & \\
\hline I- $23-17$ & & & & & & & & & & & $X$ & & & \\
\hline I- $23-18$ & & & & & & & & & & & $X$ & & & \\
\hline I-23-19 & & & & & & & & & & & $X$ & & & \\
\hline I- $23-20$ & & & & & $X$ & & & & & & & & & \\
\hline I-23-21 & & & & $X$ & & & & & & & & & & \\
\hline I- $23-22$ & & & & & & & & & & & & & $X$ & \\
\hline \multirow[t]{3}{*}{ I- $23-23$} & & & & & & & & & & & $X$ & & & \\
\hline & 0 & 0 & 1 & 5 & 1 & 0 & 0 & 1 & 1 & 0 & 8 & 2 & 4 & 23 \\
\hline & C1 & $\mathrm{C2}$ & $\mathbf{C 3}$ & $\mathrm{C4}$ & C5 & C6 & L1 & L2 & $\mathbf{L 3}$ & L4 & L5 & L6 & I & SUM \\
\hline I- $25-01$ & & & & & & & & & & $X$ & & & & \\
\hline I- $25-02$ & & & & & & & & & & $X$ & & & & \\
\hline I- $25-03$ & & & & $X$ & & & & & & & & & & \\
\hline I- $25-04$ & & & & & & & & & & & $X$ & & & \\
\hline I- $25-05$ & & & & & & & & & & & & & $X$ & \\
\hline I-25-06 & & & & & & & & & & & $X$ & & & \\
\hline I- $25-07$ & & & & & & & & & & & & & $X$ & \\
\hline I- $25-08$ & & & & & & & & & $X$ & & & & & \\
\hline I-25-09 & & & & & & & & & & & $X$ & & & \\
\hline $\mathrm{I}-25-10$ & & & & & & & & & & & & & $X$ & \\
\hline I-25-11 & & & & & & & & & & & & & $X$ & \\
\hline
\end{tabular}


Consequential Matrix

(Aggregated)

\begin{tabular}{|c|c|c|c|c|c|c|c|c|c|c|c|c|c|c|}
\hline & C1 & C2 & C3 & C4 & C5 & C6 & L1 & L2 & L3 & L4 & L5 & L6 & I & SUM \\
\hline I- $25-12$ & & & & & & & & & $X$ & & & & & \\
\hline I- $25-13$ & & & & & & & & & & & & & $X$ & \\
\hline I-25-14 & & & & & & X & & & & & & & & \\
\hline I-25-15 & & & & & & $X$ & & & & & & & & \\
\hline I-25-16 & & & & & & & & & X & & & & & \\
\hline I-25-17 & & & X & & & & & & & & & & & \\
\hline I- $25-18$ & & & & & & & & & X & & & & & \\
\hline I-25-19 & & & & & & & & & & & & & X & \\
\hline I- $25-20$ & & & & & & & & & X & & & & & \\
\hline I-25-21 & & & & & & & & & & & & & X & \\
\hline I- $25-22$ & & & & X & & & & & & & & & & \\
\hline I- $25-23$ & & & & & & & & & & & & & X & \\
\hline I- $25-24$ & & & X & & & & & & & & & & & \\
\hline I- $25-25$ & & & $X$ & & & & & & & & & & & \\
\hline I- $25-26$ & & & & X & & & & & & & & & & \\
\hline I- $25-27$ & & & & & & & & & & & & & X & \\
\hline I- $25-28$ & & & & & & & & & & X & & & & \\
\hline I- $25-29$ & & & & & & & & & & & & & X & \\
\hline I- $25-30$ & & & & $\mathrm{X}$ & & & & & & & & & & \\
\hline \multirow[t]{3}{*}{ I- $25-31$} & & & & & & & & $X$ & & & & & & \\
\hline & 0 & 0 & 3 & 4 & 0 & 2 & 0 & 1 & 5 & 3 & 3 & 0 & 10 & 31 \\
\hline & C1 & C2 & $\mathbf{C 3}$ & C4 & C5 & C6 & L1 & L2 & L3 & L4 & L5 & L6 & I & SUM \\
\hline I-26-01 & & & $X$ & & & & & & & & & & & \\
\hline I-26-02 & & & & & & & & & & & $X$ & & & \\
\hline I-26-03 & & & & & & & & $X$ & & & & & & \\
\hline I-26-04 & & & X & & & & & & & & & & & \\
\hline I-26-05 & & & & X & & & & & & & & & & \\
\hline I-26-06 & & & & & & & & & & & & & $X$ & \\
\hline I-26-07 & & & & & & & & & & $X$ & & & & \\
\hline I-26-08 & & & & & & & & & & $X$ & & & & \\
\hline I-26-09 & & & & $X$ & & & & & & & & & & \\
\hline I-26-10 & & & $X$ & & & & & & & & & & & \\
\hline I-26-11 & & & & $X$ & & & & & & & & & & \\
\hline I-26-12 & & & & & & & & & & & X & & & \\
\hline I-26-13 & & & & & & & & & & & & & $X$ & \\
\hline I-26-14 & & & & & & & & & & & $X$ & & & \\
\hline I-26-15 & & & & & & & & & $\mathrm{X}$ & & & & & \\
\hline I-26-16 & & & & & & & & & $X$ & & & & & \\
\hline I-26-17 & & $X$ & & & & & & & & & & & & \\
\hline I-26-18 & & & & & & & & & & & $X$ & & & \\
\hline I-26-19 & & & & & & & & $\mathrm{X}$ & & & & & & \\
\hline I-26-20 & & & & & & & & & & $X$ & & & & \\
\hline I-26-21 & & & & X & & & & & & & & & & \\
\hline
\end{tabular}




\section{Consequential Matrix}

(Aggregated)

\begin{tabular}{|c|c|c|c|c|c|c|c|c|c|c|c|c|c|c|}
\hline & C1 & C2 & $\mathbf{C 3}$ & C4 & C5 & C6 & L1 & L2 & $\mathbf{L 3}$ & L4 & L5 & L6 & I & SUM \\
\hline I-26-22 & & & & & & & & & $X$ & & & & & \\
\hline I-26-23 & & & & & & & & & & & $X$ & & & \\
\hline I-26-24 & & & & & & & & & X & & & & & \\
\hline I-26-25 & & & & & & & & & $X$ & & & & & \\
\hline I-26-26 & & & & $X$ & & & & & & & & & & \\
\hline I-26-27 & & & & & & & & X & & & & & & \\
\hline I- $26-28$ & & & & X & & & & & & & & & & \\
\hline I-26-29 & & & & & & & & & & & & $X$ & & \\
\hline I-26-30 & & & & & & & & & & & X & & & \\
\hline I-26-31 & & & & & & & & & & X & & & & \\
\hline I-26-32 & & & & & & & & & $X$ & & & & & \\
\hline I-26-33 & & & X & & & & & & & & & & & \\
\hline I-26-34 & & & & & & & & & & X & & & & \\
\hline I-26-35 & & & & & & & & & & $X$ & & & & \\
\hline I-26-36 & & & & & & & & X & & & & & & \\
\hline I-26-37 & & & & & & & & & & $X$ & & & & \\
\hline I-26-38 & & & X & & & & & & & & & & & \\
\hline I-26-39 & & & & & & & & & & & & & $X$ & \\
\hline I-26-40 & & & & & & & & & & & X & & & \\
\hline I-26-41 & & & & & & & & X & & & & & & \\
\hline I-26-42 & & X & & & & & & & & & & & & \\
\hline I-26-43 & & & & $X$ & & & & & & & & & & \\
\hline I-26-44 & & & & & & & & X & & & & & & \\
\hline I-26-45 & & & & X & & & & & & & & & & \\
\hline I-26-46 & & & & X & & & & & & & & & & \\
\hline I-26-47 & & & & & & & & & & & X & & & \\
\hline I-26-48 & & & X & & & & & & & & & & & \\
\hline I-26-49 & & & X & & & & & & & & & & & \\
\hline I- $26-50$ & & & & & & & & & & & X & & & \\
\hline I-26-51 & & & & & & & & & & & $X$ & & & \\
\hline I-26-52 & & & & & & & & & & & $X$ & & & \\
\hline I-26-53 & & & X & & & & & & & & & & & \\
\hline I-26-54 & & & & & & & & & & & X & & & \\
\hline I-26-55 & & & $X$ & & & & & & & & & & & \\
\hline I-26-56 & & & & & & & & & & & X & & & \\
\hline I-26-57 & & & & X & & & & & & & & & & \\
\hline I-26-58 & & & & & & & & & & & $X$ & & & \\
\hline I-26-59 & & & X & & & & & & & & & & & \\
\hline I-26-60 & & & X & & & & & & & & & & & \\
\hline \multirow[t]{2}{*}{ I-26-61 } & & & & & & & & & & & & $X$ & & \\
\hline & 0 & 2 & 11 & 10 & 0 & 0 & 0 & 6 & 6 & 7 & 14 & 2 & 3 & 61 \\
\hline
\end{tabular}


Consequential Matrix

(Aggregated)

\begin{tabular}{|c|c|c|c|c|c|c|c|c|c|c|c|c|c|c|}
\hline & C1 & C2 & C3 & C4 & C5 & C6 & L1 & L2 & L3 & L4 & L5 & L6 & I & SUM \\
\hline I-27-01 & & & $X$ & & & & & & & & & & & \\
\hline I-27-02 & & & & X & & & & & & & & & & \\
\hline I-27-03 & & & & & & & & & & & & & X & \\
\hline I-27-04 & & & & & & & & & X & & & & & \\
\hline I-27-05 & & & & & & & & & & & & & X & \\
\hline I-27-06 & & & & & & & & & & X & & & & \\
\hline I-27-07 & & & & X & & & & & & & & & & \\
\hline I-27-08 & & & & X & & & & & & & & & & \\
\hline I-27-09 & & & & & & & & & & & X & & & \\
\hline I-27-10 & & & & & & & & & & & & & X & \\
\hline I-27-11 & & & & & & & & & & & & & $\mathrm{X}$ & \\
\hline I-27-12 & & & & & & & & & & & & & $X$ & \\
\hline I-27-13 & & & & X & & & & & & & & & & \\
\hline I-27-14 & & & & & & & & X & & & & & & \\
\hline I-27-15 & & & & & & & & $X$ & & & & & & \\
\hline I-27-16 & & & & & & & & & & & & & X & \\
\hline I-27-17 & & & & & & & & & & & X & & & \\
\hline I-27-18 & & & & & & & & & & & & & X & \\
\hline I-27-19 & $X$ & & & & & & & & & & & & & \\
\hline I-27-20 & & & & & & & & & & & X & & & \\
\hline I-27-21 & & & & & & & & & & & X & & & \\
\hline I-27-22 & & & & & & & & & & & & & X & \\
\hline I- $27-23$ & & & $X$ & & & & & & & & & & & \\
\hline \multirow[t]{3}{*}{ I-27-24 } & & & & & & & & & & & & & $X$ & \\
\hline & 1 & 0 & 2 & 4 & 0 & 0 & 0 & 2 & 1 & 1 & 4 & 0 & 9 & 24 \\
\hline & C1 & C2 & $\mathbf{C 3}$ & C4 & C5 & C6 & L1 & L2 & L3 & L4 & L5 & L6 & I & SUM \\
\hline I-28-01 & & & & & & & & & & $X$ & & & & \\
\hline I-28-02 & & & & & & & & & $\mathrm{X}$ & & & & & \\
\hline I-28-03 & & & & $X$ & & & & & & & & & & \\
\hline I-28-04 & & & & & & & & & & & & & $X$ & \\
\hline I-28-05 & & & & $X$ & & & & & & & & & & \\
\hline I-28-06 & & & & & & & & & & & $X$ & & & \\
\hline I-28-07 & & & & & & & & & & & $X$ & & & \\
\hline I-28-08 & & & & & & & & & & & X & & & \\
\hline I-28-09 & & & & $X$ & & & & & & & & & & \\
\hline I-28-10 & & & & $X$ & & & & & & & & & & \\
\hline I-28-11 & & & $X$ & & & & & & & & & & & \\
\hline I-28-12 & & & $X$ & & & & & & & & & & & \\
\hline I-28-13 & & & & & & & & $\mathrm{X}$ & & & & & & \\
\hline I-28-14 & & & & & & & & & & & $X$ & & & \\
\hline I- $28-15$ & & & & & & & & $\mathrm{X}$ & & & & & & \\
\hline I-28-16 & & & & & & & & $\mathrm{X}$ & & & & & & \\
\hline I-28-17 & & & & & & & & X & & & & & & \\
\hline
\end{tabular}




\section{Consequential Matrix}

(Aggregated)

\begin{tabular}{|c|c|c|c|c|c|c|c|c|c|c|c|c|c|c|}
\hline & C1 & C2 & C3 & C4 & C5 & C6 & L1 & L2 & L3 & L4 & L5 & L6 & I & SUM \\
\hline I-28-18 & & & & & & & & & & & & & $\mathrm{X}$ & \\
\hline I-28-19 & & & X & & & & & & & & & & & \\
\hline I- $28-20$ & & & & & & & & & & & & & X & \\
\hline I-28-21 & & & & & & & & & & & & & $\mathrm{X}$ & \\
\hline I- $28-22$ & & $X$ & & & & & & & & & & & & \\
\hline I-28-23 & & $X$ & & & & & & & & & & & & \\
\hline I-28-24 & & & X & & & & & & & & & & & \\
\hline I-28-25 & & & $X$ & & & & & & & & & & & \\
\hline I-28-26 & & & & & & & & & & & X & & & \\
\hline I-28-27 & & & X & & & & & & & & & & & \\
\hline I-28-28 & & & & & & & & & & & & & X & \\
\hline I-28-29 & & & & & & & & & & & X & & & \\
\hline I-28-30 & & & X & & & & & & & & & & & \\
\hline I-28-31 & & & & X & & & & & & & & & & \\
\hline I-28-32 & & & & & & & & & & & X & & & \\
\hline I-28-33 & & & & & & & & & & & X & & & \\
\hline I-28-34 & & & & & & & & & & & X & & & \\
\hline I-28-35 & & & & & & & & X & & & & & & \\
\hline I-28-36 & & & X & & & & & & & & & & & \\
\hline I-28-37 & & & & & & & & X & & & & & & \\
\hline I-28-38 & & & & & & & & & & & X & & & \\
\hline I-28-39 & & & & & & & & & & & $X$ & & & \\
\hline I- $28-40$ & & & X & & & & & & & & & & & \\
\hline I-28-41 & & & & & & & & & & & X & & & \\
\hline I-28-42 & & & & & & & & & & X & & & & \\
\hline I-28-43 & & & X & & & & & & & & & & & \\
\hline I-28-44 & & & & & & & & & & & & & X & \\
\hline I- $28-45$ & & & & & & & & & & & $X$ & & & \\
\hline I-28-46 & & $X$ & & & & & & & & & & & & \\
\hline I-28-47 & & & $X$ & & & & & & & & & & & \\
\hline I-28-48 & & & & & & & & & & X & & & & \\
\hline I-28-49 & & & & & & & & & & & & & $X$ & \\
\hline I-28-50 & & & & & & & & & & & $X$ & & & \\
\hline I-28-51 & & & $X$ & & & & & & & & & & & \\
\hline I-28-52 & & & & & & & & & X & & & & & \\
\hline I-28-53 & & & & $X$ & & & & & & & & & & \\
\hline \multirow[t]{3}{*}{ I-28-54 } & & & & & & & & & $X$ & & & & & \\
\hline & 0 & 3 & 12 & 6 & 0 & 0 & 0 & 6 & 3 & 3 & 14 & 0 & 7 & 54 \\
\hline & C1 & $\mathrm{C2}$ & C3 & C4 & C5 & C6 & L1 & L2 & $\mathbf{L 3}$ & L4 & L5 & L6 & I & SUM \\
\hline I-29-01 & & & $\mathrm{X}$ & & & & & & & & & & & \\
\hline I-29-02 & & & & $X$ & & & & & & & & & & \\
\hline I-29-03 & & & & & & & & & & & & & X & \\
\hline I-29-04 & & & & X & & & & & & & & & & \\
\hline
\end{tabular}




\section{Consequential Matrix}

(Aggregated)

\begin{tabular}{|c|c|c|c|c|c|c|c|c|c|c|c|c|c|c|}
\hline & C1 & C2 & C3 & C4 & C5 & C6 & L1 & L2 & L3 & L4 & L5 & L6 & I & SUM \\
\hline I-29-05 & & & & & & & & & & & $X$ & & & \\
\hline I-29-06 & & & & & & & & & & & & & $X$ & \\
\hline I-29-07 & & & & & X & & & & & & & & & \\
\hline I-29-08 & & & & & & & & & & & X & & & \\
\hline I-29-09 & & & & & X & & & & & & & & & \\
\hline I-29-10 & & & $X$ & & & & & & & & & & & \\
\hline I-29-11 & & & $X$ & & & & & & & & & & & \\
\hline I-29-12 & & & $X$ & & & & & & & & & & & \\
\hline I-29-13 & & & & & & & & & & & & & X & \\
\hline I-29-14 & $X$ & & & & & & & & & & & & & \\
\hline I-29-15 & & & & $X$ & & & & & & & & & & \\
\hline I-29-16 & & & & & & & & & & & & & X & \\
\hline I-29-17 & & & & & & & & & $X$ & & & & & \\
\hline I-29-18 & & & & & & & & & & & & & $X$ & \\
\hline I-29-19 & & & & & & & & & & & X & & & \\
\hline I-29-20 & & & X & & & & & & & & & & & \\
\hline I-29-21 & & & X & & & & & & & & & & & \\
\hline I-29-22 & & & & & & & & & & & X & & & \\
\hline I-29-23 & & & & & & & & & $X$ & & & & & \\
\hline I-29-24 & & & X & & & & & & & & & & & \\
\hline I-29-25 & & & & & X & & & & & & & & & \\
\hline I-29-26 & & & $X$ & & & & & & & & & & & \\
\hline I- $29-27$ & & & & $X$ & & & & & & & & & & \\
\hline I- $29-28$ & & & & & & & & & & & & & $X$ & \\
\hline I-29-29 & & & & & & & & & & & X & & & \\
\hline I-29-30 & & & & & & & & & $X$ & & & & & \\
\hline I-29-31 & & & & & & & & & & & & & $X$ & \\
\hline I-29-32 & & & & & & & & & $X$ & & & & & \\
\hline I-29-33 & & & & $X$ & & & & & & & & & & \\
\hline I-29-34 & & & & $X$ & & & & & & & & & & \\
\hline I-29-35 & & & & & & & & & & & & & $X$ & \\
\hline I-29-36 & & & & & & & & & & & & & $X$ & \\
\hline I-29-37 & & & & & & & & $X$ & & & & & & \\
\hline I-29-38 & & & & & & & & & & & & & $X$ & \\
\hline I-29-39 & & & & & & & & & & & $X$ & & & \\
\hline I-29-40 & & & & & & & & $X$ & & & & & & \\
\hline I-29-41 & & & & & & & & & & & & & $X$ & \\
\hline I-29-42 & & & $X$ & & & & & & & & & & & \\
\hline I-29-43 & & & & & & & & & & & & & $\mathrm{X}$ & \\
\hline I-29-44 & & & & & & & & & & & & $X$ & & \\
\hline I-29-45 & & & & $X$ & & & & & & & & & & \\
\hline I-29-46 & & & & & & & & & & X & & & & \\
\hline I-29-47 & & & & X & & & & & & & & & & \\
\hline I-29-48 & & & & & & & & & & & $X$ & & & \\
\hline
\end{tabular}




\section{Consequential Matrix}

(Aggregated)

\begin{tabular}{|c|c|c|c|c|c|c|c|c|c|c|c|c|c|c|}
\hline & C1 & $\mathrm{C} 2$ & $\mathrm{C3}$ & C4 & $\mathrm{C5}$ & C6 & L1 & L2 & $\mathbf{L 3}$ & L4 & L5 & L6 & I & SUM \\
\hline I-29-49 & & & & $\mathrm{X}$ & & & & & & & & & & \\
\hline I-29-50 & & & & & & & & & & & & & $X$ & \\
\hline I-29-51 & & & & & & & & & & $X$ & & & & \\
\hline I-29-52 & & & & & & $X$ & & & & & & & & \\
\hline I-29-53 & & & & & & & & & $\mathrm{X}$ & & & & & \\
\hline I-29-54 & & & $X$ & & & & & & & & & & & \\
\hline I-29-55 & & & & $X$ & & & & & & & & & & \\
\hline I-29-56 & $X$ & & & & & & & & & & & & & \\
\hline I-29-57 & & & & & & & & & $X$ & & & & & \\
\hline I-29-58 & & & & & & & & & & & & & $X$ & \\
\hline I-29-59 & & & & & & & & & & & & & $X$ & \\
\hline I-29-60 & & & & $X$ & & & & & & & & & & \\
\hline I-29-61 & & & & & & & & & & & $\mathrm{X}$ & & & \\
\hline I-29-62 & & & & $X$ & & & & & & & & & & \\
\hline I-29-63 & & & & & & & $X$ & & & & & & & \\
\hline I-29-64 & & & & & & & & & & $X$ & & & & \\
\hline I-29-65 & & & & & & & & $X$ & & & & & & \\
\hline I-29-66 & & $X$ & & & & & & & & & & & & \\
\hline I-29-67 & & & & $X$ & & & & & & & & & & \\
\hline I-29-68 & & & & & & & & & $X$ & & & & & \\
\hline I-29-69 & & & & & & & & $X$ & & & & & & \\
\hline I-29-70 & & & & & & & & & $X$ & & & & & \\
\hline I-29-71 & & & & & & & & & & & $X$ & & & \\
\hline I-29-72 & & & & & & & & & & & & & X & \\
\hline I-29-73 & & & & & & & & & $X$ & & & & & \\
\hline \multirow[t]{3}{*}{ I-29-74 } & & & $X$ & & & & & & & & & & & \\
\hline & 2 & 1 & 11 & 13 & 3 & 1 & 1 & 4 & 9 & 3 & 9 & 1 & 16 & 74 \\
\hline & C1 & $\mathrm{C2}$ & C3 & C4 & C5 & C6 & L1 & L2 & L3 & L4 & L5 & L6 & I & SUM \\
\hline I-30-01 & & & $X$ & & & & & & & & & & & \\
\hline I- $30-02$ & & & & $X$ & & & & & & & & & & \\
\hline I- $30-03$ & & & $X$ & & & & & & & & & & & \\
\hline I- $30-04$ & & & & $X$ & & & & & & & & & & \\
\hline I- $30-05$ & & & & & & & & & & $X$ & & & & \\
\hline I-30-06 & & & & $X$ & & & & & & & & & & \\
\hline I- $30-07$ & & & & & & & & & & & $X$ & & & \\
\hline I- $30-08$ & & & & & & & & & $X$ & & & & & \\
\hline I-30-09 & & & & $X$ & & & & & & & & & & \\
\hline I- $30-10$ & & & & $\mathrm{X}$ & & & & & & & & & & \\
\hline I- $30-11$ & & & & $X$ & & & & & & & & & & \\
\hline I- $30-12$ & & & $X$ & & & & & & & & & & & \\
\hline I- $30-13$ & & & & & & & & & & & $X$ & & & \\
\hline I- $30-14$ & & & $X$ & & & & & & & & & & & \\
\hline I- $30-15$ & & & & & & & & & & & & X & & \\
\hline
\end{tabular}




\section{Consequential Matrix}

(Aggregated)

\begin{tabular}{|c|c|c|c|c|c|c|c|c|c|c|c|c|c|c|}
\hline & C1 & $\mathrm{C} 2$ & C3 & C4 & C5 & C6 & L1 & L2 & L3 & L4 & L5 & L6 & I & SUM \\
\hline I-30-16 & & & & $\mathrm{X}$ & & & & & & & & & & \\
\hline I-30-17 & & & & X & & & & & & & & & & \\
\hline I- $30-18$ & & & & & & & & & X & & & & & \\
\hline I-30-19 & & & & & & & & & & & X & & & \\
\hline I-30-20 & & & & & & & & & & & $X$ & & & \\
\hline I-30-21 & & & & & & & & & $X$ & & & & & \\
\hline I-30-22 & & & & X & & & & & & & & & & \\
\hline I-30-23 & & & & & & & & & X & & & & & \\
\hline I-30-24 & & & & & & & & & $X$ & & & & & \\
\hline I-30-25 & & & & & & & & & $X$ & & & & & \\
\hline I-30-26 & & & & & & & & & & $X$ & & & & \\
\hline I- $30-27$ & & & & & & & & & & $X$ & & & & \\
\hline I- $30-28$ & & & & & & & & & X & & & & & \\
\hline I-30-29 & & & & & & & & & $X$ & & & & & \\
\hline I- $30-30$ & & & & $X$ & & & & & & & & & & \\
\hline I-30-31 & & & & & & & & & $X$ & & & & & \\
\hline I-30-32 & & & & & & & & & & & X & & & \\
\hline I-30-33 & & & & & & & & & & $X$ & & & & \\
\hline I-30-34 & & & & & & & & & & $X$ & & & & \\
\hline I-30-35 & & & & & & & & & X & & & & & \\
\hline I- $30-36$ & & & & & & & & & & & X & & & \\
\hline I- $30-37$ & & & & & & & & & & & & & $\mathrm{X}$ & \\
\hline I-30-38 & & & & & & & & & & $X$ & & & & \\
\hline I-30-39 & & & & $X$ & & & & & & & & & & \\
\hline I-30-40 & & & $X$ & & & & & & & & & & & \\
\hline I-30-41 & & & & $X$ & & & & & & & & & & \\
\hline I-30-42 & & $X$ & & & & & & & & & & & & \\
\hline I- $30-43$ & & & & $X$ & & & & & & & & & & \\
\hline I-30-44 & & & & $X$ & & & & & & & & & & \\
\hline I-30-45 & & & & & & & & & & & X & & & \\
\hline I-30-46 & & & & & & & & & X & & & & & \\
\hline I-30-47 & & & & & & & & & X & & & & & \\
\hline I-30-48 & & & & & & & & & & & & & X & \\
\hline I- $30-49$ & & & & $X$ & & & & & & & & & & \\
\hline I-30-50 & & & & & & & & & & & & & $X$ & \\
\hline I-30-51 & & & & $X$ & & & & & & & & & & \\
\hline I- $30-52$ & & & & & & & & & $X$ & & & & & \\
\hline I- $30-53$ & & & & & & & & $\mathrm{X}$ & & & & & & \\
\hline I-30-54 & & & & & & & & & X & & & & & \\
\hline I-30-55 & & $\mathrm{X}$ & & & & & & & & & & & & \\
\hline I-30-56 & & & & $X$ & & & & & & & & & & \\
\hline I-30-57 & & & & $X$ & & & & & & & & & & \\
\hline I- $30-58$ & & & $X$ & & & & & & & & & & & \\
\hline I-30-59 & & & & & & & & & $\mathrm{X}$ & & & & & \\
\hline
\end{tabular}


Consequential Matrix

(Aggregated)

\begin{tabular}{|c|c|c|c|c|c|c|c|c|c|c|c|c|c|c|}
\hline & C1 & C2 & C3 & C4 & C5 & C6 & L1 & L2 & L3 & L4 & L5 & L6 & I & SUM \\
\hline I-30-60 & & & & & & & & & & $\mathrm{X}$ & & & & \\
\hline I-30-61 & & & & & & & & & X & & & & & \\
\hline I-30-62 & & & & X & & & & & & & & & & \\
\hline I-30-63 & & & & & & & & & & & & & X & \\
\hline I-30-64 & & & & & & & & & & & & & $X$ & \\
\hline I-30-65 & & & & & & & & & & & & & $X$ & \\
\hline I-30-66 & & & & & & & & & & & & & $X$ & \\
\hline I-30-67 & & & & X & & & & & & & & & & \\
\hline I-30-68 & & & & & & & & & & & & & X & \\
\hline I-30-69 & & & & & & & & & & & X & & & \\
\hline I-30-70 & & & & & & & & & & & $X$ & & & \\
\hline I-30-71 & & & & & & & & & & & & & X & \\
\hline I-30-72 & & & & & & & & & & & $\mathrm{X}$ & & & \\
\hline I-30-73 & & & & & & & & & & & & & $X$ & \\
\hline \multirow[t]{3}{*}{ I-30-74 } & & & & & & & & & $\mathrm{X}$ & & & & & \\
\hline & 0 & 2 & 6 & 20 & 0 & 0 & 0 & 1 & 17 & 7 & 10 & 1 & 10 & 74 \\
\hline & C1 & C2 & C3 & C4 & C5 & C6 & L1 & L2 & L3 & L4 & L5 & L6 & I & SUM \\
\hline I-31-01 & & & & & & & & & & & $\mathrm{X}$ & & & \\
\hline I-31-02 & & & & & & & & & & & X & & & \\
\hline I-31-03 & & & & & & & & & & $X$ & & & & \\
\hline I-31-04 & & & & & & & & & & & X & & & \\
\hline I-31-05 & & & & & & & & & X & & & & & \\
\hline \multirow[t]{3}{*}{ I-31-06 } & & & & & & & & & $X$ & & & & & \\
\hline & 0 & 0 & 0 & 0 & 0 & 0 & 0 & 0 & 2 & 1 & 3 & 0 & 0 & 6 \\
\hline & C1 & C2 & C3 & C4 & C5 & C6 & L1 & L2 & L3 & L4 & L5 & L6 & I & SUM \\
\hline I-32-01 & & & & & & & & & & & & & $\mathrm{X}$ & \\
\hline I-32-02 & & & $X$ & & & & & & & & & & & \\
\hline I-32-03 & & & & & & & & & $X$ & & & & & \\
\hline I-32-04 & & & & & & & & & & & & X & & \\
\hline I-32-05 & & & & $X$ & & & & & & & & & & \\
\hline I-32-06 & & & & $X$ & & & & & & & & & & \\
\hline I-32-07 & & & & $X$ & & & & & & & & & & \\
\hline I-32-08 & & & & & & & & & & & X & & & \\
\hline I-32-09 & & & & & & & & & & & & & $X$ & \\
\hline I- $32-10$ & & & & & & & & & & & & & $X$ & \\
\hline I-32-11 & & & & $X$ & & & & & & & & & & \\
\hline I-32-12 & & & & & & & & & & & $X$ & & & \\
\hline I- $32-13$ & & & & & & & & & X & & & & & \\
\hline I-32-14 & & & & & & & & & & & & & $X$ & \\
\hline I-32-15 & & & & & & & & & $X$ & & & & & \\
\hline I-32-16 & & & & & & & & & $X$ & & & & & \\
\hline I-32-17 & & & & $X$ & & & & & & & & & & \\
\hline
\end{tabular}




\section{Consequential Matrix}

(Aggregated)

\begin{tabular}{|c|c|c|c|c|c|c|c|c|c|c|c|c|c|c|}
\hline & C1 & C2 & C3 & C4 & C5 & C6 & L1 & L2 & $\mathbf{L 3}$ & L4 & L5 & L6 & I & SUM \\
\hline I-32-18 & & & & & & & & & & & $X$ & & & \\
\hline I-32-19 & & & & & & & & X & & & & & & \\
\hline I-32-20 & & & & X & & & & & & & & & & \\
\hline I-32-21 & & & & $X$ & & & & & & & & & & \\
\hline I-32-22 & & & & $X$ & & & & & & & & & & \\
\hline I-32-23 & & & & & & & & & & & & & X & \\
\hline I-32-24 & & & & & X & & & & & & & & & \\
\hline I-32-25 & & & & X & & & & & & & & & & \\
\hline I-32-26 & & X & & & & & & & & & & & & \\
\hline I-32-27 & & & & X & & & & & & & & & & \\
\hline I-32-28 & & & & $X$ & & & & & & & & & & \\
\hline I-32-29 & & & & & & & & & X & & & & & \\
\hline I-32-30 & & & & & & & & & & & & & $\mathrm{X}$ & \\
\hline I-32-31 & & & X & & & & & & & & & & & \\
\hline I-32-32 & & & $\mathrm{X}$ & & & & & & & & & & & \\
\hline I-32-33 & & & & & & & & & & & & & X & \\
\hline I-32-34 & & & & & & & & & & & $\mathrm{X}$ & & & \\
\hline I-32-35 & X & & & & & & & & & & & & & \\
\hline I-32-36 & & & & & & & $\mathrm{X}$ & & & & & & & \\
\hline I-32-37 & & & & & & & & & X & & & & & \\
\hline I-32-38 & & & & & & & & & $\mathrm{X}$ & & & & & \\
\hline I-32-39 & & & & & & & & & $\mathrm{X}$ & & & & & \\
\hline I- $32-40$ & & & & & & & & X & & & & & & \\
\hline I-32-41 & & & & & & & & & & & X & & & \\
\hline I-32-42 & & & X & & & & & & & & & & & \\
\hline I-32-43 & & & & $X$ & & & & & & & & & & \\
\hline I-32-44 & X & & & & & & & & & & & & & \\
\hline I-32-45 & X & & & & & & & & & & & & & \\
\hline I-32-46 & & & & & & & & & & & X & & & \\
\hline I-32-47 & & & & & & & & & $X$ & & & & & \\
\hline & 3 & 1 & 4 & 12 & 1 & 0 & 1 & 2 & 9 & 0 & 6 & 1 & 7 & 47 \\
\hline & 14 & 22 & 118 & 170 & 22 & 7 & 5 & 40 & 184 & 94 & 176 & 23 & 139 & 1014 \\
\hline
\end{tabular}


Figure 1 Aggregated Column Chart for the Whole Project

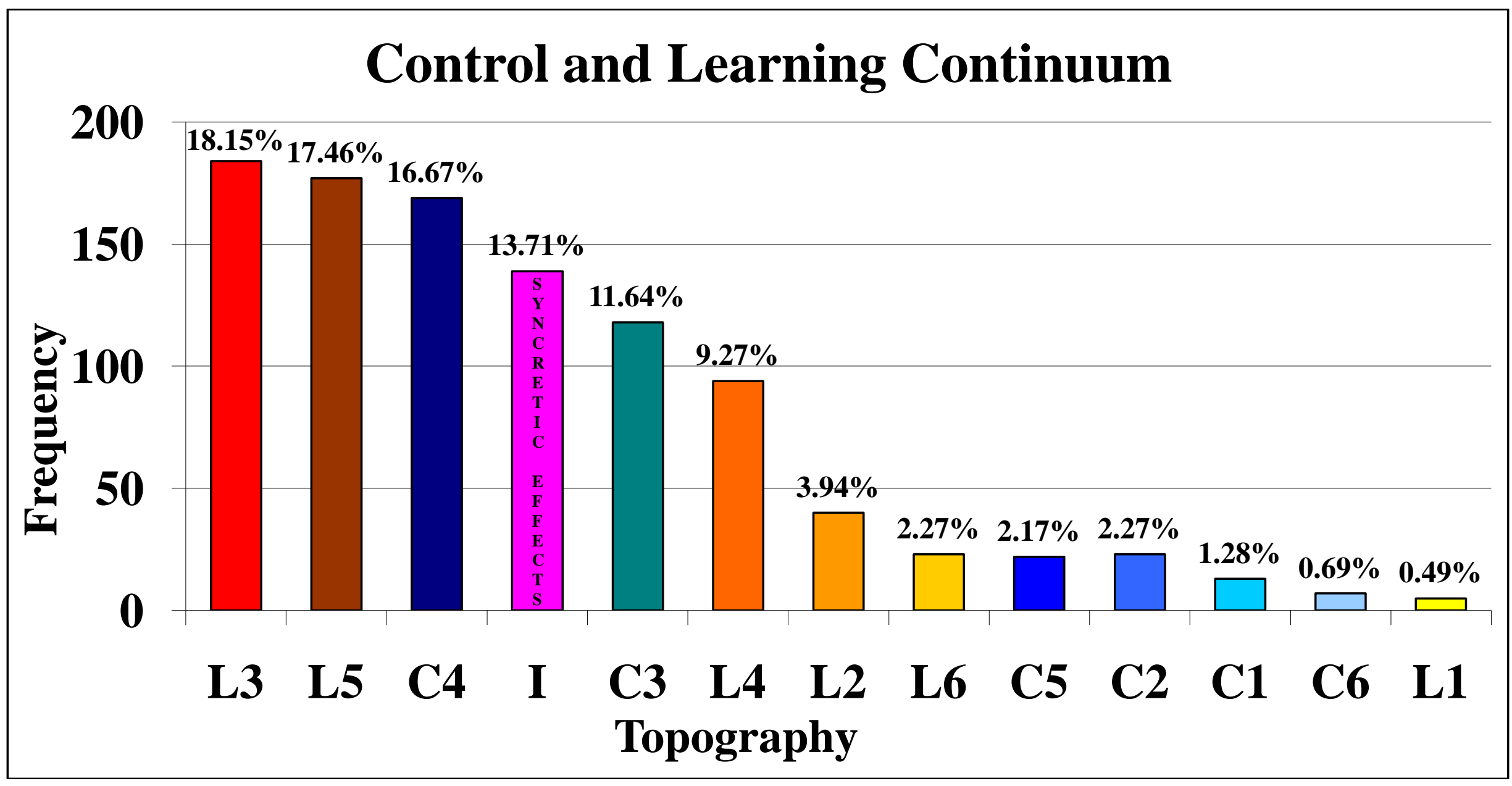




\section{Appendix A}

Scanned copy of the original interview coded for Mr. McIntosh (Interviewee 14)

1
2
3
4
5
6
7
8
9
10




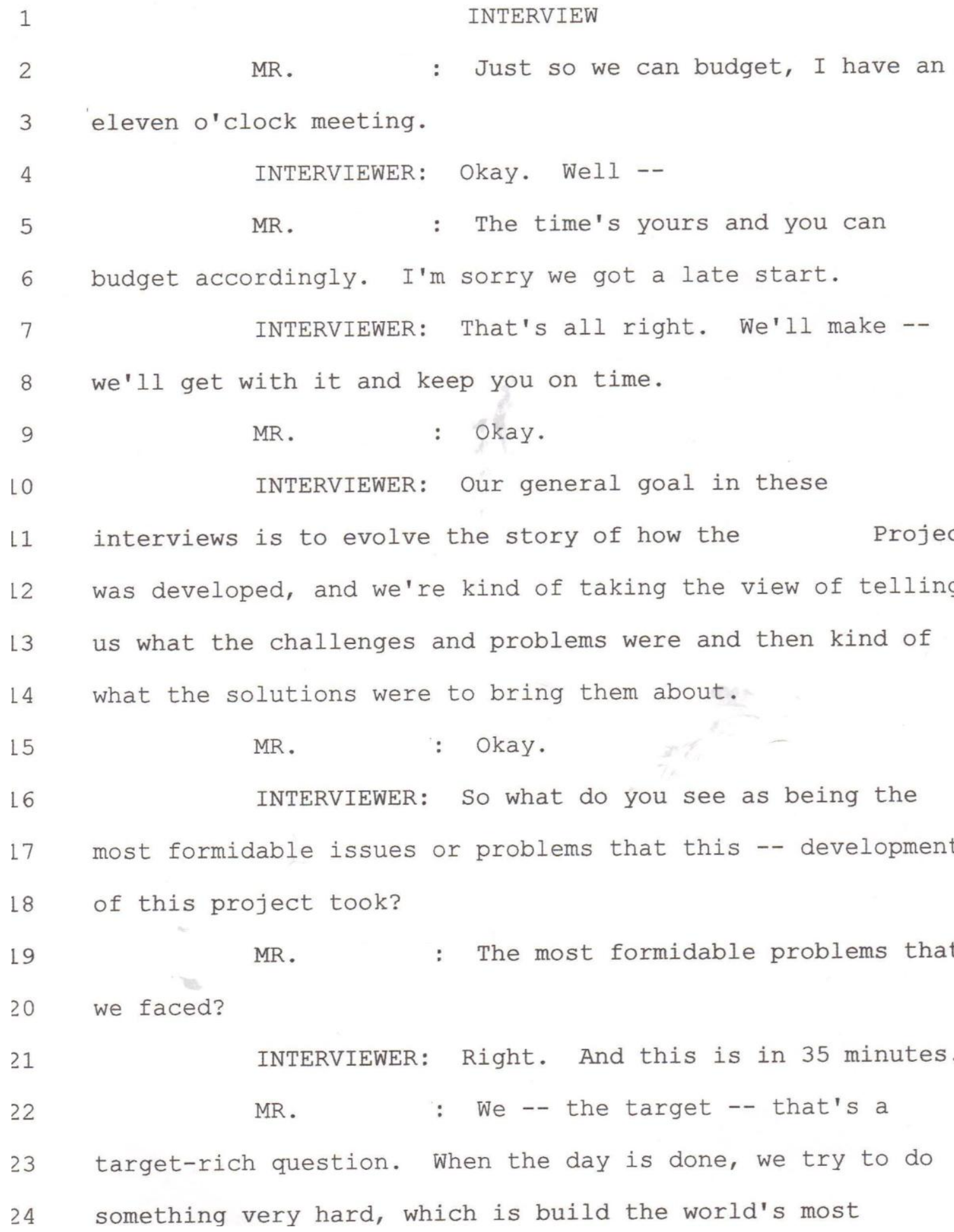




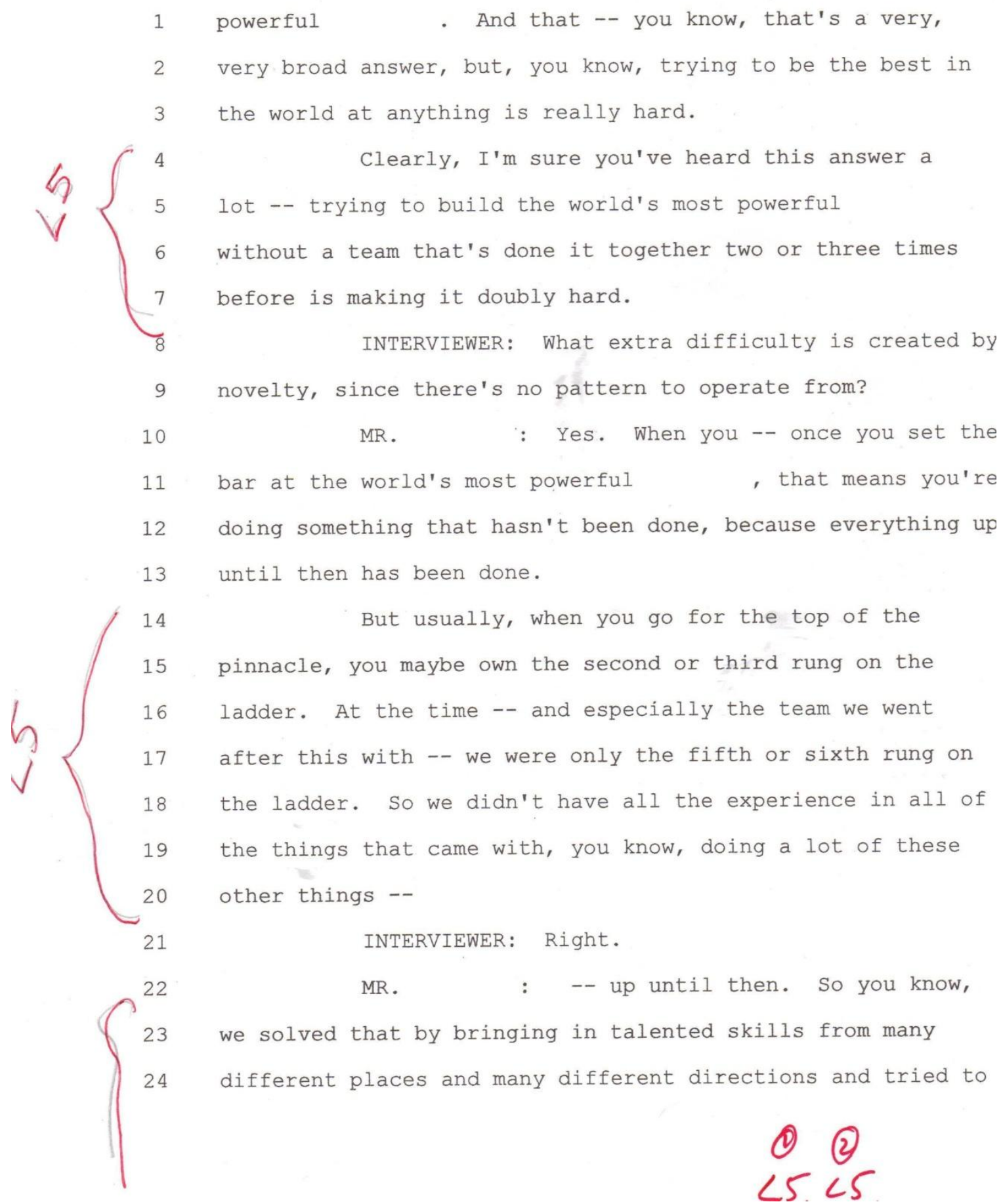



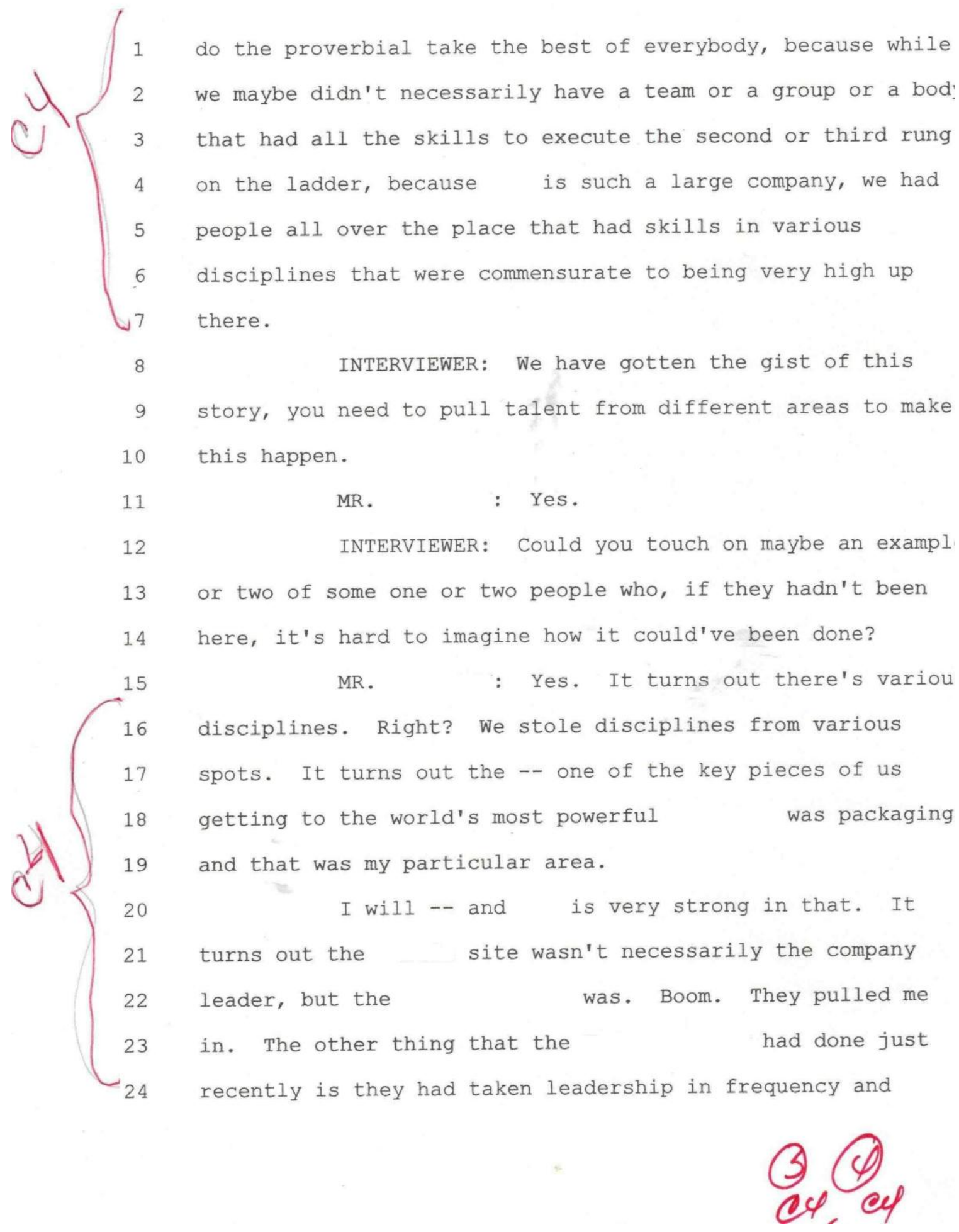


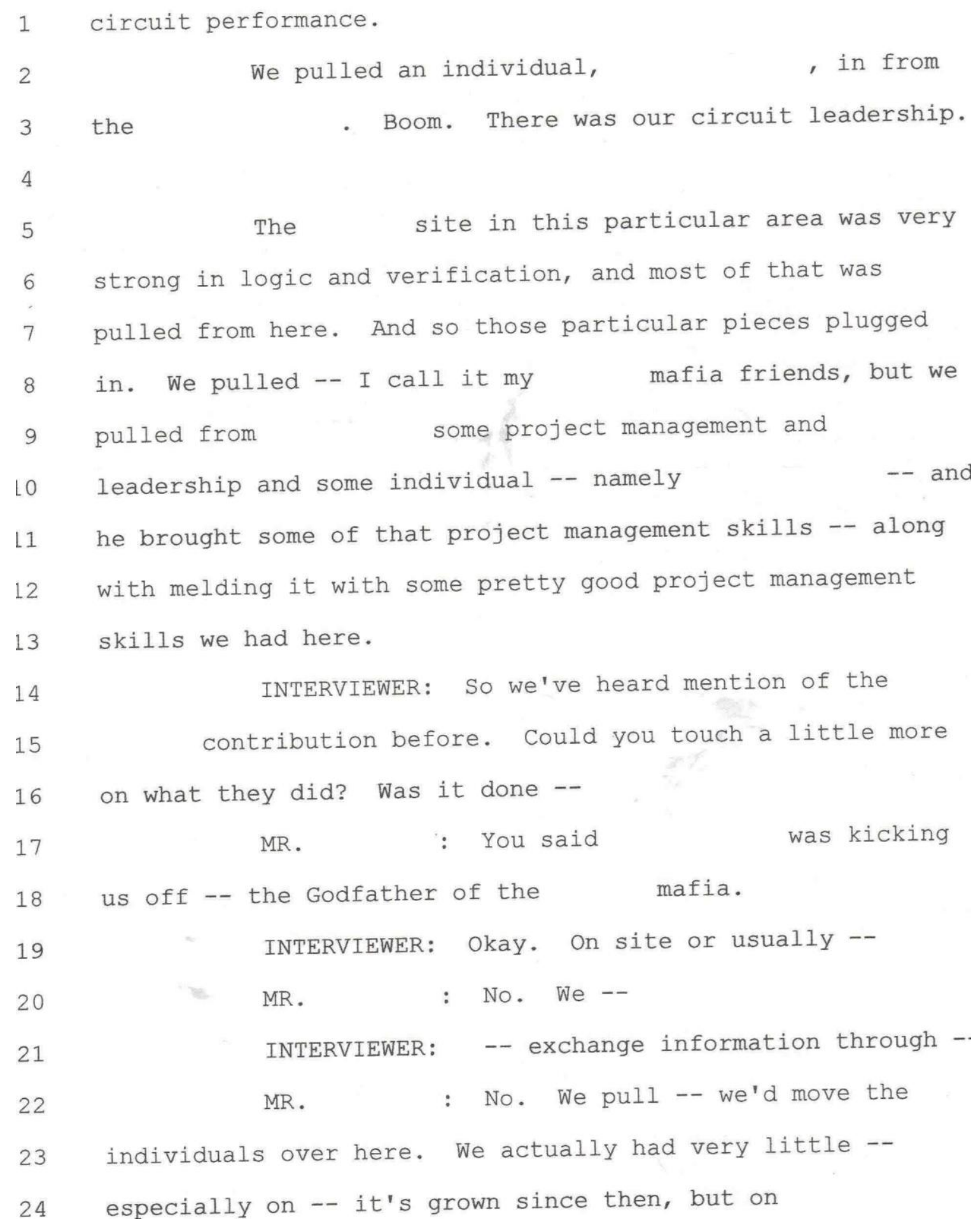




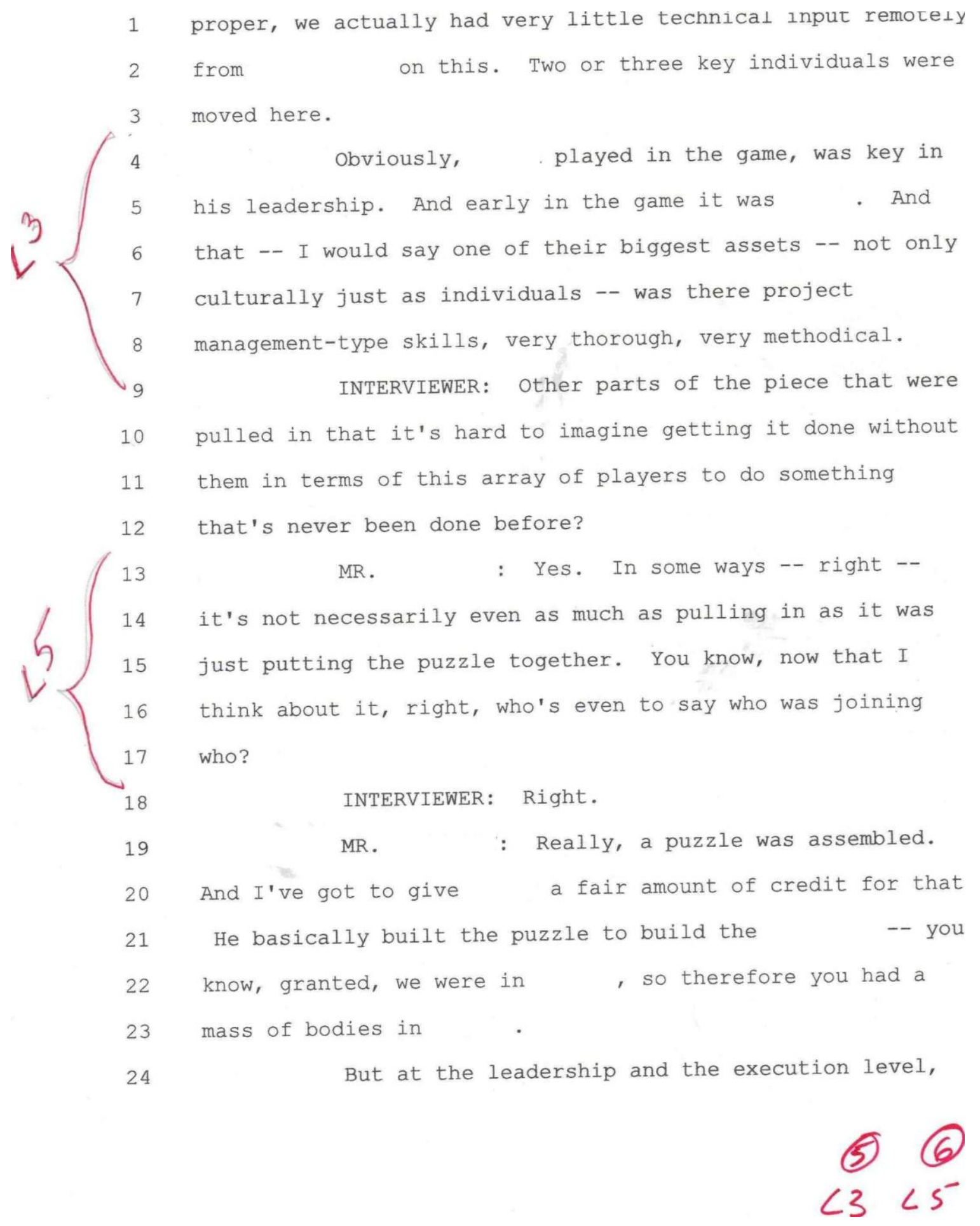


1 you know, it wasn't dominated by any one particular thing.

2 I think he went -- and within the constraints handed to

3 him -- you know, people and availability -- and just built

4 the pieces everywhere.

So he drew from just a lot of different places --

6 so packaging, circuits came from the Logic

7 leadership mainly came from - Logic and the entrs

8 leadership came from . Project management had a very

9 strong influence from . 


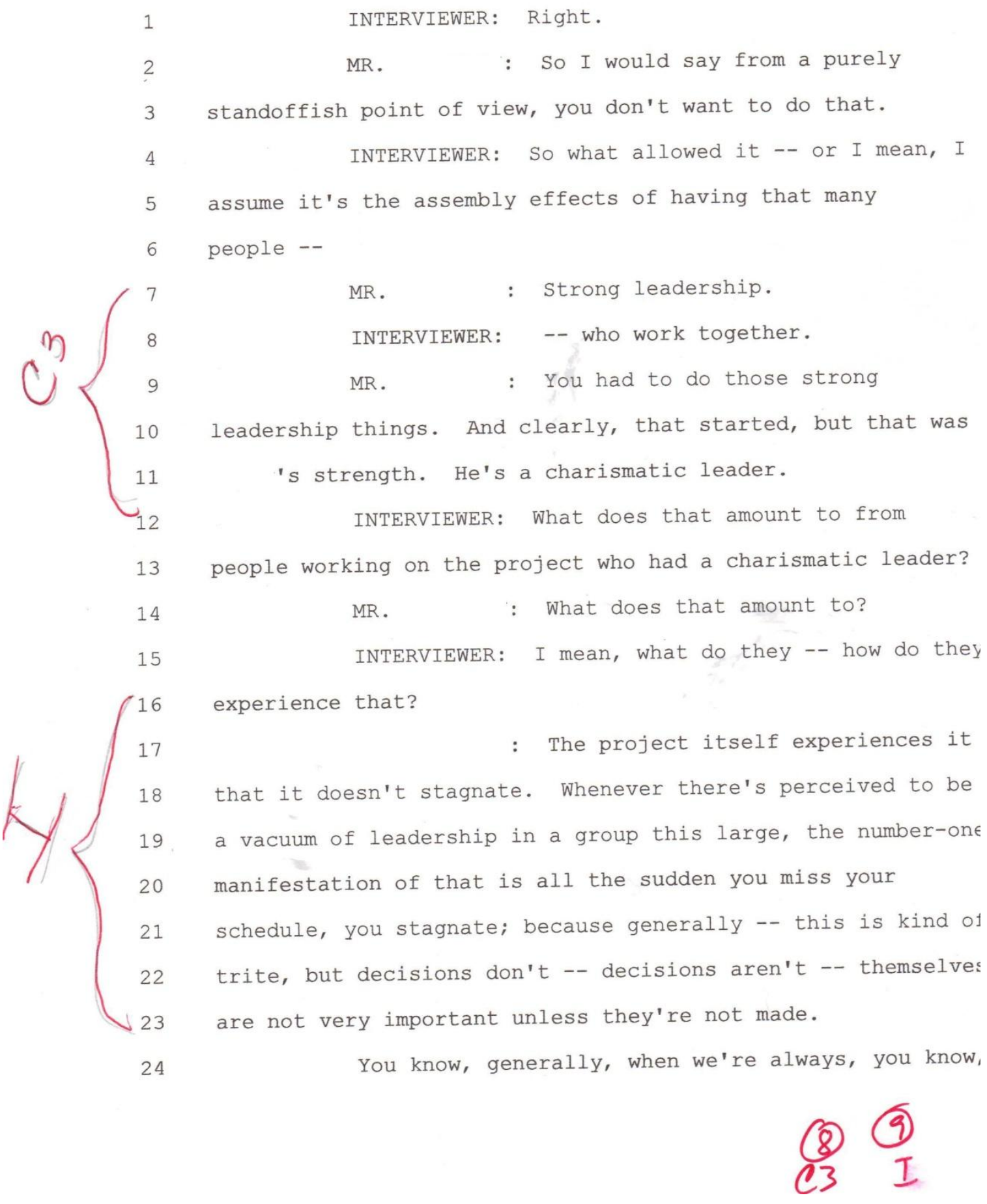




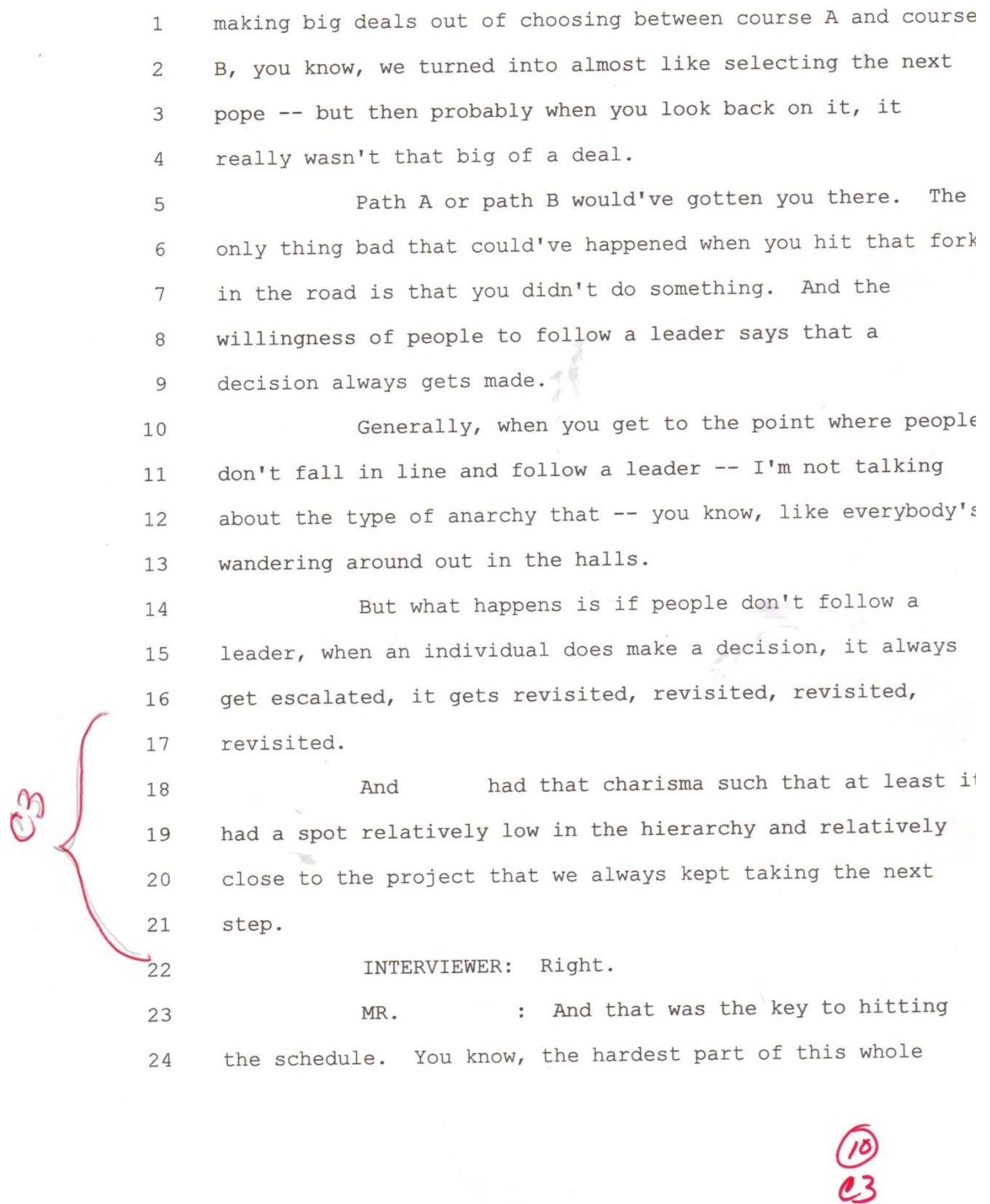


1 thing and the biggest strength of this project now, even

2 with the luxury of looking backwards, is that we got the

3 product to market on time -- which is almost the biggest

4 lever in this industry to taking leadership -- I mean, put

5 that -- put the out a year later and you're not --

6 it's almost out because the industry goes so fast in

$7 \quad$ leadership. INTERVIEWER: How does that level of action, movement, ripple out? What does that mean to people that things continue to be made; does it mean that they just -by not stalling that they don't have to worry about what comes next or they won't have lost momentum?

17 things and you stall for too long anywhere, it's a death 18 spiral. I don't know how else to say it. INTERVIEWER: Right. 


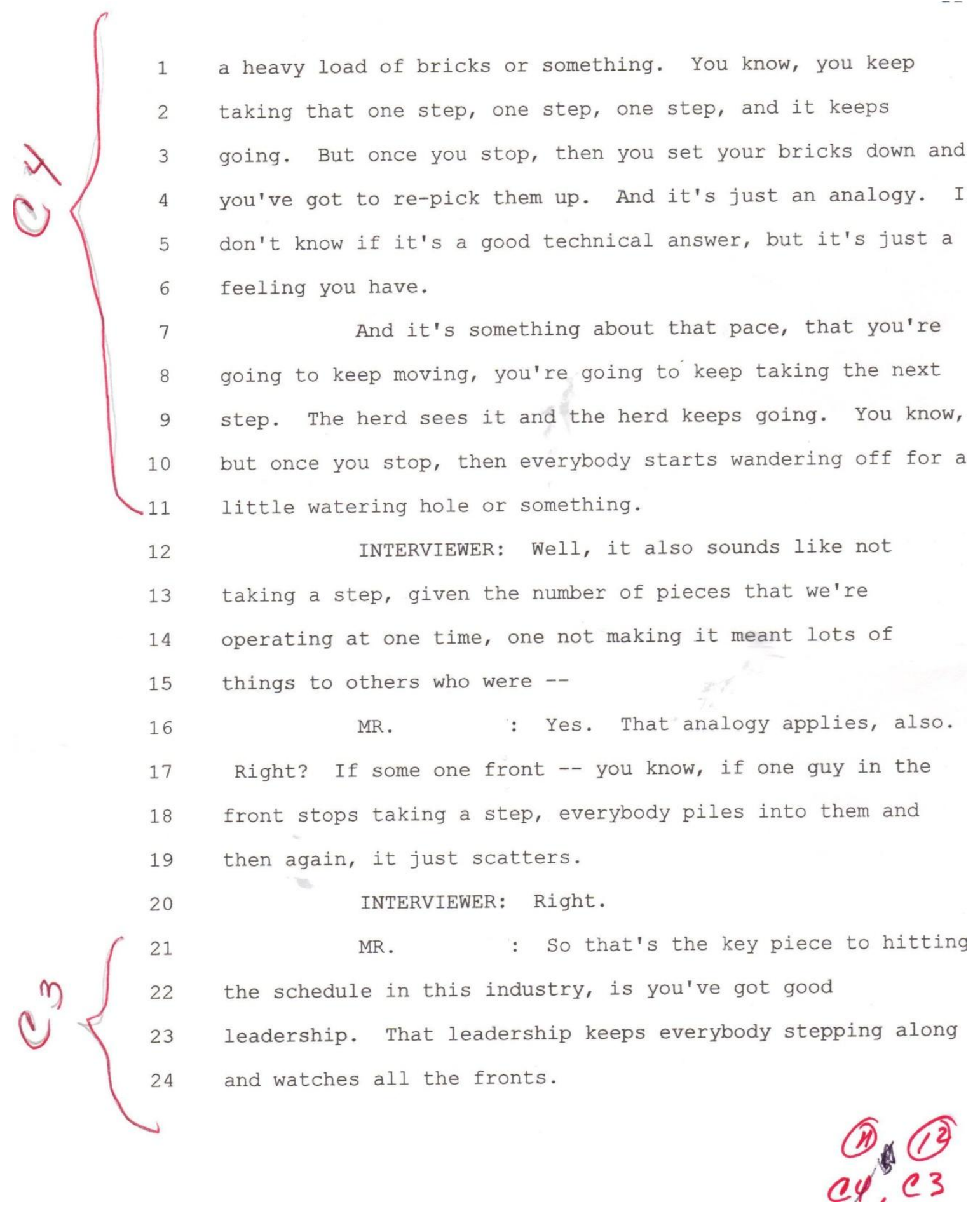


INTERVIEWER: Are there other things you could identify as being kind of the source of why this complex thing came together in the way it did?

MR. $\quad$ : Sheer hard work. I mean -- you know, I mean, you can't talk about how we got the complexity without talking about individual -- the individual contributions of a large number of people that just, you know, stayed with it. I don't know how that feeds into anything you're really looking for here.

But clearly, the individuals and, you know, the core of people just really wanting to get it done and making all the contributions and sacrifices was a big piece to getting it done. INTERVIEWER: Well, this -- I mean, this is the place where the end of your schedule does come into play, because there's a thing in complexity theory called a bifurcation point. It's essentially a fork in the road. And the solution to what happened at the fork in the road is that once you make a choice it takes more energy to push through to the next level once that's done. So two of the things you identified -- if the choice is made on time and, two, the energy to push through them once they've been decided, so that you make $A$ the right solution -- if that's the one you chose -- by the 


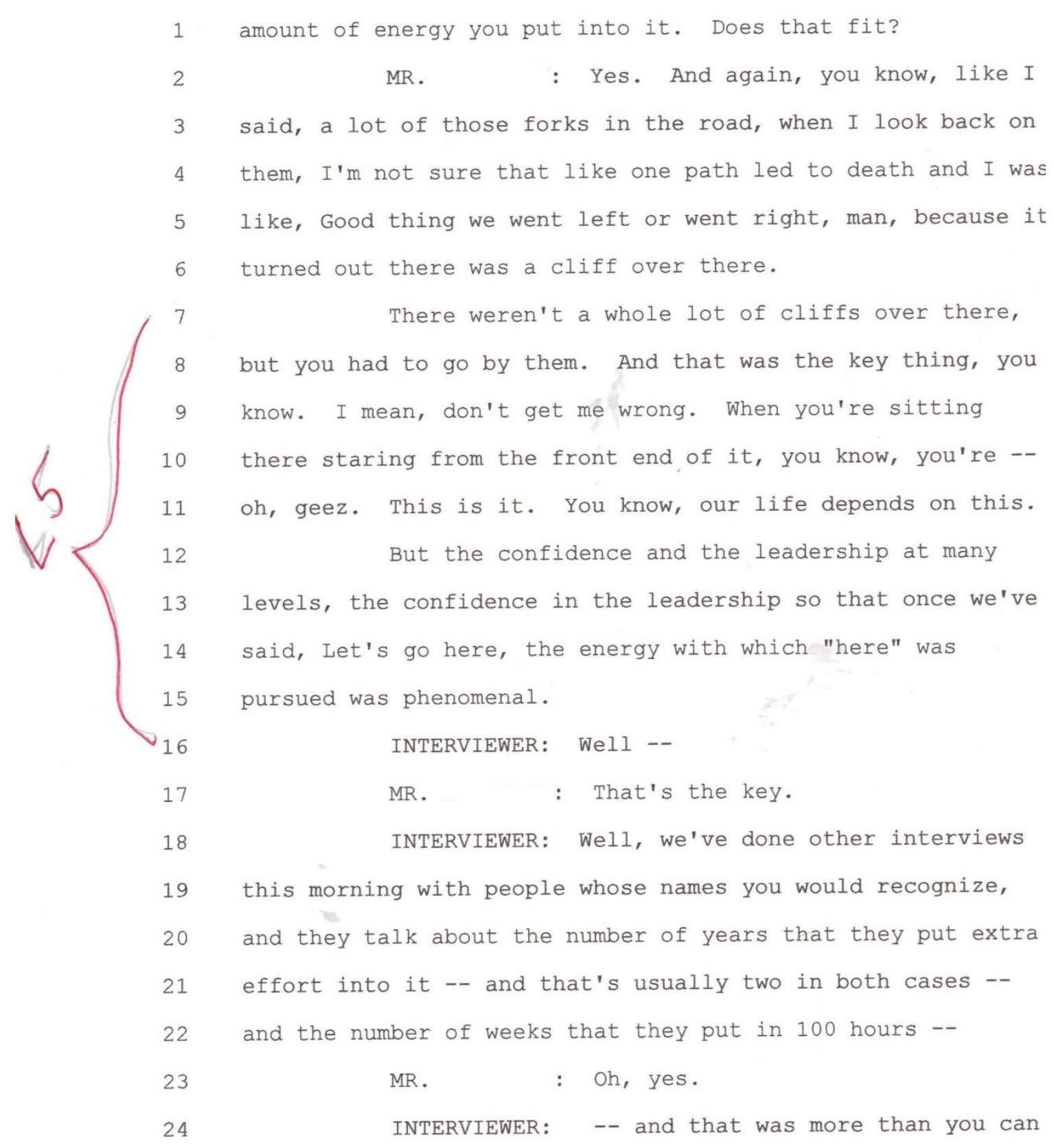




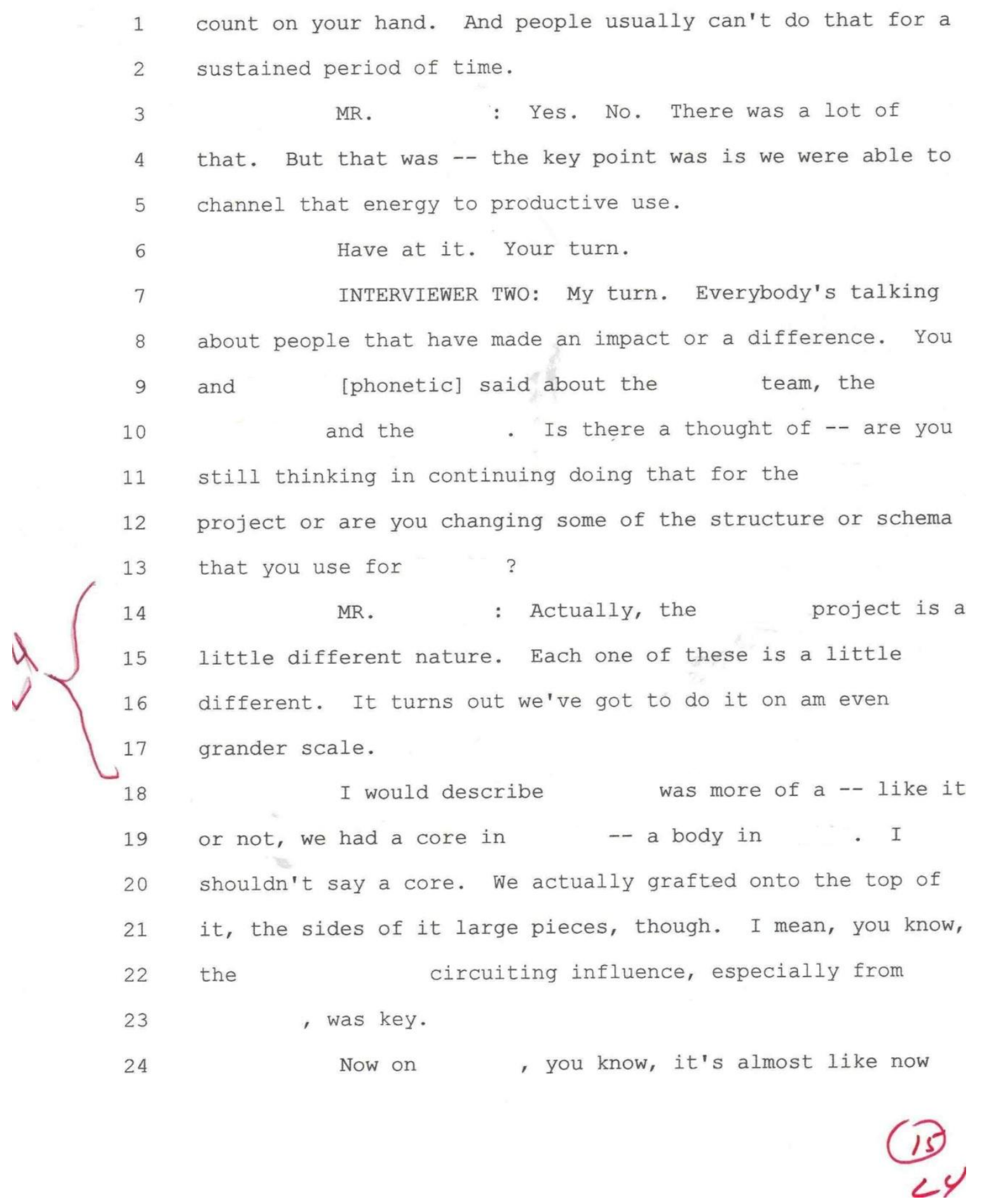


2

3

4

that two big continents are being pushed together and we're getting even a broader cross-section of [inaudible] strengths. So in a lot of ways, -- there's not nearly as many decisions to be made on forming a team, because we're doing a smaller step now. You know, if we're not on the top rung, we're at least on the second, you know -- one or two rung. So now we're taking two teams, merging them together for a lot of other reasons. So in a lot of ways, the team is being handed to us much more than like, you know, you're sitting here six rungs down, go find, you know -- go to free agency, go where to try to, you know, get a team together. So that's a different problem. This -- it turns out this go around the challenge is much more what's worth doing than how to do it.

In , the problem was just as plain as the nose on our face what we had to do. You know, a few very key things -- performance, and it was more of how to do it. It turns out this next go around is a little more challenging to sift out what do we have to do than how to. Rightly or wrongly, we have a very large degree of confidence now in our capabilities and skills, having been through . So I feel like for right now, when wt look forward now, one thing has given us is a lot of 


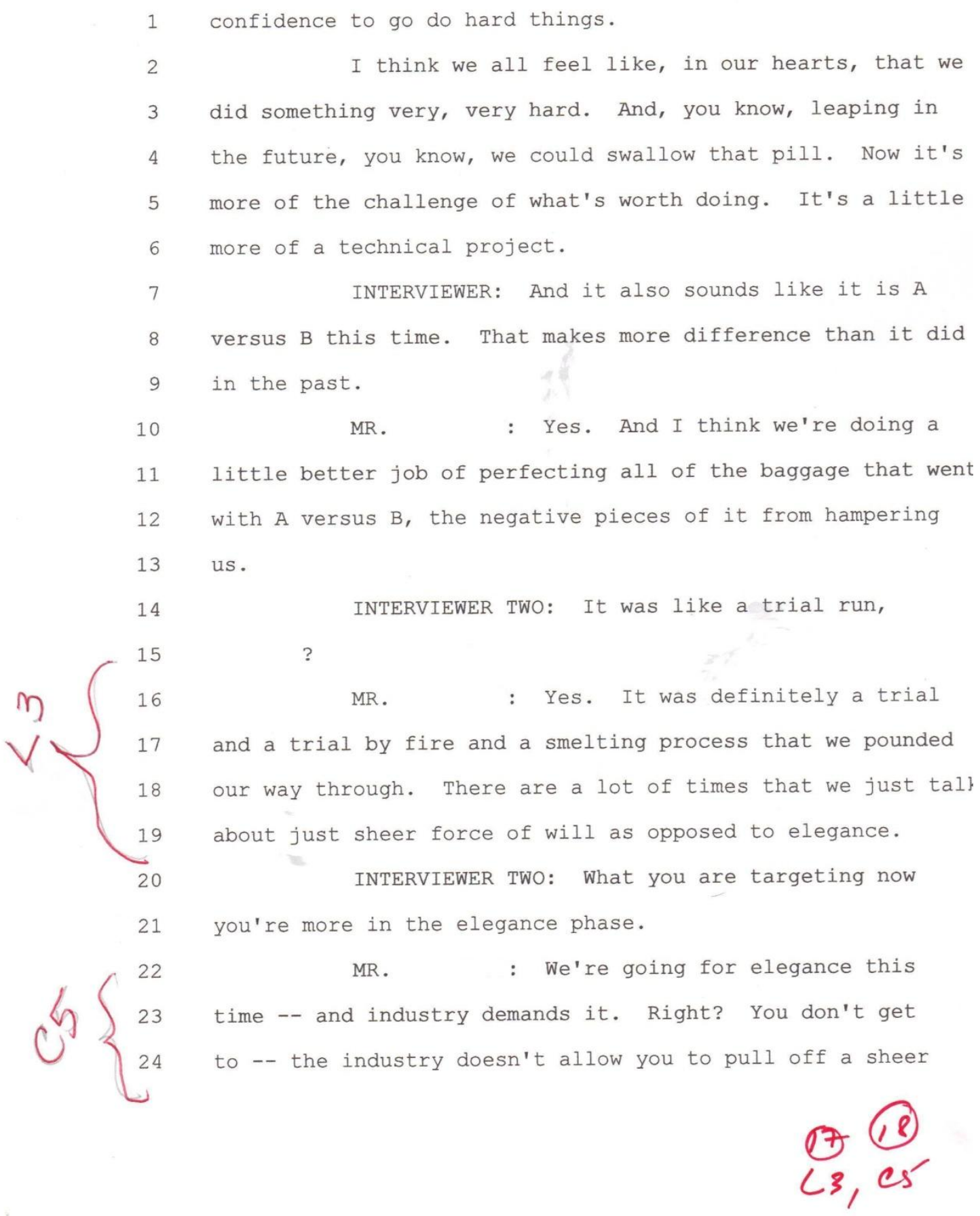


1 force of will maneuver over and over again, because they are 2 expensive. They're expensive in people, they're expensive 3 in dollars, they're expensive on people. There's a lot of

4 cost to just file your way through -- emotionally, 5 physically, financially. If you keep trying to win in this industry with INTERVIEWER: Is there something -- you know, ou Lo goal is to make a book out of this. We've got a couple of L1 publishers -- [inaudible] Press is very interested in it. L2 If you picked up a book three years from now -- and that's 13 kind of ambitious -- what's the one thing in your mind that 14 would have to be in that book for this story to be told 15 correctly? What's the thing that's important not to leave 16 out?

MR. : That's a hard one. It is -- I'm

18 sure you guys have read it, especially if you're thinking

19 about doing that, The Soul of the New Machine. It's a very

20 enjoyable book. And I certainly read that as a young

21 engineer and have reread it.

I always threatened to reread it while we were

23 building the , because I tend to always forget. My

24 mind pushes things out. 


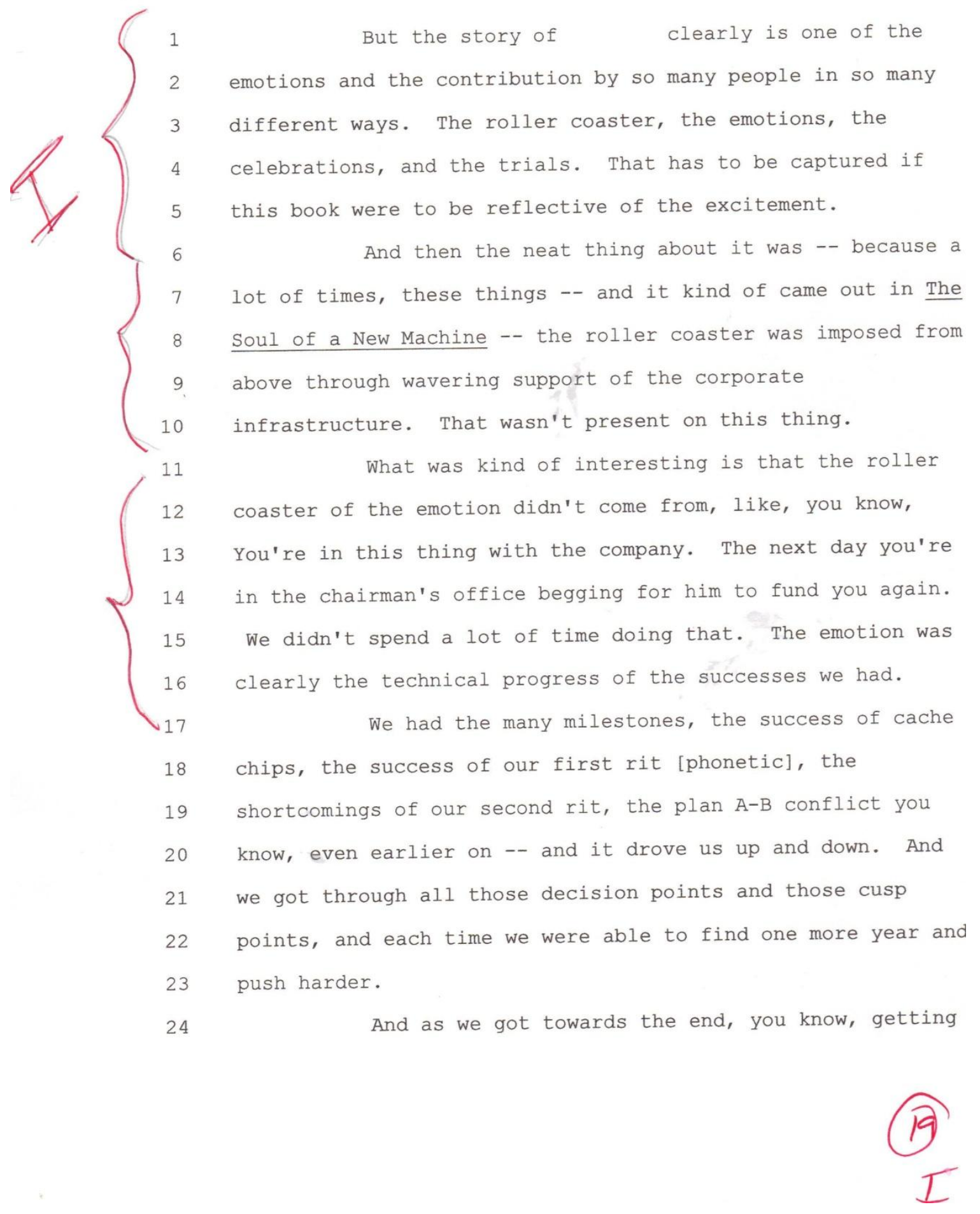




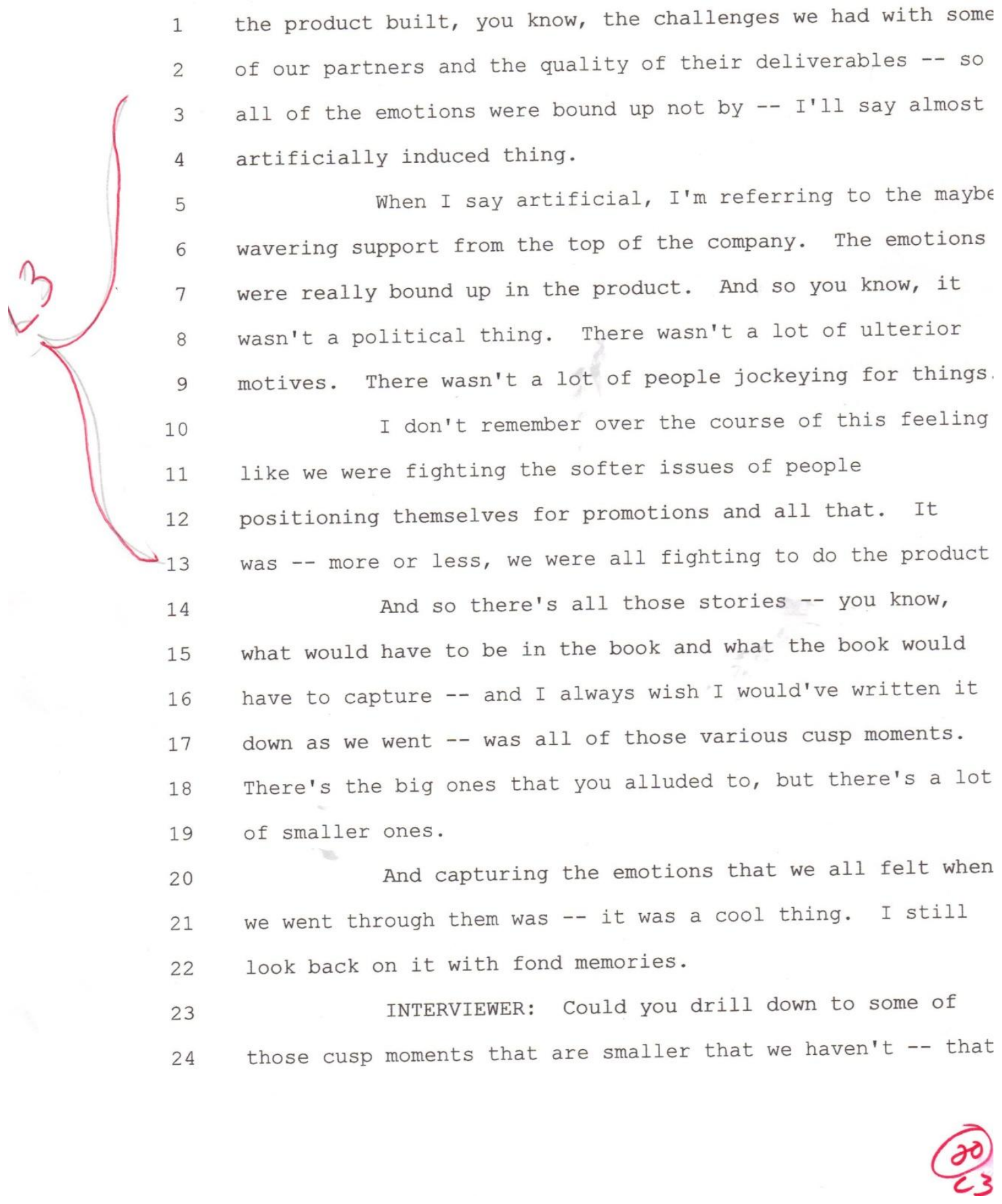




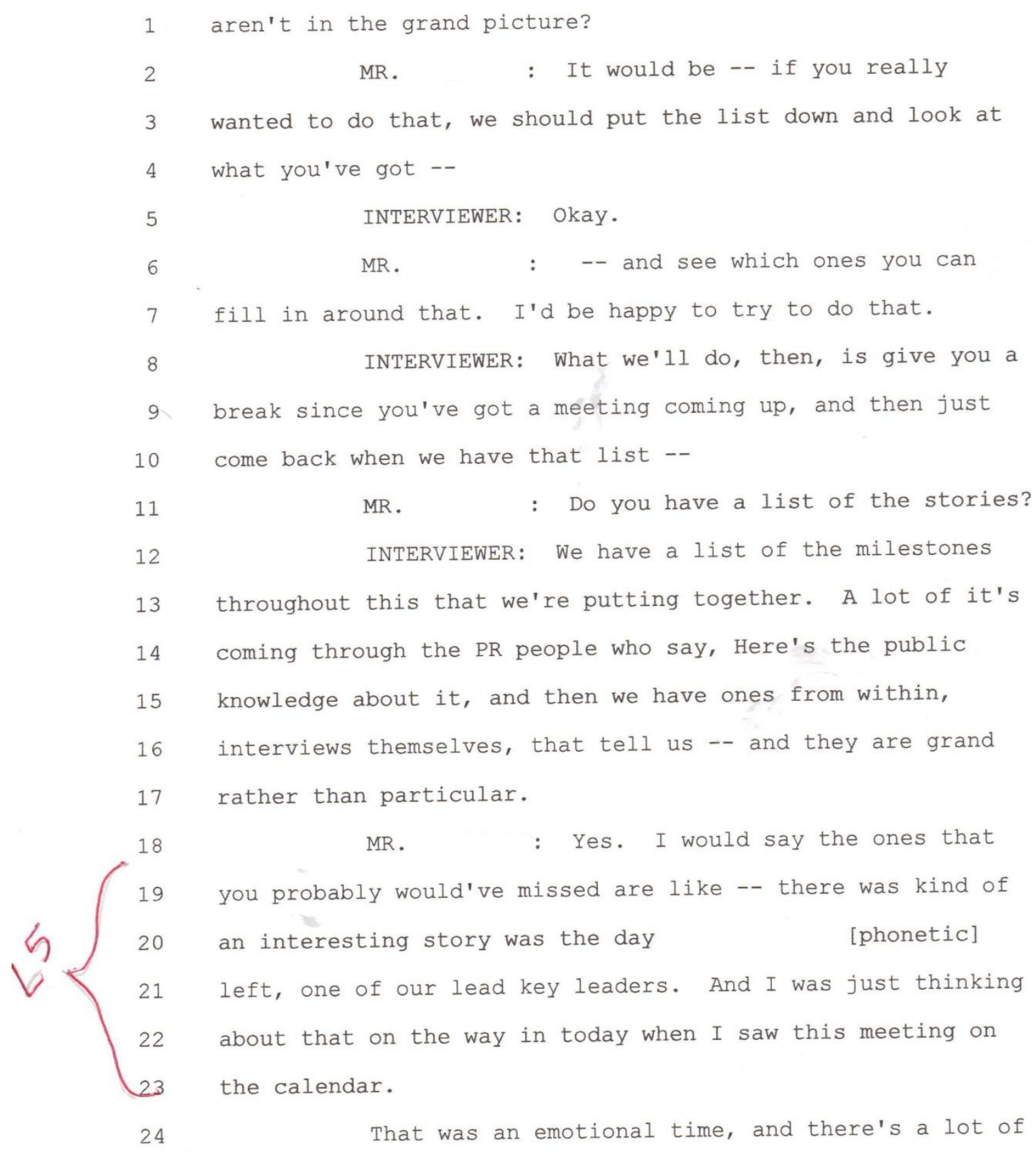

(2) 
humor around this story. It ends up with all the guys out

MR. $\quad$ : Oh, no. There wasn't. We were all -- boy, were we in the hot water that night. 
MR.

: Well, that was my house.

INTERVIEWER: Really? That you had just sold and

3 it was empty and they had the big meeting?

4

MR. : Well, yes. That was the plan A-B party. That was my house up in emotional one. We had a lot of emotions that day. That was a big point. That's a very common story to point to. That was kind of one of the launching ones. Then you got the time when we got the test chip rit out, and 's boss's boss and and and myself were drinking -- well, and I were here and and [phonetic] were on the Tel. We were popping the cork of champagne there in that conference room and laughing and scratching and having a pretty good time out there -you know, one of our -- I'd hate to count up the number of all-nighters we had with that job, but that was another very emotional one.

I remember

was so excited. He was calling every executive of the whole company on the phone, dialing them in with and $I$, telling the whole world that the first, you know, rit got out. And that was -- you know, we ended up talking to the senior VPs and all that, telling them that the rit had gotten out. That was a pretts bia milestone. 


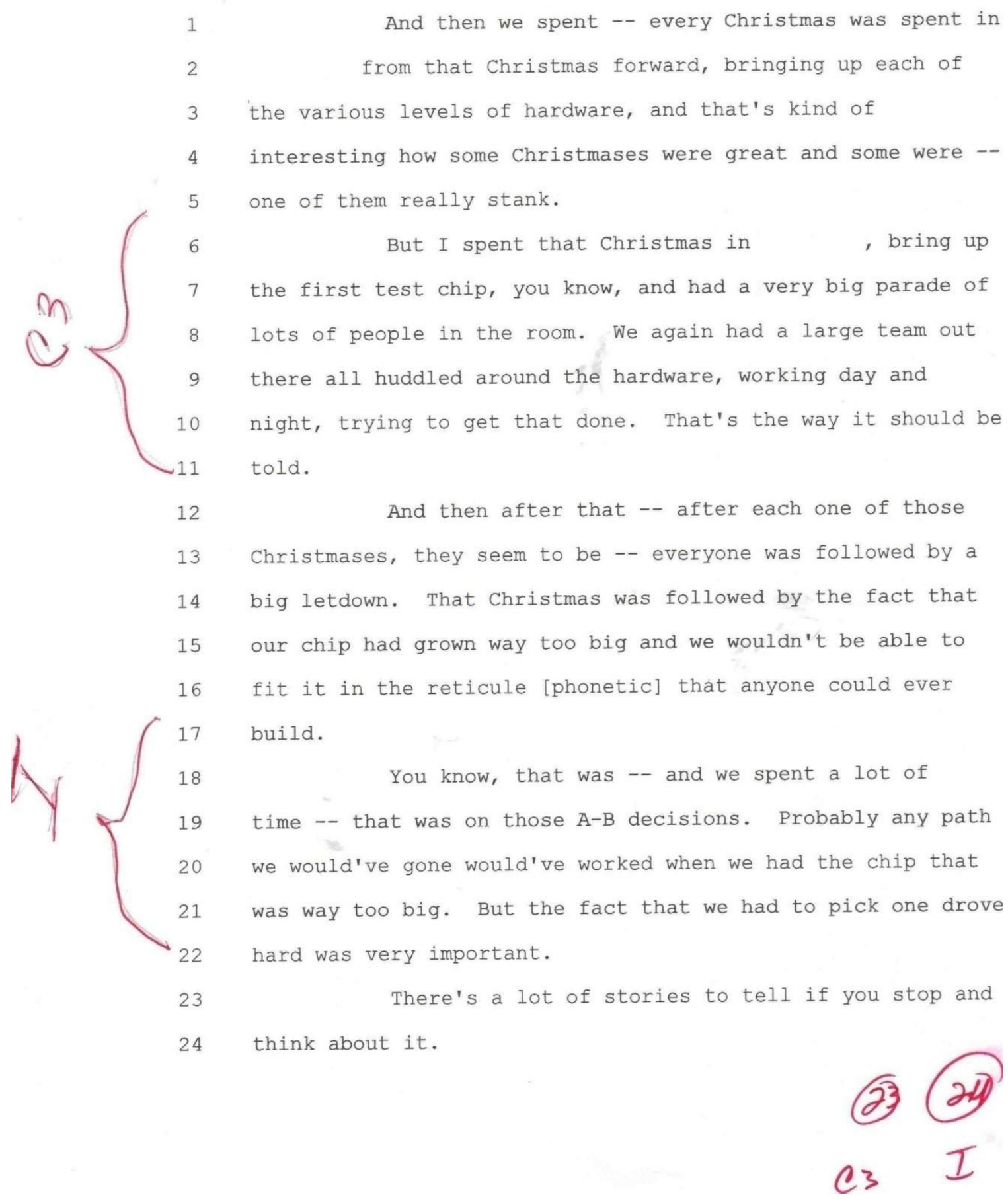

117 
1

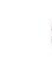

9

L1 New Machine is.

L3 entertaining read. Like I said, the only thing I like about

14 this story even more than The Soul of a New Machine is that

15 the emotion wasn't impressed upon. The Soul of the New

16 Machine was constantly fighting wavering management

17 support --

INTERVIEWER: Well, you had the same idea of what would make this good that we do, and that is you can talk about the technology; but to an outsider, it's foreign enough to them that you need just enough to let them know why it was important. The thing that you're talking about here -- in other words, the emotion that came together to make it happen is why someone would be interested in reading this book --

MR. $\quad:$ Yes. INTERVIEWER: -- which is what The Soul of the

MR. : Right. That's why that book's an t 


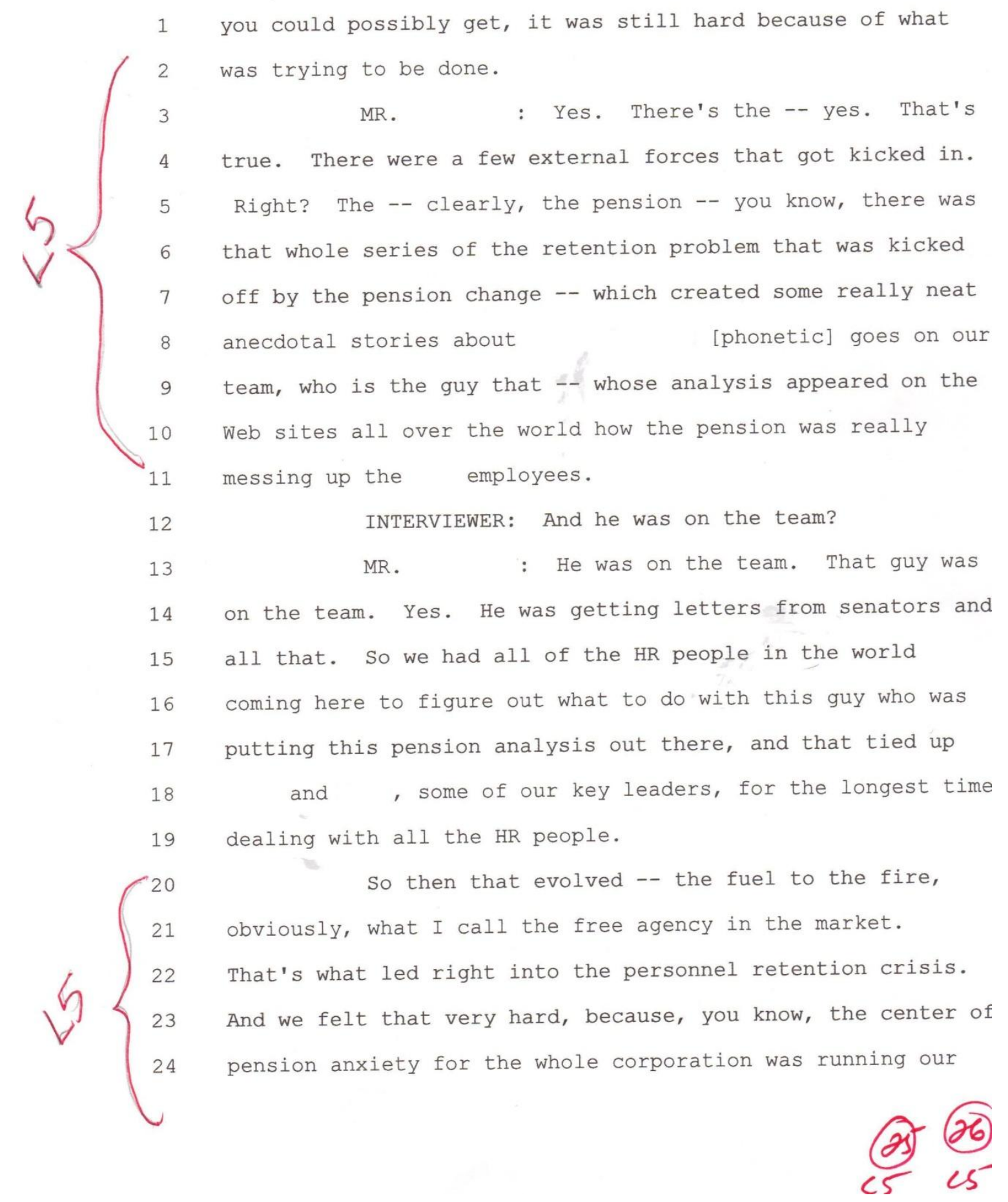


1 team.

3 alternatives at the same time.

5 you had the free agency coming in at the phenomenal, you

6 know, stealing from the company bonuses. And so that created a really big challenge. I think that one culminated

9 probably the highest, most valued player on the whole team

10 that left the team.

a list of them. 
1 that on time off between other than 8:00 and 5:00 for us to

2 meet with you? I know you stay pretty busy. remember. meet with right now.

MR. $\quad$ : Yes. If you're really going to do this, have you thought about getting two or three of us INTERVIEWER: Fantastic. I mean, the part -MR. $\quad$ : I mean, the best thing to do is to have us jog each other's memory. INTERVIEWER: He's right. MR. : The whole battle here is to

INTERVIEWER: See, where this got started to kind of take some definition is when we -- when you mentioned The Soul of a New Machine, and that's what we wanted to do here on this topic. And we know in common is it's emotionality and the drive of the people, and that story of the events that they went through is what makes that a story, not the technology that we're talking about.

MR. $\quad$ : Yes. You know, my team that I have right now -- you've talked to already this morning. If you were to grab, , and, I think the four of us -- I'll go talk to them. I'm going to

INTERVIEWER: All right. 
21 afternoon.

the day or -and --

MR.

: Let me see --

INTERVIEWER: I mean, we --

MR .

: -- see how much effort

collectively that they're willing to put into it.

INTERVIEWER: Sure. Well, people seem so time-

and effort-conscious on the job here. If we met on a

Saturday morning or something like that, you know, it kind

of gets a little more relaxed.

MR .

: okay. Let me -- what is your plan

right now? Are you leaving or are you here for the rest of

INTERVIEWER: We have kind of an informal meeting with one of our sponsors, but --

MR. : If I wanted to reach you, what's the best way to reach you so I can go talk to the guys

INTERVIEWER: Right. Let's see if I can give you one that's not --

MR. : Is your cell phone on here?

INTERVIEWER: All right. I'll be there this

MR. : You'll be there this afternoon? ] will give you a call back. Let me talk to the guys and see what the best way to do this. I know we've all talked aboul 
L it. Everybody's got interests. INTERVIEWER: Well, the job part amounts to a

3 lot. I mean, and just getting a little different views to

4 what happened, let that go somewhere.

5

MR.

: Let me talk to the guys and we'l]

6

call you at this office number and we'll figure it out.

(Whereupon, the interview was concluded.)

$\circ$

Names were eliminated to protect identities. 


\section{Appendix B}

\section{Example of the individual Consequential Matrix for Mr. McIntosh (Interviewee 14)}

\section{Mr. McIntosh* (Interviewee Fourteen)}

\begin{tabular}{|c|c|c|c|c|c|c|c|}
\hline ID & \# & Control & Learning & Syncretic & Intv. & P-R & Quotation \\
\hline $\mathbf{C}$ & 01 & & $\begin{array}{l}\text { Be the best at } \\
\text { anything }\end{array}$ & & $\mathrm{I}-14$ & $3-1$ & $\begin{array}{l}\text { But, you know, trying to be the best in the } \\
\text { world at anything is really hard. Clearly, I'm } \\
\text { sure you've heard this answer a lot- trying to } \\
\text { build the world's most powerful artifact* } \\
\text { without a team that's done it together two or } \\
\text { three times before is making it doubly hard. }\end{array}$ \\
\hline SC & & \multicolumn{6}{|c|}{ 1) Built something that has never done before is learning } \\
\hline $\mathbf{L 5}$ & & \multicolumn{6}{|c|}{ Learning-Environment based } \\
\hline $\mathbf{C}$ & $\mathbf{0 2}$ & & $\begin{array}{l}\text { Top of the } \\
\text { pinnacle }\end{array}$ & & $\mathrm{I}-14$ & $3-20$ & $\begin{array}{l}\text { Yes. When you- once you set the bar at the } \\
\text { world's most powerful artifact, that means } \\
\text { you're doing something that hasn't been done, } \\
\text { because everything up until then has been } \\
\text { done. But usually, when you go for the top of } \\
\text { the pinnacle, you maybe own the second or } \\
\text { third rung on the ladder. At the time- and } \\
\text { especially the team we went after this with- } \\
\text { we were only the fifth or sixth rung on the } \\
\text { ladder. So we didn't have all the experience in } \\
\text { all of the things that came with, you know, } \\
\text { doing a lot of these other things up until then. }\end{array}$ \\
\hline SC & & \multicolumn{6}{|c|}{ 1) Not having all the experience but doing it, is learning } \\
\hline $\mathbf{L 5}$ & & \multicolumn{6}{|c|}{ Learning-Environment based } \\
\hline $\mathbf{C}$ & $\mathbf{0 3}$ & $\begin{array}{l}\text { Access to the } \\
\text { best skilled } \\
\text { personnel }\end{array}$ & & & $\mathrm{I}-14$ & $4-1$ & $\begin{array}{l}\text { So you know, we solved that by bringing in } \\
\text { talented skills from many different places and } \\
\text { many different directions and tried to do the } \\
\text { proverbial take the best of everybody, because } \\
\text { while we maybe didn't necessarily have a } \\
\text { team or a group or a body that had all the } \\
\text { skills to execute the second or third rung on } \\
\text { the ladder, because XYZ is such a large } \\
\text { company, we had people all over the place } \\
\text { that had skills in various disciplines that were } \\
\text { commensurate to being very high up there. }\end{array}$ \\
\hline SC & & \multicolumn{6}{|c|}{ 1) Taking the best skilled personnel from all over the company, is control } \\
\hline $\mathbf{C 4}$ & & Control-Stru & based & & & & \\
\hline
\end{tabular}


Mr. McIntosh* (Interviewee Fourteen)

\begin{tabular}{|c|c|c|c|c|c|c|c|}
\hline ID & \# & Control & Learning & Syncretic & Intv. & $\mathbf{P}-\mathbf{R}$ & Quotation \\
\hline $\mathbf{C}$ & 04 & $\begin{array}{l}\text { Stealing } \\
\text { disciplines }\end{array}$ & & & I-14 & 4-15 & $\begin{array}{l}\text { It turns out there's various disciplines. Right? } \\
\text { We stole disciplines from various spots. It } \\
\text { turns out the -one of the key pieces of us } \\
\text { getting to the world's most powerful artifact } \\
\text { was packaging, and that was my particular } \\
\text { area. I will -and Mr. Starbucks* is very strong } \\
\text { in that. It turns out the Atascosa* site wasn't } \\
\text { necessarily the company leader, but the } \\
\text { Hidalgo* was. Boom. They pulled me in. The } \\
\text { other thing that the Hidalgo had done just } \\
\text { recently is they had taken leadership in } \\
\text { frequency and circuit performance. We pulled } \\
\text { an individual, Mr. Medici*, in from the } \\
\text { Hidalgo. Boom. There was our circuit } \\
\text { leadership. }\end{array}$ \\
\hline SC & & \multicolumn{6}{|c|}{ 1) Stealing disciplines from various locations within the company is control } \\
\hline C4 & & \multicolumn{2}{|c|}{ Control-Structure based } & & & & \\
\hline $\mathbf{C}$ & 05 & & Key leadership & & I-14 & $6-1$ & $\begin{array}{l}\text { We actually had very little technical input } \\
\text { remotely from Brian* on this. Two or three } \\
\text { key individuals were moved here. Obviously, } \\
\text { Edward* played in the game, was key in his } \\
\text { leadership. And early in the game it was } \\
\text { Rudolph*. And that -I would say one of their } \\
\text { biggest assets- not only culturally just as } \\
\text { individuals was there project management- } \\
\text { type skills, very thorough, very methodical. }\end{array}$ \\
\hline SC & & \multicolumn{6}{|c|}{ 1) Having personnel with management-type skill, allows for learning } \\
\hline $\mathbf{L 3}$ & & \multicolumn{6}{|c|}{ Learning-Personnel based } \\
\hline & & & & & & & \\
\hline
\end{tabular}


Mr. McIntosh* (Interviewee Fourteen)

\begin{tabular}{|c|c|c|c|c|c|c|c|}
\hline ID & \# & Control & Learning & Syncretic & Intv. & $\mathbf{P}-\mathbf{R}$ & Quotation \\
\hline $\mathbf{C}$ & 06 & & $\begin{array}{l}\text { Putting a puzzle } \\
\text { together }\end{array}$ & & $\mathrm{I}-14$ & $6-13$ & $\begin{array}{l}\text { In some ways it's not necessarily even as } \\
\text { much as pulling in as it was just putting the } \\
\text { puzzle together. You know, now that I think } \\
\text { about it, right, who's even to say who was } \\
\text { joining who? Really, a puzzle was assembled. } \\
\text { And I've got to give Mr. Starbucks* a fair } \\
\text { amount of credit for that. He basically built } \\
\text { the puzzle to build the artifact -you know, } \\
\text { granted, we were in Atascosa, so therefore } \\
\text { you had a mass of bodies in Atascosa. But at } \\
\text { the leadership and the execution level, you } \\
\text { know, it wasn't dominated by any one } \\
\text { particular thing. I think he went and within the } \\
\text { constraints handed to him -you know, people } \\
\text { and availability- and just built the pieces } \\
\text { everywhere. }\end{array}$ \\
\hline SC & & \multicolumn{6}{|c|}{ 1) Building something with the constraints handed to him, is learning from the environment } \\
\hline $\mathbf{L 5}$ & & \multicolumn{6}{|c|}{ Learning-Environment based } \\
\hline $\mathbf{C}$ & 07 & & Unusual casting & & $\mathrm{I}-14$ & $7-13$ & $\begin{array}{l}\text { INTERVIEWER: Is that unusual for there to } \\
\text { be that much casting? Interviewee Fourteen: } \\
\text { Oh, of course it is. Yes. That's what I'm } \\
\text { saying. That was unusual because normally, if } \\
\text { you're doing it right in this industry, you're } \\
\text { doing, you know, the climb-the-ladder thing. } \\
\text { Right? You get your nucleus, you get it set, } \\
\text { and then you evolve. And you take the wrong } \\
\text { top rung by just passing one rung over. }\end{array}$ \\
\hline SC & & \multicolumn{6}{|c|}{ 1) Not doing the usual climb-the-ladder thing is learning from the environment } \\
\hline $\mathbf{L 5}$ & & \multicolumn{6}{|c|}{ Learning-Environment based } \\
\hline & & & & & & & \\
\hline $\mathbf{C}$ & 08 & $\begin{array}{l}\text { Strong } \\
\text { Leadership }\end{array}$ & & & $\mathrm{I}-14$ & $8-7$ & $\begin{array}{l}\text { Strong leadership. You had to do those strong } \\
\text { leadership things. And clearly, that started, } \\
\text { but that was Mr. Starbuck's strength. He's a } \\
\text { charismatic leader. }\end{array}$ \\
\hline SC & & \multicolumn{6}{|c|}{ 1) Having strong leadership is control } \\
\hline $\mathbf{C 3}$ & & \multicolumn{6}{|c|}{ Control-Personnel based } \\
\hline & & & & & & & \\
\hline
\end{tabular}


Mr. McIntosh* (Interviewee Fourteen)

\begin{tabular}{|c|c|c|c|c|c|c|c|}
\hline ID & \# & Control & Learning & Syncretic & Intv. & $\mathbf{P}-\mathbf{R}$ & Quotation \\
\hline $\mathbf{C}$ & 09 & & & $\begin{array}{l}\text { Experien- } \\
\text { cing } \\
\text { stagnation }\end{array}$ & $\mathrm{I}-14$ & 8-17 & $\begin{array}{l}\text { The project itself experiences it that it doesn't } \\
\text { stagnate. When-ever there's perceived to be a } \\
\text { vacuum of leadership in a group this large, the } \\
\text { number-one manifestation of that is all the } \\
\text { sudden you miss your schedule, you stagnate; } \\
\text { because generally - this is kind of trite, but } \\
\text { decisions don't - decisions aren't - themselves } \\
\text { are not very important unless they're not made }\end{array}$ \\
\hline SC & & \multicolumn{6}{|c|}{ 1) Vacuum of leadership is forces you to learn } \\
\hline SC & & \multicolumn{6}{|c|}{ 2) Decisions made, speaks of control } \\
\hline I & & \multicolumn{6}{|c|}{ Interdependence between Control and learning } \\
\hline $\mathbf{C}$ & 10 & & $\begin{array}{l}\text { Taking the next } \\
\text { step }\end{array}$ & & I-14 & $9-16$ & $\begin{array}{l}\text { But what happens is if people don't follow a } \\
\text { leader, when an individual does make a } \\
\text { decision, it always get escalated, it gets } \\
\text { revisited, revisited, revisited, revisited. And } \\
\text { Vinny* had that charisma such that at least it } \\
\text { had a spot relatively low in the hierarchy and } \\
\text { relatively close to the project that we always } \\
\text { kept taking the next step. }\end{array}$ \\
\hline SC & & \multicolumn{6}{|c|}{ 1) Charisma to inspire others to take the next step, speaks of learning } \\
\hline $\mathbf{L 3}$ & & \multicolumn{6}{|c|}{ Learning-Personnel based } \\
\hline $\mathbf{C}$ & 11 & $\begin{array}{l}\text { Keeping the herd } \\
\text { going }\end{array}$ & & & I-14 & $11-7$ & $\begin{array}{l}\text { And it's something about that pace that you're } \\
\text { going to keep moving, you're going to keep } \\
\text { taking the next step. The herd sees it and the } \\
\text { herd keeps going. You know, but once you } \\
\text { stop, then everybody starts wandering off for } \\
\text { a little watering hole or something. }\end{array}$ \\
\hline SC & & \multicolumn{6}{|c|}{ 1) Continuing the next step at a pace imposed by the environment is control } \\
\hline C4 & & \multicolumn{6}{|c|}{ Control-Environment based } \\
\hline $\mathbf{C}$ & 12 & $\begin{array}{l}\text { Watching all } \\
\text { fronts }\end{array}$ & & & I-14 & $\begin{array}{l}11- \\
21\end{array}$ & $\begin{array}{l}\text { So that's the key piece to hitting the schedule } \\
\text { in this industry, is you've got good leadership. } \\
\text { That leadership keeps everybody stepping } \\
\text { along and watches all the fronts. }\end{array}$ \\
\hline SC & & \multicolumn{6}{|c|}{ 1) Control over all fronts, is exploitation of structure. } \\
\hline $\mathbf{C 3}$ & & \multicolumn{6}{|c|}{ Control-Structure based } \\
\hline
\end{tabular}


Mr. McIntosh* (Interviewee Fourteen)

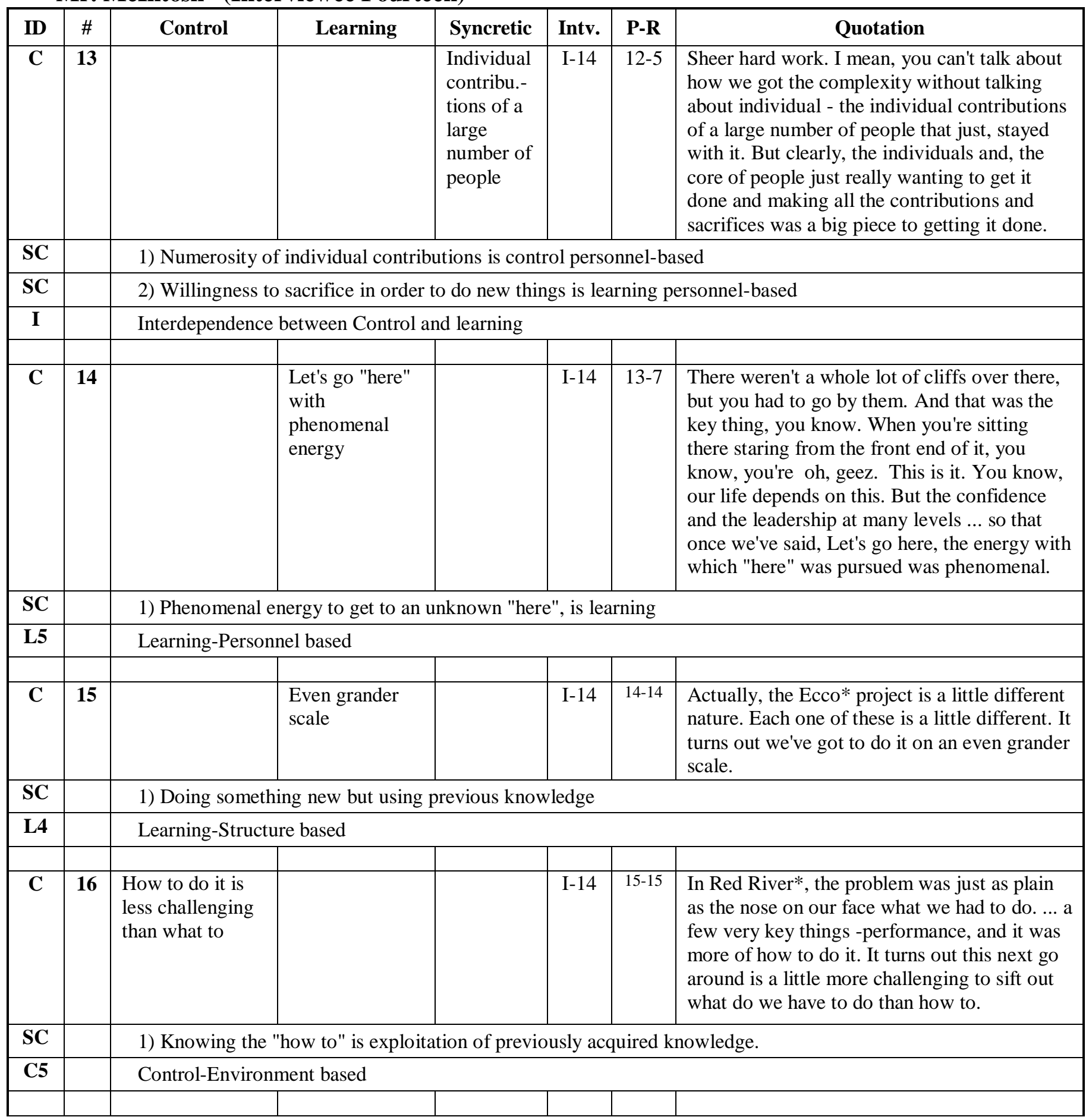


Mr. McIntosh* (Interviewee Fourteen)

\begin{tabular}{|c|c|c|c|c|c|c|c|}
\hline ID & \# & Control & Learning & Syncretic & Intv. & P-R & Quotation \\
\hline $\mathbf{C}$ & 17 & & $\begin{array}{l}\text { Sheer force of } \\
\text { will }\end{array}$ & & $\mathrm{I}-14$ & $16-16$ & $\begin{array}{l}\text { It was definitely a trial and a trial by fire and a } \\
\text { smelting process that we pounded our way } \\
\text { through. There are a lot of times that we just } \\
\text { talk about just sheer force of will as opposed } \\
\text { to elegance. }\end{array}$ \\
\hline SC & & \multicolumn{6}{|c|}{ 1) Pounding the way through with just sheer force of will, speaks of learning } \\
\hline $\mathbf{L 3}$ & & \multicolumn{6}{|c|}{ Learning-Personnel based } \\
\hline $\mathbf{C}$ & 18 & $\begin{array}{l}\text { The industry } \\
\text { does not allow }\end{array}$ & & & I-14 & $16-22$ & $\begin{array}{l}\text { The industry doesn't allow you to pull off a } \\
\text { sheer force of will maneuver over and over } \\
\text { again, because they are expensive. If you keep } \\
\text { trying to win in this industry with that sheer } \\
\text { force of will, you will financially lose; so } \\
\text { you've got to get the elegance }\end{array}$ \\
\hline SC & & \multicolumn{6}{|c|}{ 1) Not being allow by the industry, is control } \\
\hline C5 & & \multicolumn{6}{|c|}{ Control-Environment based } \\
\hline $\mathbf{C}$ & 19 & & & $\begin{array}{l}\text { Roller } \\
\text { coaster of } \\
\text { emotions }\end{array}$ & I-14 & $18-1$ & $\begin{array}{l}\text { But the story of Red River clearly is one of } \\
\text { the emotions and the contribution by so many } \\
\text { people in so many different ways. The roller } \\
\text { coaster, the emotions, the celebrations, and } \\
\text { the trials. What was kind of interesting is that } \\
\text { the roller coaster of the emotion didn't come } \\
\text { from; -You're in this thing with the company. } \\
\text { The next day you're in the chairman's office } \\
\text { begging for him to fund you again. We didn't } \\
\text { spend a lot of time doing that. The emotion } \\
\text { was clearly the technical progress of the } \\
\text { successes we had. }\end{array}$ \\
\hline SC & & \multicolumn{6}{|c|}{ 1) Begging for funds in the chairman's office is control } \\
\hline SC & & \multicolumn{6}{|c|}{ 2) The roller coaster of emotions was not drive by the company } \\
\hline $\mathbf{I}$ & & \multicolumn{6}{|c|}{ Interdependence between Control and learning } \\
\hline $\mathbf{C}$ & 20 & & $\begin{array}{l}\text { No ulterior } \\
\text { motives }\end{array}$ & & I-14 & $19-1$ & $\begin{array}{l}\text { The challenges we had with some of our } \\
\text { partners and the quality of their deliverables - } \\
\text { so all of the emotions were bound up not by } \\
\text { I'll say almost artificially induced thing. When } \\
\text { I say artificial, I'm referring to the maybe } \\
\text { wavering support from the top of the } \\
\text { company. The emotions were really bound up } \\
\text { in the product. And so you know, it wasn't a } \\
\text { political thing. There wasn't a lot of ulterior } \\
\text { motives. There wasn't a lot of people } \\
\text { jockeying for things. }\end{array}$ \\
\hline
\end{tabular}


Mr. McIntosh* (Interviewee Fourteen)

\begin{tabular}{|c|c|c|c|c|c|c|c|}
\hline ID & \# & Control & Learning & Syncretic & Intv. & $\mathbf{P}-\mathbf{R}$ & Quotation \\
\hline SC & & \multicolumn{6}{|c|}{ 1) Emotions tied to the delivery of the product (learning), not to ulterior motives } \\
\hline $\mathbf{L 3}$ & & \multicolumn{6}{|c|}{ Learning-Personnel based } \\
\hline & & & & & & & \\
\hline $\mathbf{C}$ & 21 & & $\begin{array}{l}\text { Key leaders } \\
\text { leaving }\end{array}$ & & $\mathrm{I}-14$ & $19-20$ & $\begin{array}{l}\text { And capturing the emotions that we all felt } \\
\text { when we went through them was -it was a } \\
\text { cool thing. I still look back on it with fond } \\
\text { memories. ...there was kind of an interesting } \\
\text { story was the day Roger Bently* left, one of } \\
\text { our lead key leaders. }\end{array}$ \\
\hline SC & & \multicolumn{6}{|c|}{ 1) Key leaders leaving and learning from that emotion, shows a learning environment } \\
\hline $\mathbf{L 5}$ & & \multicolumn{6}{|c|}{ Learning-Environment based } \\
\hline $\mathbf{C}$ & 22 & & $\begin{array}{l}\text { Holding on } \\
\text { together }\end{array}$ & & $\mathrm{I}-14$ & $21-16$ & $\begin{array}{l}\text { But that was one of those -just one of those } \\
\text { things. I remember we spent a lot of time } \\
\text { staring at each other, wondering if we were all } \\
\text { going to be able to hold the team together, } \\
\text { hold ourselves together to the end to get it } \\
\text { done. It turns out there was only still two of us } \\
\text { left on the project at the end that were on that } \\
\text { boat. }\end{array}$ \\
\hline SC & & \multicolumn{6}{|c|}{ 1) Adapting to team members leaving the group is learning. } \\
\hline $\mathbf{L 3}$ & & \multicolumn{6}{|c|}{ Learning-Personnel based } \\
\hline $\mathbf{C}$ & 23 & $\begin{array}{l}\text { Working day and } \\
\text { night }\end{array}$ & & & $\mathrm{I}-14$ & $23-6$ & $\begin{array}{l}\text { I spent that Christmas in Victoria*, bring up } \\
\text { the first test device, and had a very big parade } \\
\text { of lots of people in the room. We again had a } \\
\text { large team out there all huddled around the } \\
\text { hardware, working day and night, trying to get } \\
\text { that done. }\end{array}$ \\
\hline SC & & \multicolumn{6}{|c|}{ 1) Lots of people huddled around the hardware working day and night, speaks of control. } \\
\hline $\mathbf{C 3}$ & & \multicolumn{6}{|c|}{ Control-Personnel based } \\
\hline $\mathbf{C}$ & 24 & & & $\begin{array}{l}\text { A-B } \\
\text { decisions }\end{array}$ & I-14 & $23-15$ & $\begin{array}{l}\text { The fact that our device had grown way too } \\
\text { big and we wouldn't be able to fit it in the } \\
\text { reticule that anyone could ever build. That } \\
\text { was on those A-B decisions. Probably any } \\
\text { path we would've gone would've worked } \\
\text { when we had the device. But the fact that we } \\
\text { had to pick one drove hard was very } \\
\text { important. }\end{array}$ \\
\hline SC & & \multicolumn{6}{|c|}{ 1) Deciding between A and B, is control. } \\
\hline SC & & \multicolumn{6}{|c|}{ 2) Product bigger than anyone could ever build, is learning. } \\
\hline
\end{tabular}


Mr. McIntosh* (Interviewee Fourteen)

\begin{tabular}{|c|c|c|c|c|c|c|c|}
\hline ID & $\#$ & Control & Learning & Syncretic & Intv. & $\mathbf{P}-\mathbf{R}$ & Quotation \\
\hline $\mathbf{I}$ & & \multicolumn{6}{|c|}{ Interdependence between Control and learning } \\
\hline $\mathbf{C}$ & 25 & & $\begin{array}{l}\text { Retention } \\
\text { problems }\end{array}$ & & $\mathrm{I}-14$ & $25-4$ & $\begin{array}{l}\text { This one was just one clearly of just trying to } \\
\text { fight the troubles of creating a winner. There } \\
\text { were a few external forces that got kicked in. } \\
\text {..clearly, the pension, there was that whole } \\
\text { series of the retention problem that was } \\
\text { kicked off by the pension change (a guy in our } \\
\text { team) whose analysis appeared on the Web } \\
\text { sites all over the world (on) how the pension } \\
\text { was really messing up the employees. }\end{array}$ \\
\hline SC & & \multicolumn{6}{|c|}{ 1) Creating a winner despite problems in the environment is learning. } \\
\hline $\mathbf{L 5}$ & & \multicolumn{6}{|c|}{ Learning-Environment based } \\
\hline & & & & & & & \\
\hline $\mathbf{C}$ & 26 & & $\begin{array}{l}\text { Losing MVP at } \\
\text { critical times }\end{array}$ & & $\mathrm{I}-14$ & $26-6$ & $\begin{array}{l}\text { That created a really big challenge. I think } \\
\text { that one culminated then when Roger Bently } \\
\text { finally left. He was one of our -probably the } \\
\text { highest, most valued player on the whole team } \\
\text { that left the team. }\end{array}$ \\
\hline SC & & \multicolumn{6}{|c|}{ 1) Adapting to the departure of high ranking members of the team is learning } \\
\hline L5 & & \multicolumn{6}{|c|}{ Learning-Environment based } \\
\hline & & & & & & & \\
\hline & & 8 & 14 & 4 & & & \\
\hline
\end{tabular}

C Means Category

SC Means Sub Category

Total C Total L S

C1 Control-Budget based

C2 Control-Time based

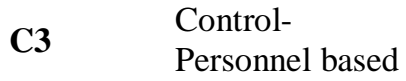

C4 Control-

Structure based

C5 Control-

Environment

$\begin{array}{llll} & & \text { L1 } & \begin{array}{l}\text { Learning-Budget based } \\ \text { Learning-Time based }\end{array} \\ & & \text { L2 } & \begin{array}{l}\text { Learning-Personnel based } \\ 3\end{array} \\ 3 & 5 & \text { L3 } & \text { Learning-Structure based } \\ 2 & 1 & \text { L4 } & \\ & 8 & \text { L5 } & \text { Learning-Environment based }\end{array}$


Mr. McIntosh* (Interviewee Fourteen)

\begin{tabular}{|c|c|c|c|c|c|c|c|}
\hline ID & $\#$ & Control & Learning & Syncretic & Intv. & P-R & Quotation \\
\hline \multicolumn{8}{|c|}{ based } \\
\hline \multirow{3}{*}{$\begin{array}{c}\text { C6 } \\
\text { S }\end{array}$} & & Control-Geograph & ased & & & L6 & Learning-Geography based \\
\hline & & Syncretic effects & & & 4 & & \\
\hline & & Total & 8 & 14 & 4 & 26 & \\
\hline
\end{tabular}

*Pseudonym used to disguise identity. 
Appendix C

Individual Column Chart for Mr. McIntosh (Interviewee 14)

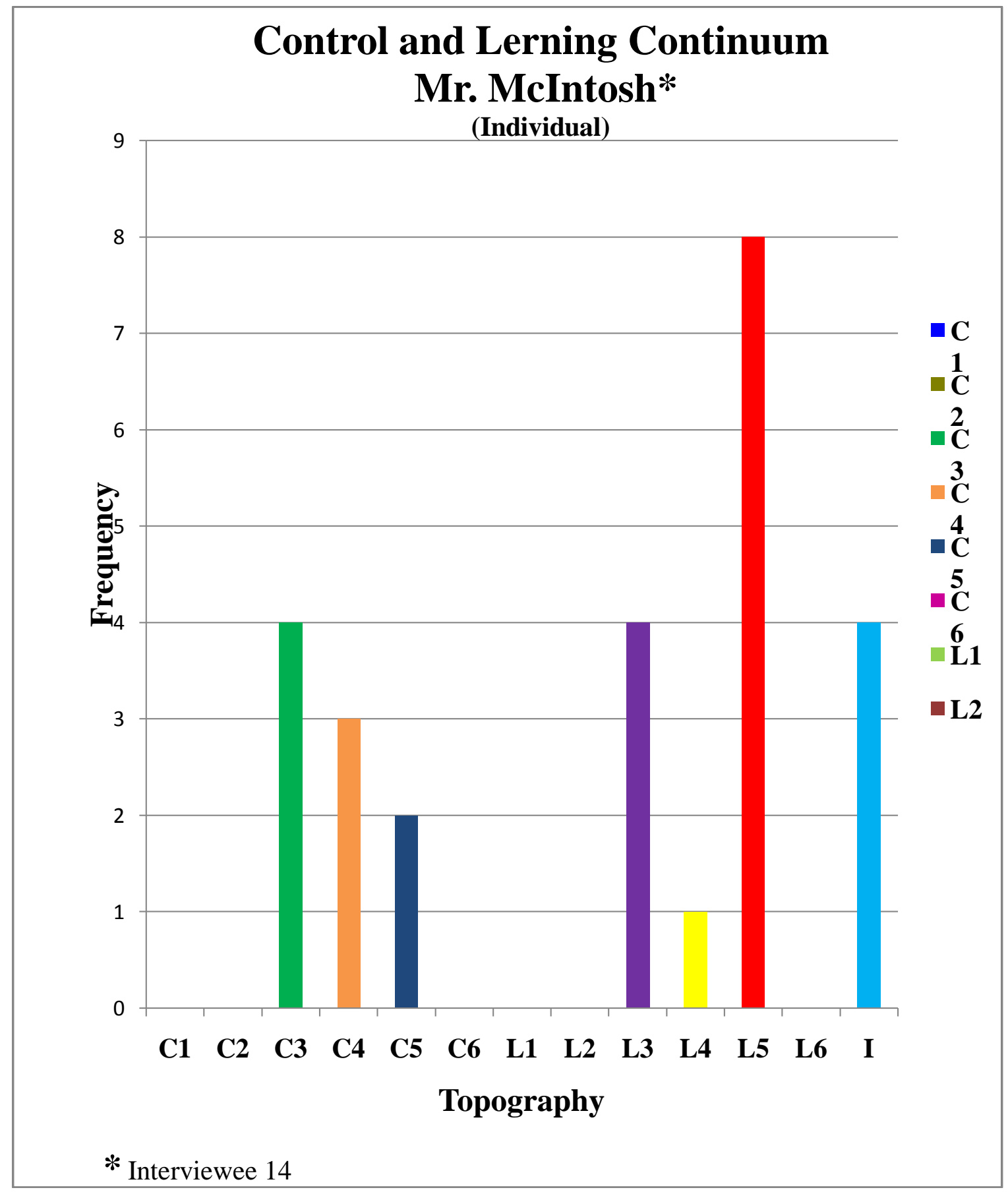




\section{Bibliography}

Ahissar, M., \& Hochstein, S. (1993). Attentional control of early perceptual learning. Psychology, 90, 5718-5722.

Auyang, S. Y. 1999, May). Synthetic analysis of complex systems theories. First part of a talk presented to the department of History of Science in the University of Sydney. Sydney, Australia.

Baerman, M., Brown, D., \& Corbett, G. G. (2005). The syntax-morphology interface: A study of syncretism. Cambridge, England: Cambridge University Press.

Barabási, A. (2002). Linked: The new science of networks. Cambridge, Mass.: Perseus Publishing.

Baron, R. M., \& Kenny, D. A. (1986). The moderator-mediator variable distinction in social psychological research: Conceptual, strategic, and statistical considerations. Journal of Personality and Social Psychology, 51 (6), 1173-1182.

Bernstein, N. A. (1967). The co-ordination and regulation of movements. Oxford: Pergamon Press.

Bhatt, G. D. (2000). Organizing knowledge in the knowledge development cycle. Journal of Knowledge Management, 4 (1), 15-26.

Boisot, M., \& Child, J. (1999). Organizations as adaptive systems in complex environments: The case of China. Organization Science, 10 (3), 237-252.

Brennan, L. (2001). Total quality management in a research and development environment. Integrated Manufacturing Systems, 12 (2), 94-102.

Brown, S. L., \& Eisenhardt, K. M. (1997). The art of continuous change: Linking complexity theory and time-paced evolution in relentlessly shifting organizations. Administrative Science Quarterly , 42 (1), 1-34.

Browning, L. D., Greene, R. W., Sitkin, S. B., Sutcliffe, K. M., \& Obstfeld, D. (2009). Constitutive complexity: Military entrepreneurs and the synthetic character of communication flows. In L. L. Putnam, \& A. M. Nicotera (Eds.), Building theories of organization: The constitutive role of communication (pp. 89-116). New York: Routledge. 
Cardinal, L. B., Sitkin, S. B., \& Long, C. P. (2004). Balancing and rebalancing in the creation and evolution of organizational control. Organization Science, 15 (4), 411-431.

Choi, T. Y., Dooley, K. J., \& Rungtusanatham, M. (2001). Supply networks and complex adaptive systems: Control versus emergence. Journal of Operations and Management, 19 (3), 351-366.

Christensen, C. M., Anthony, S. D., \& Roth, E. A. (2004). Seeing what's next: Using the theories of innovation to predict industry change. Boston: Harvard Business School Press.

Corbin, J., \& Strauss, A. (1996). Analytic ordering for theoretical purposes. Qualitative Inquiry, 2 (2), 139-150.

Creswell, J. W. (1998). Qualitative inquiry and research design: choosing among five traditions. Ca.: Thousand Oaks.

Deming, W. E. (1986). Out of the crisis. Boston, MA: MIT Press.

Dooley, K. J., Johnson, T. L., \& Bush, D. H. (1995). TQM, chaos, and complexity. Human Systems Management, 14 (4), 1-16.

Fiol, C. M., \& O'Connor, E. J. (2003). Waking up! mindfulness in the face of bandwagons. Academy of Management Review, 28, 54-70.

Flamholtz, E. G., K-Das, T., \& Tsui, A. S. (1985). Toward an integrative framework of organizational control. Accounting Organizations and Society, 10 (1), 35-50.

Gell-Mann, M. (1994). Complexity: Metaphors, models and reality (Vol. XIX). (C. P. Meltzer, Ed.) Santa Fe, New Mexico: SFI Studies in the Sciences of Complexity, Addison-Wesley.

Gell-Mann, M. (1995). The quark and the jaguar: Adventures in the simple and the complex. New York: Henry Holt and Company, LLC.

Glaser, B., \& Strauss, A. (1967). Discovery of grounded theory. Chicago: Aldine.

Hackman, J. R., \& Wageman, R. (1995, June). Total quality management: Empirical, conceptual, and practical issues. Administrative Science Quarterly, 309-342. 
Holland, J. H. (1995). Can there be a unified theory of complex adaptive systems. In H. J. Morowitz, J. L. Singer, \& S. S. Complexity (Ed.), The mind, the brain, and complex adaptive systems (pp. 45-50). Santa Fe, New Mexico: Addison-Wesley.

Huber, G. P. (1991). Organizational learning: The contributing processes and the literatures. Organization Science, 2 (1 Special Issue: Organizational Learning: Papers in Honor of (and by) James G. March), 88-115.

Ishikawa, K. (1984). Guide to quality control. (J. H. Loftus, Trans.) Tokyo: 3A Corporation.

Juran, J. M. (May 20, 1986.). The quality trilogy: A universal approach to managing for quality. ASQC 40th Annual Quality Congress, (pp. 1-9). Anaheim, CA.

Kerlinger, F. N. (1965). Foundations of behaviour research: Educational and psicological inquiry. New York: New York University.

Kuhn, T. (1962). The structure of scientific revolutions. Chicago: University of Chicago Press.

Lado, A. A., Boyd, N. G., \& Hanlon, S. G. (1997). Competition, cooperation, and the search for economic rents: A syncretic model. Academy of Management Review, 22 (1), 110-141.

Lau, R. S., \& Anderson, C. A. (1998). A three-dimensional perspective of total quality management. International Journal of Quality \& Reliability Management, 15 (1), $85-98$.

Laughlin, R. (2005). A different universe: Reinventing physics from the bottom down. (B. Books, Ed.) New York, NY, USA: Perseus Publishing.

Leonard-Barton, D. (1992). The factory as a learning laboratory. Sloan Management Review, 34 (1), 23-38.

Levinthal, D. A., \& Rerup, C. (2004). Bridging mindful and less mindful perspectives in organizational learning. Academy of Management meeting 2003. Seattle.

Levitt, B., \& March, J. G. (1988). Organizational learning. Annual Review of Sociology, 14, 319-340.

Mainzer, K. (2004). Thinking in complexity: The computational dynamics of matter, mind, and mankind (4th ed.). Berlin Heidelberg: Springer-Verlag. 
March, J. G. (1991). Exploration and exploitation in organizational learning. Organization Science, 2 (1), 71-87.

March, J. G., Sproull, L. S., \& Tamuz, M. (2003). Learning from samples of one or fewer. Quality and Safety in Health Care, 12 (6), 465-471.

Miyamoto, H., Kawato, M., Setoyama, T., \& Susuki, R. (1988). Feedback-error-learning neural network for trajectory control of a robotic manipulator. Neural Networks, Volume 1, Issue 3, 1988, Pages 251-265, 1 (3), 251-265.

Morgan, G., \& Smircich, L. (1980). The case for qualitative research. The Academy of Management Review, 5 (4), 491-500.

Morrison, K. M. (1990). Baptism an alliance: The symbolic mediations of religious syncretism. Ethnohistory, 37 (4), 416-437.

Mosse, D. (1994). The politics of religious synthesis. In C. Stewart, \& S. Rosalind, Syncretism/anti-syncretism: The the politics of religious synthesis (pp. 85-144). London, England: Routledge.

Naveh, E., \& Erez, M. (2004). Innovation and attention to detail in the quality improvement paradigm. Management Science, 50 (11), 1576-1586.

Nonaka, I. (1994). A dynamic theory of organizational knowledge creation. Organization Science , 5 (1), 14-37.

Otley, D., Broadbent, J., \& Berry, A. (1995). Research in management control: An overview of its development. British Journal of Management, 6 (Special), S31S44.

Ouchi, W. G. (1979). A conceptual framework for the design of organizational control mechanisms. Management Science, 25 (9), 833-848.

Peters, T. J., \& Waterman, R. H. (1982). In search of excellence: Lessons from America's best-run companies. New York: Harfer \& Rown, Publishers, Inc.

Prajogo, D., \& Sohal, A. (2001). TQM and innovation: A literature review and research framework. Technovation, 21, 539-558.

Sitkin, S. B., Sutcliffe, K. M., \& Schroeder, R. G. (1994). Distinguishing control from learning in total quality management: A contingency perspective. Academy of Management Review, 19 (3), 537-564. 
Sousa, R., \& Voss, C. A. (2001). Quality management: Universal or context dependant? Production and Operations Management, 10 (4 ), 383-404.

Stewart, C. (1999). Syncretism and its synonyms:Reflections on cultural mixture. Diacritics, 29 (3), 40-62.

Stewart, C., \& Shaw, R. (1994). Introduction: problematizing syncretism. In C. Stewart, \& R. Shaw, Syncretism/anti-syncretism: The politics of religious synthesis (1st ed., pp. 1-26). London, England: Routledge.

Strauss, A. L., \& Corbin, J. (1998). Basics of qualitative research: techniques and procedures for developing grounded theory ( 2 nd ed.). Ca.: Thousand Oaks.

Sutcliffe, K., Sitkin, S., \& Browning, L. D. (2000). Tailoring process management to situational requirements: Beyond the control and exploration dichotomy. In R. Cole, \& W. Scott, The quality movement and organization theory (pp. 315-330). Sage Publications, Thousand Oaks.

Tannenbaum, A. S. (1962). Control in organizations: Individual adjustment and organizational performance. Administrative Science Quarterly, 7 (2), 236-257.

van der Veer, P. (1994). Syncretism, multiculturalism and the discourse of tolerance. In C. Stewart, \& R. Shaw, Syncretism/anti-syncretism: the politics of religious synthesis (pp. 196-211). London: Routledge.

Watts, D. J. (2003). Six degrees the science of a connected age. New York, N.Y.: W. W. Norton \& Company.

Webster, J. (1997). Necessary comparissons: A post colonial approach to religious syncretism in the Roman provinces. World Archaeology, 28 (3),

Weick, K. E., \& Sutcliffe, K. M. (2001). Managing the unexpected. San Francisco: Jossey-Bass.

Weick, K. E., Sutcliffe, K. M., \& Obstfeld, D. (1999). Organizing for high reliability: Processes of collective mindfulness. Research in Organizational Behavior, 21, $81-123$

Woodward, J. (1965). Industrial organization: Theory and practice. London: Oxford University Press. 


\section{Vita}

Carmen A. Romo de Vivar y Sandoval is a native of Monclova, Coahila Mexico. She credits her parents Joaquín Romo de Vivar y Martínez de Troncoso and Esperanza Sandoval de Romo de Vivar with her lifelong love of learning and her desire to continue her education. Carmen attended Universidad Autónoma de Coahuila in Mexico for her Bachelor's in Business and Accounting. She worked as project manager for many years before pursuing her Master's degree in Business Administration from ITESM Monterrey, Mexico. This research constitutes the final phase of her doctorate program at The University of Texas at Austin in Interdisciplinary Studies.

Permanent address: 2610 Friar Tuck Rd., San Antonio, TX. 78209

This dissertation was typed by the author.

This dissertation was edited by Tanya E. DaMommio M Ed. 